Dinâmica de Partículas e Aprendizado Competitivo para Detecção de Comunidades em Redes Complexas 



\title{
Dinâmica de Partículas e Aprendizado Competitivo para Detecção de Comunidades em Redes Complexas
}

\author{
Ronaldo Luiz Alonso
}

Orientador: Prof. Dr. Zhao Liang

Tese apresentada ao Instituto de Ciências Matemáticas e de Computação - ICMC-USP, como parte dos requisitos para obtenção do título de Doutor em Ciências - Ciências de Computação e Matemática Computacional. 



\section{Agradecimentos}

\section{- A Deus.}

- A meu orientador e amigo Zhao Liang pela dedicação, trabalho, atenção e paciência durante todos esses anos.

- A meus amigos Marcos Quiles, João Bertini, Fabricio Breve e Thiago Cristiano pela imensa ajuda recebida durante a elaboração deste trabalho.

- Aos professores e secretárias do ICMC e aos professores do IFSC pela dedicação, esmero e atenção dispensados a mim.

- Ao LSITEC/USP, ao CREA/SP, à FAPESP e à Godigital pelas oportunidades de trabalho.

- A todos que direta ou indiretamentamente ajudaram na concretização desta tese. 



\section{Resumo}

O estudo de redes complexas tem alavancado um tremendo interesse em anos recentes. Uma das características salientes de redes complexas é a presença de comunidades, ou grupos de nós densamente conectados. A detecção de comunidades pode não apenas ajudar a entender as estruturas topológicas de redes complexas, mas também pode fornecer novas técnicas para aplicações reais, como mineração de dados. Neste trabalho, primeiro foi proposto ${ }^{1}$ um novo modelo para detecção de comunidades em redes complexas. Em seguida este modelo foi reformulado em termos de sistema contínuo e alguns resultados de análise matemática foram obtidos. Neste modelo várias partículas caminham na rede e competem umas com as outras para marcar seu próprio território e rejeitar partículas intrusas. O processo de competição entre partículas atinge o equilíbrio dinâmico quando cada comunidade tem apenas uma partícula. Esta abordagem não apenas pode obter bons resultados na detecção de comunidades, como também apresenta diversas características interessantes: 1) O processo de competição de partículas é similar a muitos processos naturais e sociais, tais como competição de animais por recursos, exploração territorial por humanos (animais), campanhas eleitorais, etc.. Portanto, o modelo proposto neste trabalho pode ser útil para simular a dinâmica evolutiva de tais processos. 2) Neste modelo, nós introduzimos uma regra para controlar o nível de aleatoriedade do passeio da partícula. Descobrimos que uma pequena porção de aleatoriedade pode aumentar bastante a taxa de detecção de comunidades. Nossa descoberta é análoga ao notável fenômeno chamado ressonância estocástica onde o desempenho de um sistema determinístico não-linear pode ser bastante melhorado através da introdução de um certo nível de ruído. É interessante notar que tal fenômeno é observado em uma situação diferente aos sistemas clássicos de ressonância estocástica. 3) Nossa descoberta indica que a aleatoriedade tem um papel importante em sistemas evolutivos. Ela serve para automaticamente escapar de armadilhas

1 O modelo apresentado no capítulo 3 foi desenvolvido em conjunto com outros pesquisadores, ver artigo aceito para publicação sobre este modelo (Quiles et al., 2008). 
não desejáveis e explorar novos espaços, isto é, ela é um descobridor de novidades. 4) Uma análise quantitativa para processo de competição entre duas particulas e duas comunidades foi conduzida, a qual é um passo de avanço para desenvolvimento de teoria fundamental de aprendizado competitivo. 


\section{Abstract}

Study of complex networks has triggered tremendous interests in recent years. One of the salient features of complex networks is the presence of communities, or groups of densely connected nodes. Community detection can not only help to understand the topological structure of complex networks, but also provide new techniques for real applications, such as data mining. In this work, a new model for complex network community detection was proposed firstly ${ }^{1}$. Then this model was reformulated in terms of continuous system and some results of mathematical analysis were obtained. In this model, several particles walk in the network and compete with each other to mark their own territory and reject particle intruders. The particle competition process reaches dynamics equilibrium when each community has only one particle. This approach not only can get good community detection results, but also presents several interesting features: 1) The particle competition process is rather similar to many natural and social processes, such as resource competition by animals, territory exploration by humans (animal), election campaigns, etc.. Thus, the model proposed in this work may be useful to simulate dynamical evolution of such processes. 2) In this model, a rule to control the level of randomness of particle walking is introduced. We found a small portion of randomness can largely improve the community detection rate. Such a finding is analogous to a remarkable phenomenon called stochastic resonance (SR) where the performance of a nonlinear deterministic system can be largely enhanced by introducing a certain level of noise. Interestingly, such a SRtype phenomenon is observed in quite a different situation from classical SR systems. 3) Our finding indicates that randomness has an important role in evolutionary systems and in machine learning. It serves to automatically escape some undesirable traps and explore new spaces, i.e., it is a novelty finder. 4) A quantitative analysis for two particle competition in two communities is provided. This is an step toward the development of fundamental theory for

1 The model presented in chapter 3 was developed jointly with other researchers, see the accepted paper about this model (Quiles et al., 2008) 
competitive learning. 


\section{Sumário}

Resumo iii

Sumário $\quad$ ix

Lista de Figuras . . . . . . . . . . . . . . . . . . . xii

Lista de Algoritmos . . . . . . . . . . . . . . . . . xiii

1 Introdução 1

1.1 Objetivos e Motivações . . . . . . . . . . . . . 5

1.2 Organização do Documento . . . . . . . . . . . . . 6

2 Redes Complexas, Aprendizado Competitivo e Caminhada Aleatória 7

2.1 Redes Complexas . . . . . . . . . . . . . . 7

2.1.1 Modelos de rede ................ . . 9

2.1.2 Detecção de comunidades em redes complexas . . . . . . 15

2.1.3 Sobreposição de comunidades . . . . . . . . . . . 23

2.2 Caminhada Aleatória . . . . . . . . . . . . . . 25

2.2.1 Definição ..................... 25

2.2.2 Passeio Aleatório Unidimensional . . . . . . . . . . 25

2.2.3 Passeio Aleatório Bidimensional . . . . . . . . . . . . 28

2.2.4 Caminhada Aleatória em Grafos . . . . . . . . . . . . . . 29

2.2.5 Processos Estocásticos e Caminhadas Aleatórias . . . . . . 30

2.2.6 Teorema de Perron-Frobenius . . . . . . . . . . . . . . 34

2.2.7 Equação Mestra . . . . . . . . . . . . . . . . 35

2.3 Aprendido Competitivo . . . . . . . . . . . . . . 36

2.3.1 Redes Neurais ART . . . . . . . . . . . . 37

2.3.2 Mapas Auto-Organizáveis de Kohonen (SOM) . . . . . . . 39

2.3.3 Growing Neural Gas . . . . . . . . . . . . . . . . . . . . . . 42

2.4 Considerações Finais . . . . . . . . . . . . . . . . . 42 
3 Competição de Partículas para Detecção de Comunidades 45

3.1 Descrição do Modelo . . . . . . . . . . . . . . . 46

3.2 Simulações Computacionais . . . . . . . . . . . . 48

3.3 Considerações Finais . . . . . . . . . . . . . . . . 61

4 Descrição Quantitativa do Processo 63

4.1 Processos Estocásticos em Grafos . . . . . . . . . . . . . . . . 63

4.2 Processo de Demarcação . . . . . . . . . . . . . . . . . 64

4.3 Comunidades Separadas . . . . . . . . . . . . . . . 68

4.4 Modelagem com Taxas de Crescimento . . . . . . . . . . . 71

4.5 Duas comunidades conectadas . . . . . . . . . . . . . . . 74

4.6 Modelagem como sistema autônomo . . . . . . . . . . . 77

4.7 Análise do Ponto de Equilíbrio . . . . . . . . . . . . 77

4.8 Modelagem para mais de duas comunidades . . . . . . . . . 81

4.9 Considerações Finais . . . . . . . . . . . . . . . . . . 82

5 Conclusões $\quad \mathbf{8 3}$

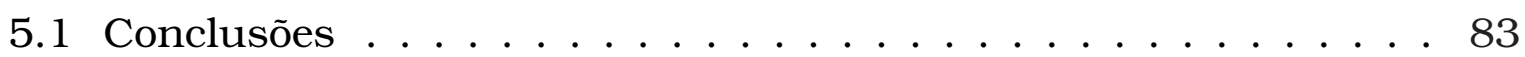

5.2 Trabalhos Futuros . . . . . . . . . . . . . . . . 84

$\begin{array}{ll}\text { Referências Bibliográficas } & 87\end{array}$ 


\section{Lista de Figuras}

2.1 Rede randômica . . . . . . . . . . . . . . . . 10

2.2 Rede de mundo pequeno . . . . . . . . . . . . . . . . 12

2.3 Coeficiente de cluster e média dos menores caminhos . . . . . . 13

2.4 Rede livre de escala . . . . . . . . . . . . . . . . . . . . 15

2.5 Exemplo de rede com três comunidades . . . . . . . . . . 16

2.6 Sobreposição de Comunidades . . . . . . . . . . . . . . . . . 24

2.7 Exemplo simples de Grafo de Transição. . . . . . . . . . . . . . . 33

2.8 Arquitetura básica de uma rede ART1 . . . . . . . . . . . . . 37

2.9 Arquitetura básica de uma rede SOM . . . . . . . . . . . . . . 40

2.10Exemplos de vizinhanças utilizadas em uma rede SOM . . . . . 40

3.1 Ilustração do processo de detecção . . . . . . . . . . . . 5 50

3.2 Taxa de detecção de comunidade correta vs. $p_{\text {det }} \ldots \ldots \ldots$. . . . . 51

3.3 Séries temporais . . . . . . . . . . . . . . . . . 52

3.4 Resultados variando o número de partículas . . . . . . . . . 53

3.5 Rede inicial e final . . . . . . . . . . . . . . . . . . 55

3.6 Percentegam de acerto para Figura $3.5 \ldots \ldots \ldots 5$

3.7 Rede inicial e final . . . . . . . . . . . . . . . . . . 55

3.8 Percentegam de acerto para Figura $3.7 \ldots \ldots \ldots 6$

3.9 Rede inicial e final . . . . . . . . . . . . . . . . 56

3.10 Percentegam de acerto para Figura $3.9 \ldots \ldots$. . . . . 56

3.11 Rede inicial e final . . . . . . . . . . . . . . . . 57

3.12 Percentegam de acerto para Figura $3.11 \ldots \ldots 7$

3.13Rede inicial e final . . . . . . . . . . . . . . . 57

3.14 Percentegam de acerto para Figura $3.13 \ldots \ldots$. . . . . 58

3.15Rede inicial e final . . . . . . . . . . . . . . . 58

3.16Percentegam de acerto para Figura $3.15 \ldots \ldots \ldots 8$

3.17Rede inicial e final . . . . . . . . . . . . . . . . . 59

3.18 Percentegam de acerto para Figura $3.17 \ldots \ldots \ldots$ 
3.19Rede inicial e final . . . . . . . . . . . . . . . . . . . . 59

3.20 Percentegam de acerto para Figura $3.19 \ldots \ldots$. . . . . . 60

3.21 Detecção de comunidades na rede de amizades . . . . . . . . 60

3.22 Detecção de comunidades na rede social . . . . . . . . . . . . . 61

4.1 Exemplo de um Grafo com duas comunidades . . . . . . . 65

4.2 Regiões ocupadas durante o movimento de partículas. . . . . . . 65

4.3 Potencial de um vértice em função do número de visitas. . . . . . 67

4.4 Comunidades desconectadas . . . . . . . . . . . . . . . . . 69

4.5 Exemplo de Integração numérica $\ldots \ldots$. . . . . . . . 81

4.6 Exemplo de Integração numérica . . . . . . . . . . . . . . . . 82 


\section{Lista de Algoritmos}

2.1 Algoritmo RNA ART 1 (de Pádua Braga et al., 2000) . . . . . . . 39

2.2 Algoritmo RNA SOM . . . . . . . . . . . . . . . . . . 39

2.3 Algoritmo RNA GNG: (Vargas, 2004) . . . . . . . . . . . . . . 43

2.4 Algoritmo RNA GNG: Inserção de um novo elemento . . . . . . . . 44 


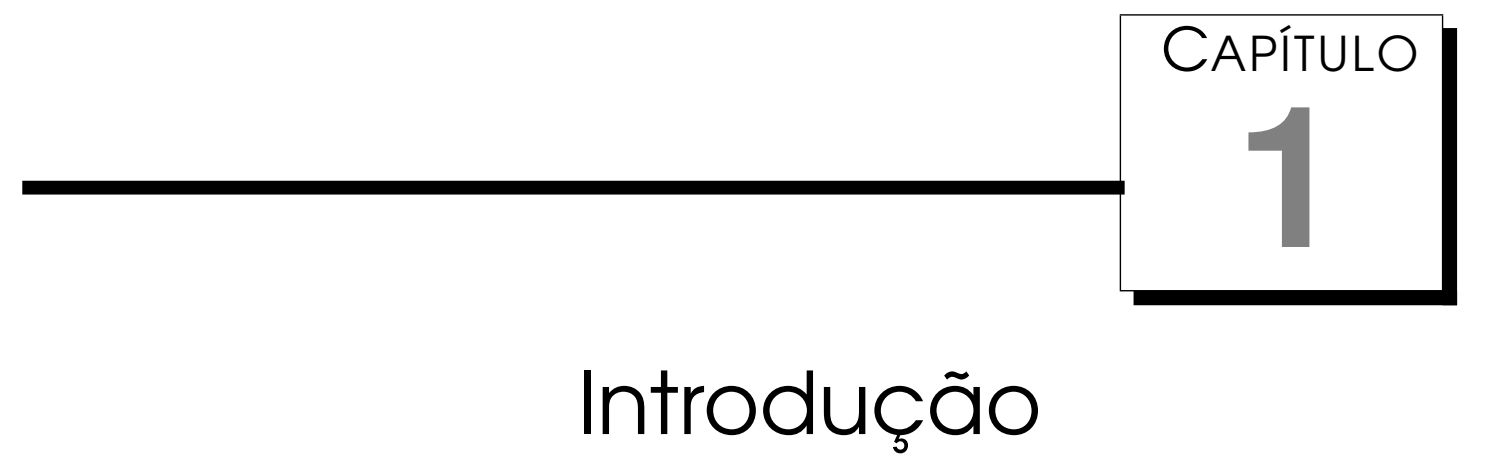

Uma rede ou grafo é uma estrutura matemática utilizada para modelar relações entre pares de uma coleção de objetos que consiste em um conjunto de vértices e arestas conectando estes vértices (Biggs \& Wilson, 1986). As redes têm emergido recentemente como um tópico unificador em sistemas complexos, presentes em praticamente todos os ramos da ciência e mudaram a maneira com que vários sistemas interconectados são modelados. As redes que modelam sistemas complexos, referidas como redes complexas são redes que possuem topologia não trivial, isto é, não formam estruturas que se repetem como as redes regulares e podem ser compostas por uma grande quantidade de vértices. Muitas redes existentes na natureza, bem como na sociedade, podem ser caracterizadas como redes complexas, tais como: a internet (Barabasi \& Albert, 1999), a world wide web (Albert et al., 1999), redes neurais biológicas (White et al., 1986), redes sociais entre individuos (Faust, 2005) e entre companhias e organizacões (Mizruchi, 1982), cadeias alimentares (Montoya \& Solé, 2002), redes do metabolismo (Jeong et al., 2000) e de distribuição como a corrente sanguínea (West et al., 1999), as rotas de entrega postal e a distribuição de energia elétrica (Albert et al., 2004). De acordo com Strogatz (Strogatz, 2001), algumas das principais características inerentes a este tipo de rede são:

- Complexidade estrutural: a representação pode resultar em visualizações complicadas; Esse é o caso de redes onde os vértices estão em uma dimensão maior ou igual a 3.

- Evolução: a estrutura pode ser modificada a cada instante devido a inclusão e remoção de vértices e conexões; 
- Diversidade de conexões: as conexões entre os vértices podem ter muitas variações em suas características como a capacidade, o comprimento, a largura, sentido, etc;

- Dinâmica complexa: além da estrutura, o que influencia em grande escala nos estados de uma rede é sua dinâmica, podendo ser entendida como o tráfego de informações, a relação entre os vértices, distribuição de funções, etc; No caso de uma rede de tráfego, por exemplo, os vértices podem desempenhar diferentes funções na dinâmica de tráfego da rede, caracterizando assim a complexidade.

Durante os últimos anos, vários pesquisadores têm desenvolvido métodos para caracterizar esse tipo de rede, proporcionando novos conhecimentos com relação à propriedade desses sistemas interconectados e suas organizações. A clássica metáfora inspirada nas redes sociais (Price, 1965), que coloca os indivíduos como vértices da rede e as arestas representando as interações entre esses indivíduos, é atualmente usada na representação da grande maioria das redes, desde redes de iterações moleculares (Hartwell et al., 1999) à internet (Faloutsos et al., 1999). Impulsionado pela melhoria do poder computacional e pela disponibilidade de várias bases de dados representando redes reais, hoje o estudo das redes complexas abrange várias áreas da ciência que vão da biologia à computação, passando pela física e economia (Bornholdt \& Schuster, 2003). As redes complexas podem ser vistas como uma ferramenta para a representação de dados e suas inter-relações (Zhou, 2003b). A representação de dados como uma rede intricada de indivíduos e suas relações permite encontrar e esclarecer propriedades, tais como, a distribuição dos graus, betweenness (separabilidade), diâmetro da rede, resistência a ataques e falhas, transição de fases em relação à média do grau, evolução de redes e determinação de comunidades, entre outras. O estudo dessas propriedades permite desenvolver métodos que possam ser aplicados a diversos objetivos, como melhorar a dinâmica e o fluxo em uma rede, prever o comportamento de uma rede, entender a causa de maus funcionamentos, entender a propagação de doenças, proteger a rede em casos de ataques ou falhas, etc.

Dentre as diversas propriedades mencionadas, uma propriedade em especial parece ser comum a diversos tipos de redes nas mais variadas áreas; trata-se da estrutura de comunidades. Tais comunidades podem ser definidas como grupos de vértices da rede cujas conexões entre vértices de um mesmo grupo são densas, enquanto que conexões entre vértices de grupos diferentes são esparsas. Redes que possuem estrutura modular variam de redes sociais, redes de metabolismo e redes de transporte a Internet e a World Wide Web. (Albert \& Barabási, 2002; Newman, 2003; Dorogovtsev \& Mendes, 2003; 
Guimera et al., 2003). Muitas técnicas têm sido desenvolvidas para a detecção de comunidades, tais como, os métodos espectrais (Pothen et al., 1990), e técnicas baseadas em "betweenness" (Newman \& Girvan, 2004), otimização de modularidade (Newman, 2004), detecção baseada no modelo de Potts (Reichardt \& S.Bornholdt, 2004), sincronização (Arenas et al., 2006), e random walks (Zhou, 2003b). A habilidade de encontrar e analisar esses grupos pode trazer benefícios no entendimento e na visualização da estrutura da rede (Newman \& Girvan, 2004). Mais ainda, recentemente descobriu-se que muitos desses vértices que estão dispostos em comunidades fazem parte de mais de uma comunidade, i.e. as áreas entre comunidades não são necessariamente esparsas e, de fato existem áreas de sobreposição entre comunidades (Palla et al., 2005). Essas comunidades representam padrões de interação entre vértices da rede e sua identificação é crucial na análise e no entendimento dos mecanismos de crescimento e formação da rede, bem como nos processos que ocorrem na mesma (Clauset, 2005). De maneira geral, a estrutura em comunidades revela similaridade, segundo algum critério, por meio de conexões entre os vértices pertencentes a um mesmo grupo. Por exemplo, em redes sociais a presença de comunidades pode revelar grupos de indivíduos com mesmos interesses, relações de amizade, relações profissionais, etc; enquanto que em redes biológicas, o agrupamento de células pode revelar funções. A identificação de comunidades em redes complexas é, portanto, um modelo de agrupamento ou clusterização de dados dispostos em forma de rede. A transformação da similaridade presente nos dados em grafos para resolver problemas de clusterização, constitui uma área bem estabelecida, conhecida como clusterização baseada em grafos (Kernighan \& Lin, 1970). A abordagem, na qual a informação é codificada em vértices e a proximidade/afinidade é definida por meio das arestas, aplica-se diretamente às redes complexas (Reichardt \& Bornholdt, 2006). Considerando este cenário, pode-se dizer que as redes complexas são apropriadas para a análise de dados em geral, especialmente para grandes bases de dados.

Um outro tópico que motiva este rabalho é o processo de aprendizado competitivo. Competitividade é um processo natural largamente observado em organismos vivos compartilhando recursos limitados, tais como água, comida, companheiros, território, reconhecimento, etc. A competição, para biólogos evolutivos, é um importante mecanismo de adaptação e evolução de espécies para sobreviver em um ambiente dinâmico com mudanças rápidas e recursos limitados. Acredita-se que a competição acontece até mesmo entre genes individuais (Dawkins, 1990) e, desta forma, o comportamento das espécies é controlado por genes de modo a mantê-los dentro da população. Em alguns casos, os organismos podem até mesmo excretar alguns componentes 
químicos no ambiente com o objetivo de manter outros competidores distantes (Fredrickson \& Stephanopoulos, 1981). Como conseqüência, a espécie mais forte ou mais adaptada tende a forçar os outros a migrarem para outros territórios. Darwinistas Sociais alegam que a competição também serve como um mecanismo para determinar o grupo mais apto, politicamente, economicamente e ecologicamente (Burns, 1959). A competição também foi observada entre neurônios com o objetivo de refinar os circuitos neurais durante o desenvolvimento. É sugerido que a competição entre neurônios é importante na formação da memória, na qual neurônios são selecionados por sua atividade relativa durante o processo de aprendizado (Han et al., 2007). Esta descoberta está relacionada como o postulado de $\mathrm{Hebb}$, o qual sugere que a atividade correlata entre neurônios realiza modificações sinápticas (Hebb, 1949). Tal postulado, chamado de Aprendizado Hebbiano, tem sido largamente aplicado em redes neurais artificiais e aprendizado de máquina.

O aprendizado de máquina é um tópico de pesquisa importante no estudo de inteligência artificial (Mitchell, 1997). Ele se interessa pelo desenvolvimento de algoritmos que permitam que os computadores "aprendam" O aprendizado é essencial para sistemas de computadores inteligentes autônomos, como robôs móveis, os quais podem se adaptar a ambientes reais e desconhecidos (Pfeifer et al., 2007). O desenvolvimento de sistemas autônomos é uma tarefa desafiadora e o mecanismo de aprendizado precisa estar envolvido.

O processo de tomada de decisão humano é um balanço entre aleatoriedade e determinismo (Lee, 2006; Daw et al., 2006). Quando alguém tem um conhecimento completo sobre um determinado assunto, uma escolha determinística pode ser feita; por outro lado, uma decisão aleatória é tomada quando esse indivíduo nada sabe sobre o assunto. Em muitas situações, nós temos apenas um conhecimento parcial, então temos de tomar a decisão através da mistura de aleatoriedade e determinismo. Quanto mais conhecimento temos, menos aleatória é a decisão que tomamos, dependendo é claro, da natureza do problema. Considere uma situação freqüentemente encontrada, quanto um homem (ou mulher) abre a porta de sua casa a noite, a primeira coisa que ele irá fazer é acender a luz. Devido a familiaridade com sua própria casa, ele não tem dificuldade em alcançar a pequena área que contém o interruptor - a parte determinística trabalhando. Porém, como o quarto está escuro, ele não tem o completo conhecimento sobre a localização do interruptor. Neste caso, ele pode tocar aleatoriamente a pequena área algumas vezes até finalmente ter certeza da posição do interruptor - a parte aleatória em ação.

Aqui, nós gostaríamos de destacar que técnicas de aprendizado que se consistem apenas de regras determinísticas são insuficientes. Isto acontece porque o número de regras requerida para descrever completamente mesmo 
um ambiente bem específico pode ser proibitivamente alto. Em ambientes dinâmicos, a situação se torna ainda pior porque o sistema tem de continuar assimilando novos conhecimentos através do tempo. Portanto, nossa conjectura é que um certo nível de aleatoriedade ou caos é essencial para o processo de aprendizado. Tal aleatoriedade representa o estado "eu não sei" e um descobridor de novidade. Ela também pode ajudar no aprendizado de agentes, como as partículas do nosso modelo, a escapar de armadilhas no espaço físico ou de aprendizado. Aqui um exemplo concreto é dado para mostrar que tal aleatoriedade não é sempre um estado de confusão, mas sim que ele pode ser útil para o aprendizado humano (animal) ou de máquina. Esta linha de pensamento já foi adotada em teoria da informação (Shannon, 1948), a qual considera a aleatoriedade como novidade, i.e., quanto maior a entropia (incerteza), menos informação nós temos.

Neste trabalho, será proposto um modelo robusto e eficiente para detecção de comunidades em redes complexas via competição de partículas. No modelo proposto, partículas caminham pela rede e competem umas com as outras de maneira que cada uma delas tenta possuir o maior número de vértices possivel.

\subsection{Objetivos e Motivações}

Neste trabalho, estudamos o papel aleatório-determinístico combinado e o mecanismo de aprendizado competitivo. As idéias serão concretizadas através da introdução de um modelo para detecção de comunidades em redes complexas, no qual diversas partículas caminham em uma rede competindo umas com as outras para marcar seu próprio território e rejeitando partículas intrusas. O processo atinge o equilíbrio dinâmico quando cada comunidade é demarcada por apenas uma partícula. A dinâmica do modelo é similar ao processo natural de animais lutando por recursos de modo que as partículas e nós representam animais e recursos, respectivamente. No modelo proposto, também introduzimos uma regra para controlar o nível de aleatoriedade do passeio da partícula, conforme detalhado abaixo. Descobrimos que o melhor resultado é obtido quando partículas caminham quase deterministicamente, mas como um pouco de aleatoriedade. Isto é análogo ao notável fenômeno chamado ressonância estocástica (SR). Em termos gerais, ressonância estocástica significa que o desempenho de um sistema tal qual a resposta a sinais periódicos pode ser melhorado pelo ruído e ser tornado ótima com um nível de ruído diferente de zero. Se fizermos uma analogia, ruído na ressonância estocástica é como o nível de aleatoriedade no passeio da partícula e o sistema não linear é como o passeio determinístico no nosso modelo. Em 
ambos os casos, a solução ótima é obtida quando um baixo nível de ruído (aleatoriedade) é introduzido.

As motivações são as seguintes:

- Redes complexas são essenciais da comunidade moderna. O estudo de redes complexas têm importância fundamental não só para ciência da computação, mas também para muitas outras áreas da ciência;

- Detecção de comunidade em redes complexas é uma técnica importante para revelar estruturas topológicas de rede e para mineração de dados, no sentido de revelar relações topológicas entre dados de entrada;

- As técnicas atuais de detecção de comunidades apresentam alto custo computacional. Por tanto, existe necessidade de desenvolver nova técnica encontrando solução aproximadamente ótima, em vez de buscar solução ótima, que apresenta robustez e eficiência. Tal a técnica é especialmente útil para tratar redes de grande escala;

- Aleatoridade é uma propriedade que existe em muitas situações. A investigação do papel de funcionalidade de aleatoridade portanto é necessária para sistemas evolutivos e aprendizado de máquina;

- Por fim, talvez mais importante, aprendizado competitivo e caminha aleatória são estensivamente estudados separadamente. No entanto, existem poucos trabalhos envolvendo os dois mecanismos. Este trabalho pretende avançar nessa direção oferecendo uma análise quantitativa para processo aleatório competitivo.

\subsection{Organização do Documento}

O restante do texto está organizado da seguinte forma, no Capítulo 2 e dada uma breve introdução sobre redes complexas, seguidos de alguns dos principais modelos de rede, e uma revisão de algumas técnicas de detecção de comunidades, também no Capítulo 2 é feita e uma breve introdução ao aprendizado competitivo. O Capítulo 3 apresenta um novo modelo de detecção de comunidades via competição de partículas. Alguns resultados de simulações também serão mostrados neste mesmo capítulo. No Capítulo 4 são apresentadas as análises quantitativas do modelo proposto. Por fim, no Capitulo 5 são apresentados as conclusões e os futuros trabalhos. 
CAPÍTULO

\section{Redes Complexas, Aprendizado Competitivo e Caminhada Aleatória}

Neste capítulo, serão apresentadas breves revisões de alguns tópicos relevantes ao desenvolvimento desta tese: Redes complexas, aprendizado competitivo e caminhada aleatória.

\subsection{Redes Complexas}

O estudo das redes em geral teve início com o desenvolvimento da teoria dos grafos, esta por sua vez teve início em 1735, com o aclamado trabalho de Leonhard Euler sobre o problema das sete pontes de Konigsberg (atual Kalingrado). Na ocasião a população local discutia a possibilidade de atravessar as sete pontes sem passar mais que uma vez em uma mesma ponte. Euler, então, provou matematicamente a inexistência de um caminho que percorresse exatamente uma vez cada uma das pontes. Com esta prova Euler iniciou, sem a intenção, uma nova área da matemática conhecida como teoria dos grafos, que durante os séculos subseqüentes cresceu com a ajuda de vários outros matemáticos, esta teoria embasou o conhecimento atual sobre redes.

O próximo grande passo em direção à teoria das redes complexas foi dado por Erdős e Rényi, que desenvolveram o modelo mais realístico, até então, para a formação de certos tipos de redes. O modelo foi chamado de grafos aleatórios (Random Graphs) ou redes aleatórias, devido ao fato, que evidenciou o trabalho, do uso de métodos probabilísticos para resolver problemas de teoria dos grafos. A próxima importante contribuição nos estudos das redes complexas seria dada em 1967 por Stanley Milgram, então pesquisador 
de sociologia em Harvard. Milgram realizou um experimento no qual centenas de cartas foram enviadas a pessoas escolhidas de maneira aleatória. Estas cartas continham informações sobre duas pessoas escolhidas como alvo. O leitor, então, era questionado se conhecia alguma dessas pessoas e no caso de conhecer alguma delas, deveria enviar a carta a esta pessoa, caso contrário a carta deveria ser enviada a uma pessoa conhecida do leitor que, a seu ver, pudesse conhecer alguma das pessoas alvo. Acontece que o resultado do experimento foi inesperado, ficou demonstrado que a distância média entre quaisquer duas pessoas nos EUA era de aproximadamente seis. Milgram havia, portanto, descoberto a propriedade de mundo pequeno (small world) que significa que apesar da rede possuir um número muito grande de vértices, a distância média entre eles é surpreendentemente pequena (Milgram, 1967).

Apesar das conclusões de Milgram, foi somente no final da década de 1990 com a publicação de alguns resultados interessantes que o interesse em redes complexas começou a surgir. Em 1998, Watts \& Strogatz (1998) comprovaram que a média de caminhos mais curtos em uma rede pode ser dramaticamente reduzida por alteração aleatória de poucas ligações de uma rede regular. A rede resultante foi chamada de Rede de Pequeno Mundo (Small-World Network). Já em 1999, Barabasi \& Albert (1999) descobriram que muitas das redes complexas reais têm a distribuição de grau para os vértices que obedece a lei de potência (power-law): $P(k) k^{-\gamma}$, na qual $k$ é o número de conexões de um vértice escolhido aleatoriamente e $\gamma$ é o expoente de escala. Esta distribuição heterogênea significa que a probabilidade $P$ de um conjunto de vértices possuir um grande número de ligações não é pequena. As redes caracterizadas pela distribuição algébrica são chamadas de Redes Livre de Escala (Scale-free Networks).

Atualmente várias áreas da ciência utilizam a abordagem de redes complexas nas mais distintas aplicações. De forma que, inevitavelmente, esta tem sido estudada sob diversas perspectivas. Uma das abordagens de estudo é entender a estrutura de redes naturais ou criadas pelo homem, por exemplo, redes alimentares em ecossistemas, redes bioquímicas e neurais em indivíduos, redes de iterações sociais, redes tecnológicas como a internet, etc (Newman, 2003). O entendimento da topologia dessas redes permite principalmente o desenvolvimento de modelos matemáticos utilizados para simulações de eventos e processos que podem ocorrer na rede. Em uma segunda abordagem deseja-se saber como a estrutura da rede de um sistema influencia no que ocorre no sistema, e.g. a estrutura de uma rede alimentar em um dado ecossistema afeta a dinâmica de populações e espécies ou a rede de iterações humanas influencia na disseminação de doenças, etc (Albert \& Barabási, 2002). 
Neste caso a preocupação não é diretamente com a estrutura da rede, mas sim com a dinâmica de outras variáveis presentes na rede, como veículos em uma rede rodoviária, energia em uma rede elétrica, etc. Um estudo tão importante quando os já mencionados trata-se de como as redes evoluem ao longo do tempo. Redes bioquímicas, neurais, ecológicas, sociais, tecnológicas, entre outras, não são estáticas, são produto de evolução (Dorogovtsev \& Mendes, 2003). A evolução de redes reais é bastante complexa, muitas vezes estas se auto-organizam e crescem em complexidade e tamanho, e chegam até mesmo a se desintegrarem. O estudo da evolução das redes não somente trata da adição e remoção de vértices, mas abrange de certa forma, as abordagens mencionadas anteriormente, pois a evolução da estrutura está interligada às demais variáveis presentes na rede.

\subsubsection{Modelos de rede}

Os avanços recentes na computação e alguns estudos empíricos sobre redes complexas reais possibilitaram a criação de modelos mais realìsticos para esse tipo de rede. Por meio desses modelos é possível representar redes que incorporam propriedades de redes reais e dessa forma estudá-las por meio de métodos matemáticos e computacionais. O desenvolvimento desses modelos permite encontrar e esclarecer propriedades tais como, a distribuição do grau das redes, betweenness, diâmetro, resistência a ataques e falhas, transição de fases em relação à média do grau, evolução de redes e determinação de comunidades entre outras. O estudo dessas propriedades permite desenvolver métodos que possam ser aplicados a diversos objetivos, como melhorar a dinâmica e o fluxo em uma rede, prever o comportamento de uma rede, entender a causa de maus funcionamentos, entender a propagação de doenças, proteger a rede em casos de ataques ou falhas, etc. No que segue será apresentado alguns dos principais modelos de redes complexas, a saber, redes randômicas, redes de pequeno mundo e redes livre de escala. As figuras que ilustram cada instância de cada modelo, bem como sua distribuição do grau característica, foram extraídas de (da Costa et al., 2007).

Redes randômicas

Antes das recentes descobertas de Watts \& Strogatz (1998) e de Barabasi \& Albert (1999), o modelo mais usado para representar redes era o modelo de Erdős \& Rényi (1959, 1961) conhecido como grafos randômicos ou redes randômicas.

O modelo de Erdős e Rényi baseia-se em ligações aleatórias, no primeiro artigo clássico sobre redes randômicas (Erdős \& Rényi, 1959), os autores definiram uma rede com $N$ vértices conectados por $M$ arestas, que são randomicamente selecionadas entre as $N(N-1) / 2$ possiveis arestas. Resultando no total 


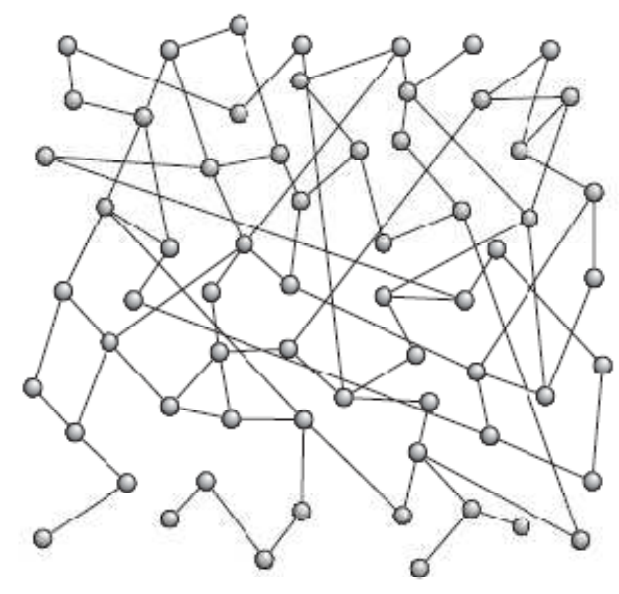

(a)

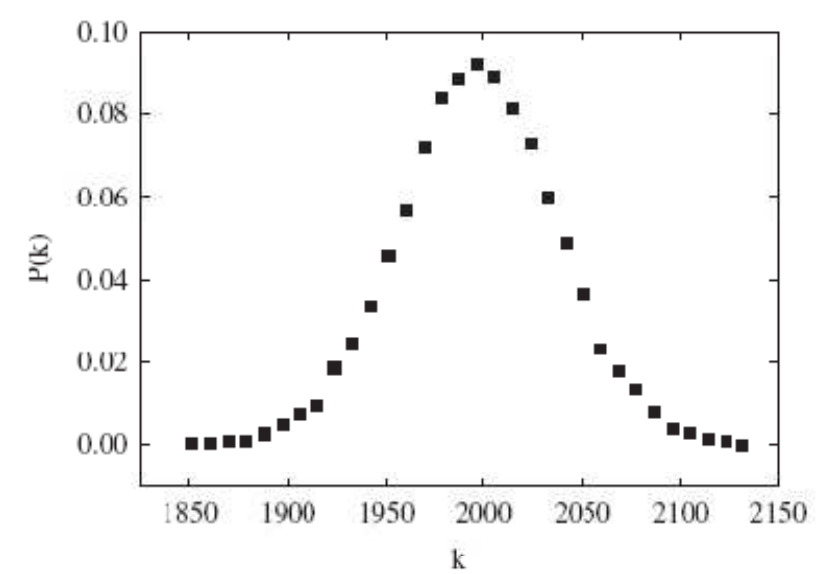

(b)

Figura 2.1: Rede randômica, (a) exemplo de rede (b) distribuição do grau para 10 redes randômicas formadas por 10.000 vértices cada, e probabilidade de conexão $P=0,2$. (da Costa et al., 2007)

de $C_{[N(N-1) / 2]}^{M}$ possíveis redes com $N$ vértices e $M$ arestas, formando um espaço de probabilidade no qual toda instância tem igual probabilidade de ocorrer. No modelo, a rede é iniciada com um conjunto de $N$ vértices totalmente desconectados e, a cada passo, um par de vértices escolhido de maneira aleatória têm probabilidade fixa $P$ de serem conectados, sendo cada par de vértices considerado apenas uma vez. Dessa forma, todas as ligações possuem a mesma probabilidade de ocorrerem; resultando em uma rede com estrutura altamente homogênea, como ilustrado na Figura 2.1.

Erdős e Rényi foram os primeiros a estudar a distribuição do grau desse tipo de rede. Em todos os modelos a distribuição do número de arestas para os diversos vértices, ou grau do vértice, é caracterizada pela distribuição do grau $P(k)$ que dá a probabilidade de um vértice selecionado aleatoriamente ter exatamente grau $k$. A distribuição do grau em redes randômicas segue a distribuição binomial apresentada na equação 2.1 .

$$
P(k)=\left(\begin{array}{c}
N-1 \\
k
\end{array}\right) p^{k}(1-p)^{N-1-k}
$$

Note que a distribuição da conectividade nesse tipo de redes quando $N$ é grande, tende à distribuição de Poisson, definida pela equação 2.2.

$$
P(k)=\frac{\langle k\rangle^{k} e^{-\langle k\rangle}}{k !}
$$

Além disso, a média do menor caminho $\langle l\rangle$ é pequena nessas redes, decaindo de forma proporcional ao logaritmo do tamanho da rede, $\langle l\rangle \sim \ln N / \ln \langle k\rangle$, sendo $\langle k\rangle=2 M / N=P(N-1) \approx P N$ o número médio de conexões na rede. O objetivo principal da teoria das redes randômicas é determinar para qual probabilidade de conexão $P$, uma determinada propriedade $Q$ da rede tem 
maior probabilidade de ocorrer. A maior descoberta de Erdős e Rényi foi que muitas propriedades importantes em redes randômicas aparecem quase que instantaneamente conforme $P(N)$ é aumentada, de modo que, para uma determinada probabilidade a maioria das redes apresenta alguma propriedade $Q$ (e.g. todo par de vértices é conectado por um caminho de arestas consecutivas). A transição entre a ocorrência de uma propriedade muito provável e uma propriedade improvável acontece muito rapidamente. Para muitas dessas propriedades existe uma probabilidade crítica para que esta ocorra, notada como $P_{c}(N)$. Toda vez que $P(N)$ cresce mais lentamente que $P_{c}(N)$ quando $N \rightarrow \infty$ quase todas as redes como probabilidade de conexão $P(N)$ não terá a propriedade $Q$. Se, no entanto, $P(N)$ crescer mais rapidamente que $P_{c}(N)$, então quase todas as redes com probabilidade de conexão $P(N)$ terá a propriedade Q.

Redes de pequeno mundo

O fato de que grandes redes reais (no caso redes sociais), terem diâmetro reduzido já havia sido constatado em 1967 por Milgram (1967). No entanto, apenas recentemente Watts \& Strogatz (1998) desenvolveram um modelo matemático para a representação de redes para as quais quisquer pares de vértices podem ser encontrados por um número pequeno de conexões, por essa razão este modelo foi chamado de Rede de Pequeno Mundo (Small-World Network). O modelo de redes de pequeno mundo surgiu quando Watts e Strogatz consideraram a possibilidade de construir uma rede randômica que tivesse algumas propriedades importantes de redes reais. As redes reais que consideraram incluíam redes neurais, redes de energia elétrica do oeste dos EUA, rede de colaboração de atores de filmes entre outras. Os autores verificaram que estas redes eram redes de pequeno mundo, i.e. o diâmetro dessas redes era consideravelmente menor que de redes construídas de maneira regular (como reticulados), com o mesmo número de vértices e arestas. A importância do trabalho de Watts e Strogatz, no entanto, deve-se ao fato de iniciarem uma importante área que consiste em modelar redes de grande escala através de gráficos aleatórios definidos por regras simples. Ao invés de considerarem o diâmetro da rede, os autores consideraram a distância média entre qualquer par de vértices $\langle l\rangle$.

$$
\langle l\rangle=\frac{1}{\frac{1}{2} N(N+1)} \sum_{i \geq j} l_{i j}
$$

Na equação, $N$ é número de vértices e $l_{i j}$ é a menor distância entre os vértices $i$ e $j$. Note que a distância de um vértice a ele mesmo é considerada, pois pode haver aplicações na qual considerar esta possibilidade possa ser 


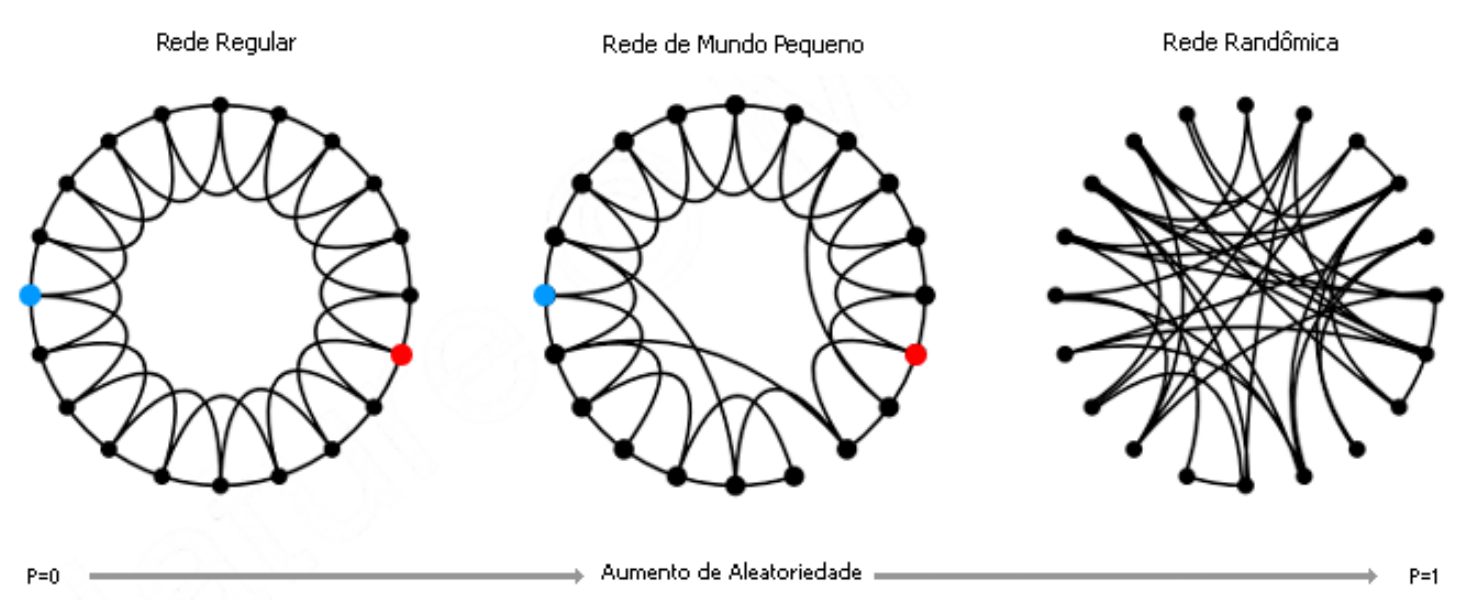

Figura 2.2: Procedimento de remanejamento de arestas do modelo de Watts \& Strogatz (1998).

interessante (Newman, 2003). Também na equação (2.3), pode acontecer de não existir caminho entre os vértices $i$ e $j$, neste caso esta distância não é considerada na média. Uma solução mais elegante para esta situação pode ser o uso da média harmônica ao invés da média convencional, maiores detalhes podem ser encontrados em (Newman, 2003).

A idéia do modelo de rede de pequeno mundo, introduzida por Watts \& Strogatz (1998), é iniciar a rede em um reticulado e, em seguida, adicionar ou remover arestas de maneira a criar alguns atalhos entre vértices distantes entre si. Considere um reticulado de dimensão unitária com $N$ vértices e com condições de borda periódicas, i.e. em formato de círculo. Neste reticulado cada vértice é conectado aos seus $k$ vizinhos mais próximos ( $k / 2$ em cada lado), e o mesmo deve verificar as desigualdades $N \gg k \gg \ln (N) \gg 1$ a fim de gerar uma rede esparsa e conectada. O processo de remanejamento das conexões percorre o reticulado vértice a vértice e cada aresta do vértice corrente é religada à outro vértice com probabilidade $P$. Este processo introduz $P N k / 2$ ligações diferentes das existentes anteriormente. Através da variação de $P$ pode-se observar a transição de um reticulado para uma rede aleatória, passando é claro pela rede de mundo pequeno, como ilustra a Figura 2.2.

De maneira mais precisa, Watts e Strogatz descobriram que algumas redes reais tendem a ser altamente clusterizadas, como reticulados e, ao mesmo tempo, terem diâmetro pequeno, como as redes randômicas. Pode-se observar na Figura 2.2, para uma rede com um número fixo de vértices, variando a probabilidade de remanejamento das conexões $P$ de maneira crescente, que existe um intervalo entre os extremos (rede regular a rede randômica) no qual a rede exibe média de caminhos pequena e coeficiente de cluster alto. Resultado verificado por simulações numéricas feitas por Watts e Strogatz (Figura 2.3).

O efeito de pequeno mundo tem implicações obvias com relação à dinâmica 


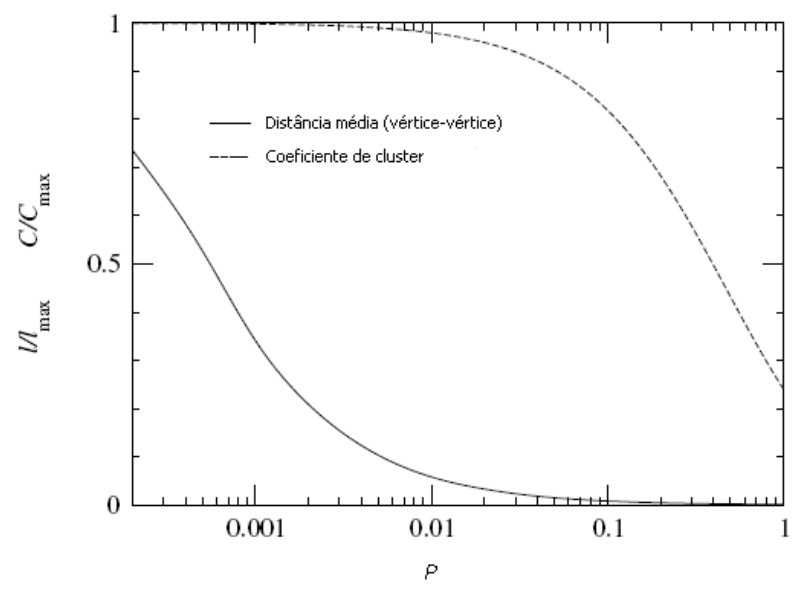

Figura 2.3: Coeficiente de cluster e média dos menores caminhos em função da probabilidade de remanejamento de conexões. (Newman, 2003).

dos processos que ocorrem na rede. Por exemplo, considerando a disseminação de um vírus em uma rede de relações humanas, o efeito de mundo pequeno implica que esta infestação será muito rápida. Vale ressaltar que o efeito de mundo pequeno pode ser observado em vários modelos de rede, como no modelo de Barabási e Albert, por exemplo.

Redes livre de escala

Recentemente a computação e a aquisição de dados sobre grandes redes reais proporcionaram informações que subsidiaram a criação de modelos mais realísticos para esse tipo de rede. Dentre esses modelos está o de Barabasi \& Albert (1999). Eles observaram que muitas das redes complexas reais têm a distribuição do grau para os vértices que obedece a lei de potência (power-law):

$$
P(k) \sim k^{-\gamma}
$$

na qual $k$ é o número de conexões de um vértice escolhido aleatoriamente e $\gamma$ é o expoente de escala. As redes caracterizadas por esta distribuição algébrica são chamadas de Redes Livre de Escala (Scale-free Networks). Redes com distribuição do grau obedecendo à lei de potência têm sido amplamente estudadas na literatura, alguns exemplos de redes livre de escala são, a WorldWide Web (WWW) (Flake et al., 2002), a Internet (Faloutsos et al., 1999), redes metabólicas (Jeong et al., 2000)), protéicas (Jeong et al., 2001), rede de e-mails (H. et al., 2002), redes de interação sexual (Liljeros et al., 2003), entre muitas outras. A origem da distribuição do grau seguindo a lei de potência observada em redes reais foi considerada inicialmente em (Barabasi \& Albert, 1999), que argumentaram que a natureza das redes livre de escala estava associada a dois mecanismos básicos, compartilhados por diversos tipos de 
redes reais. Os modelos anteriores consideravam um conjunto inicial de $N$ vértices, cujo número nunca era alterado, e as conexões eram feitas segundo algum critério. A maioria das redes reais, no entanto, representa sistemas que crescem pela adição contínua de vértices. Iniciando com um núcleo pequeno de vértices, o número de vértices aumenta durante a vida útil da rede através de subseqüentes adições de vértices. Um exemplo é a WWW cujo crescimento é exponencial em relação ao tempo, devido à adição de novas páginas. $\mathrm{O}$ segundo motivo apontado por Barabási e Albert, é que os modelos de redes anteriores assumem que a probabilidade de dois vértices serem conectados independe do grau dos vértices; i.e. novos vértices são adicionados (ou remanejados) de maneira aleatória. A maioria das redes reais, entretanto, exibe a propriedade de ligação preferencial, na qual a probabilidade de conexão depende do grau de vértice. Ainda considerando o exemplo da WWW, é mais provável que uma página adicione links de páginas populares com grau já elevado, pelo simples fato dessas páginas serem populares e fáceis de encontrar. Considerando essas duas características a rede, segundo o modelo de Barabási e Albert, é construída em duas etapas; (1) Crescimento da rede - iniciando com um grupo de vértices $\left(N_{0}\right)$, a cada iteração adiciona-se um novo vértice com $M\left(\leq N_{0}\right)$ arestas que conectam o novo vértice à $M$ vértices já presentes na rede. (2) Ligação preferencial - para a escolha dos vértices que serão ligados aos novos vértices, assume-se que a probabilidade do novo vértice conectar-se ao vértice i depende do grau do vértice $\mathbf{i}\left(k_{i}\right)$, conforme a equação (2.5).

$$
P\left(k_{i}\right)=\frac{k_{i}}{\sum_{j} k_{j}}
$$

Depois de um tempo $T$, este procedimento resulta em uma rede com $N=$ $T+N_{0}$ vértices e $M T$ arestas. Analíticamente mostra-se que este modelo evolui para um estado de escala invariante com probabilidade de que um vértice tenha $k$ arestas, seguindo a lei de potência com expoente $\gamma=3$, que é independente de $M$, único parâmetro do modelo. As simulações numéricas confirmam o resultado analítico (Albert \& Barabási, 2002).

A maior diferença entre as topologias de redes randômicas e redes livre de escala é que no caso da primeira os vértices têm aproximadamente o mesmo número de conexões, $k\langle k\rangle$, em contraste com redes livre de escala, na qual existem vários vértices com poucas ligações e alguns vértices com um número muito grande de conexões, como ilustra a Figura 2.4(a).

O modelo para redes livre de escala apresentado e alguns modelos semelhantes (ver (Barabasi \& Albert, 1999), por exemplo) consideram a rede como um sistema dinâmico, assumindo que estas redes se auto-constroem e evoluem ao longo do tempo através da adição e remoção de vértices e conexões. O 


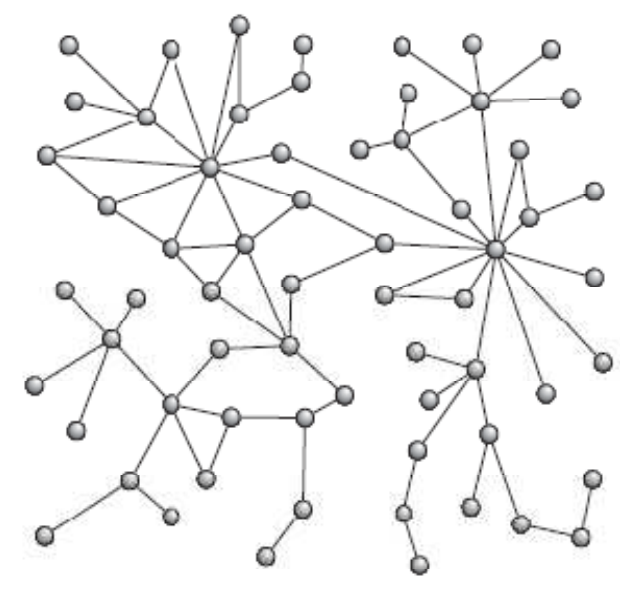

(a)

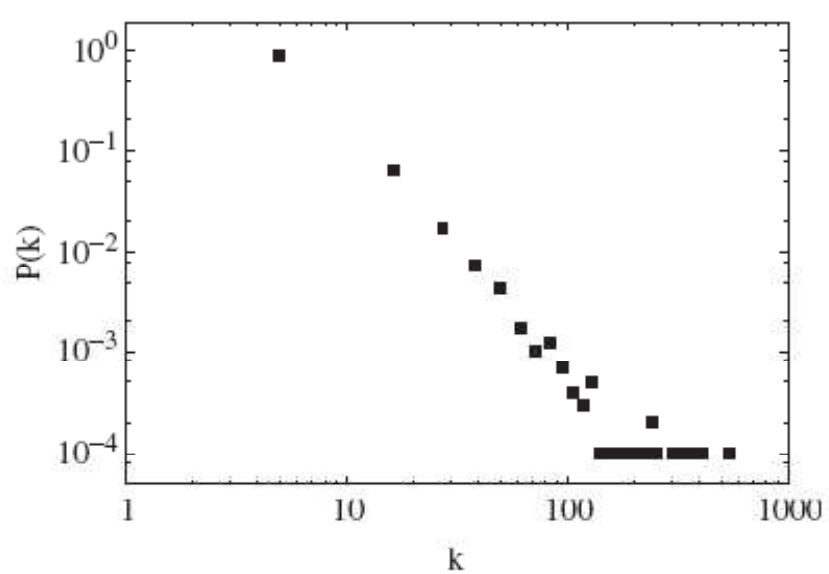

(b)

Figura 2.4: Rede livre de escala, (a) exemplo de rede (b) distribuição média do grau para 10 redes com 10.000 vértices cada e considerando $M=5$, onde $M$ é número de arestas (parâmetro do modelo). (da Costa et al., 2007).

modelo apresentado é o modelo mais simples para uma rede livre de escala, muitas modificações foram propostas para adequar o modelo a outros tipos de redes ou mesmo torná-lo mais realístico. A maioria dos sistemas complexos, no entanto, compartilha sua dinâmica e o caráter evolucionário, representado por redes complexas evolutivas, indicando que a topologia e sua evolução não podem ser analisadas separadamente.

\subsubsection{Detecção de comunidades em redes complexas}

Uma característica notável presente em diversas redes complexas, encontradas na natureza ou construídas pelo homem, é a presença de estruturas locais conhecidas como comunidades (Danon et al., 2007). Uma comunidade pode ser definida como um grupo de vértices pertencentes a uma rede, em que a quantidade de conexões entre estes vértices supera a média de conexões de toda a rede (Palla et al., 2005). Tais comunidades ou módulos são formados por vértices que possuem alguma relação de similaridade, como por exemplo, na WWW onde páginas que correspondem à tópicos semelhantes tendem a ser mais densamente conectadas entre si do que com o restante da rede (Flake et al., 2002). Varias outras redes compartilham esta propriedade, alguns exemplos são, as redes biológicas (e.g. redes metabólicas, interações gênicas e protéicas) (Jeong et al., 2000), entre outras. A Figura 2.5 ilustra uma rede dividida em estrutura de comunidades.

A detecção de comunidades em uma rede é importante para a compreensão das relações entre diferentes componentes, permite identificar funções de um componente com base nas funções de seus membros e tem aplicações nas mais diversas áreas da ciência, alguns exemplos são: balanceamento de nós em computação paralela, particionamento de circuitos, desenvolvi- 


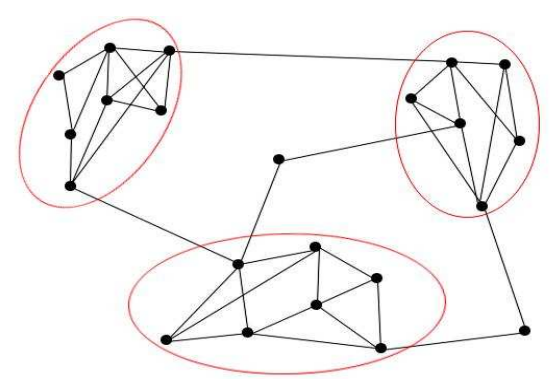

Figura 2.5: Exemplo de rede com três comunidades

mento de redes de telefonia e clusterização. A organização modular é propriedades comum presente em redes complexas, principalmente biológicas, e estão relacionadas a adaptação das redes com relação à robustez e à multitarefa (Hartwell et al., 1999). Uma característica a ser considerada quanto aos algoritmos de identificação das comunidades é que essa tarefa constitui um problema NP-completo (Danon et al., 2005). Além disso, em muitos casos, comunidades podem ser definidas hierarquicamente, como quando se tem comunidades dentro de outras comunidades (Ravasz \& Barabási, 2003). Apesar dessas dificuldades, muitos métodos têm sido propostos para identificar tais estruturas, mas o seu uso depende dos resultados desejados e das limitações existentes quanto ao poder computacional disponivel. Diversos algoritmos foram desenvolvidos para identificar comunidades em redes complexas, alguns dos principais serão apresentados a seguir.

\section{Betweenness}

O método de detecção de comunidades desenvolvido por (Newman, 2004) é baseado no conceito de betweenness (separabilidade) que é definido como uma medida que favorece (atribuir maior valor) arestas localizadas entre comunidades e desfavorece (atribuir menor valor) aquelas que se encontram dentro de uma comunidade. No método de Newmam e Girvan, a cada passo, a aresta de maior betweenness é removida, dividindo a rede em comunidades. $\mathrm{O}$ princípio em que este método baseia-se é simples, como o número de arestas conectando duas comunidades é pequeno, todos os caminhos que ligam vértices em comunidades diferentes devem passar por essas arestas. Dado um conjunto de caminhos entre vários pares de vértices, a idéia consiste em contar, para cada aresta, de quantos caminhos esta faz parte. Espera-se que este número seja maior para arestas entre diferentes comunidades e dessa forma, o encerramento iterativo destas conexões fornece uma forma de identificar as comunidades. Os passos do algoritmo podem ser definidos como:

1. Calcule os valores de betweenness de todas as arestas da rede;

2. Remova da rede a aresta de maior betweenness; 
3. Recalcule os valores de betweenness para as demais arestas;

4. Volte ao Passo 2.

Note que o betweenness é calculado toda vez que uma aresta é removida da rede. Uma outra opção seria seguir uma ordem decrescente de remoção partindo de um único cálculo do betweenneess por aresta. Apesar de ser computacionalmente mais barato e aparentemente surtir o mesmo efeito, na realidade a remoção das arestas em ordem decrescente de betweenness acarreta em um problema: Quando duas arestas conectam duas comunidades, e por algum motivo a maior parte dos caminhos gerados entre os pares de vértices passaram por apenas uma dessas arestas, o algoritmo irá remover a aresta de maior betweenness e a outra aresta continuará conectando as comunidades, podendo nunca ser removida pelo algoritmo. Por esse motivo o valor de betweenness é recalculado toda vez que uma aresta é removida.

Como mencionado anteriormente a medida de betweenness visa favorecer arestas que ligam vértices de diferentes comunidades e penalizar àquelas que ligam vértices de uma mesma comunidade. Existem inúmeras maneiras de definir medidas de betweenness que verificam esta propriedade, três delas são sugeridas por Newman (2004), a saber: betweenness de caminho mais curto (shortest-path betweenness), betweenness de caminhada aleatória (randomwalk betweenness) e betweenneess de fluxo de corrente (current-flow betweenness). Dentre essas medidas, as duas primeiras podem ser vistas como limites inferior e superior, respectivamente, para esta medida. A seguir cada uma delas é brevemente caracterizada.

\section{Betweenneess de caminho mais curto}

O exemplo mais simples para uma medida de betwenneess é o menor caminho entre dois vértices, chamado betweenneess de caminho mais curto (shortest-path betweenneess). Neste caso encontra-se o menor caminho para todo par de vértices e então, para cada aresta é contado o número de caminhos que determinada aresta faz parte. Note que o cálculo do betweenness com base em caminhos mais curtos tem complexidade $O\left(N^{2} M\right)$ em uma rede com $N$ vértices $M$ arestas (Cormen et al., 2001). Essa complexidade deve-se ao fato de que os caminhos mais curtos entre dois vértices podem ser calculados usando busca em amplitude com tempo $O(M)$, o que deve ser feito para todos os pares de vértices. Uma adaptação deste método proposta por Newman (2004) permite calcular o betweenness de todas as arestas em tempo $O(N M)$. Entretanto, Newman e Girvan notaram que apenas as arestas de um mesmo componente da aresta removida têm seus betweenness afetados; portanto apenas os betweenness dessas arestas precisam ser recalculados. A 
medida que a remoção das arestas divide a rede em comunidades, o custo computacional com cálculo do betweenness é reduzido.

\section{Modularidade}

Outro método desenvolvido por Newman \& Girvan (2004), sugere um algoritmo que otimize o valor da modularidade, medida usada para qualificar determinada partição da rede em comunidades. Trata-se de um algoritmo aglomerativo de clusterização hierárquica. Considere uma divisão particular da rede em $k$ comunidades, dessa forma define-se a matriz simétrica $C_{k \times k}$ tal que o elemento $c_{i j}$ corresponde à fração das arestas da rede que conectam vértices da comunidade $i$ à comunidade $j$. O traço da matriz $\mathrm{C}$ corresponde à fração de arestas da rede que conectam os vértices de uma mesma comunidade. No entanto o traço não revela nada sobre a disposição das comunidades. Dessa forma é necessário definir a soma da linha como $a_{i}=\sum_{j} c_{i j}$ que representa a fração de arestas que conectam a vértices na comunidade i. Este índice, proposto em (Newman, 2004), é definido como na equação 2.6.

$$
Q=\sum_{i}\left(c_{i i}-a_{i}^{2}\right)
$$

A equação 2.6 mede a fração dos vértices da rede que se encontra em comunidades, se as conexões dentro das comunidades forem randômicas, o valor de $Q$ aproxima-se do mínimo $Q=0$, indicando uma rede sem estrutura de comunidades, enquanto que valores próximos de $Q=1$, que é o maior valor, determinam estrutura modular bem definida. Para se obter uma divisão da rede em comunidades, utilizando o conceito de índice de modularidade, procede-se da seguinte forma. Inicialmente cada vértice da rede é considerado uma comunidade, e repetidamente as comunidades são agrupadas em pares $i$ e $j$ de forma a maximizar o índice de modularidade. A variação obtida pela aglomeração das comunidades $i$ e $j$ pode ser calculada pela equação 2.7.

$$
\Delta Q=c_{i j}+c_{j i}-2 a_{i} a_{j}=2\left(c_{i j}-a_{i} a_{j}\right)
$$

Na equação, $a_{j}$ corresponde à soma da coluna $j$ e é dado por $a_{j}=\sum_{i} c_{i j}$. é importante ressaltar que apenas comunidades que possuem arestas ligando seus vértices podem ser possivelmente unidas pelo algoritmo. Isso limita a um máximo de $M$ pares de comunidades, onde $M$ é o número de arestas do grafo.

\section{Caminhada aleatória}

O método de caminhada aleatória para a identificação de comunidades é baseado no conceito de movimento de uma partícula Browniana para calcular a distância entre os vértices da rede e a estrutura de comunidades da rede. 
Nesta abordagem, desenvolvida por Zhou (2003b), não é necessário a retirada de arestas ou vértices da rede. Ao invés disso, a partícula percorre a rede de maneira aleatória calculando as distâncias entre os vértices. As informações obtidas pela partícula são utilizadas para medir a distância entre os vértices, definindo as comunidades que compõem a rede e a estrutura de cada uma. Este método pode ser usado não somente na detecção de comunidades, mas também na identificação do vértice central de cada comunidade. Considere uma rede formada por um conjunto de $N$ vértices $V=\{1, \ldots, N\}$ e $M$ arestas, e considere a representação desta rede por meio de uma matriz de adjacência $A$ usada para indicar a força da interação entre os vértices. Considere $a_{i j}$ representando um elemento da matriz, dessa forma se $a_{i j}$ for igual a zero, não há conexão entre os vértices $i$ e $j$; se, no entanto, $a_{i j}=a_{j i}>0$ existe uma aresta que liga os vértices $i$ e $j$, com o valor numérico indicando a força da interação entre eles. O conjunto de vizinhos do vértice $i$ é denotado por $V_{i}$. Considerando que existe uma partícula Browniana na rede, a cada passo essa partícula move-se do vértice $i$ para um vértice $j$ com probabilidade $P_{i j}$, dada pela matriz de transferência $P$. O valor de $P_{i j}$ pode ser calculado de maneira intuitiva por: $P_{i j}=A_{i j} / \sum_{k=1}^{N} A_{i k}$. A distância $d_{i j}$ entre os vértices $i$ e $j$ é definida como a média de passos necessários para a partícula Browniana iniciar em $i$ caminhar aleatoriamente pela rede e chegar em $j$, esta pode ser calculada como mostra a equação 2.8 .

$$
d_{i j}=\sum_{k=1}^{N}\left(\frac{1}{I-B(j)}\right)_{i k}
$$

na qual $I$ é a matriz identidade $N \times N$ e $B(j)$ representa a matriz de transferência $P$ exceto que $B_{k j}(j)=0$, para todo $k \in V$. A distância entre todos os vértices da rede e $j$ pode ser encontrada por meio da solução da equação 2.9.

$$
[I-B(j)]\left\{d_{1, j}, \ldots, d_{N, j}\right\}^{t}=\{1, \ldots, 1\}^{t}
$$

Se o vértice $j$ tem a propriedade $d_{i, j} \leq d_{i, m}$ para todo $m \in V$, então $j$ é um atrator global do vértice $i$. De modo análogo, se $j \in V_{i}$ e $d_{i, j} \leq d_{i, k}$ para todo $k \in V_{i}$, então $j$ é uma atrator local de $i$. é importante notar que, em geral a distância de $i$ para $j$ é diferente da distância de $j$ para $i$, assim se $j$ é atrator de $i$, o contrário não necessariamente é verdadeiro.

Em uma rede é dividida em diferentes grupos, é esperado que o vértice $i$ esteja no mesmo grupo que seu atrator local $j$, uma vez que entre todos os vértices na vizinhança de $i V_{i}$, o vértice $j$ possui a menor distância do vértice $i$. Dessa forma Zhou define a comunidade baseada em atratores locais, ou $L$ Comunidade, como o conjunto de vértices $L=\left\{i_{1}, \ldots i_{n}\right\}$ satisfazendo uma das seguintes condições: 
1. Se o vértice $i \in L$ e o vértice $j$ é um atrator local de $i$, então $j \in L$;

2. Se $i \in L$ e o vértice $m$ tem $i$ como seu atrator local, então $m \in L$;

3. Qualquer subconjunto de $L$ que não seja uma $L$-comunidade é uma comunidade;

O método foi estendido posteriormente por Zhou (2003a) com a definição de um índice de dissimilaridade entre vértices vizinhos através da matriz de distâncias. O índice de dissimilaridade indica até que ponto dois vértices vizinhos devem pertencer à mesma comunidade, e pode ser usado na decomposição hierárquica da rede em clusters. Considerando um vértice qualquer $i$ como partida da partícula, então o conjunto $\left\{d_{i 1}, \ldots d_{i, i-1}, d_{i, i+1}, \ldots, d_{i N}\right\}$ representa o quanto longe de $i$ estão todos os outros vértices. Supondo que $i$ e $j$ sejam vizinhos mais próximos $\left(a_{i j}>0\right)$, a diferença na perspectiva com relação à rede pode ser medida através da medida de dissimilaridade $\Lambda(i, j)$,

$$
\Lambda(i, j)=\sqrt{\frac{\sum_{k \neq i, k \neq j}\left(d_{i k}-d_{j k}\right)^{2}}{(N-2)}}
$$

Se dois vértices próximos $i$ e $j$ pertencem à mesma comunidade, então a distância média $d_{i k}$ entre $i$ a qualquer vértice $k$ será similar à distância media entre $j$ e $k\left(d_{j k}\right)$, dessa forma a perspectiva da rede (baseado em $i$ e $j$ ) será similar. Conseqüentemente, o valor de $\Lambda(i, j)$ será pequeno se $i$ e $j$ pertencerem à mesma comunidade e grande caso contrário. Cada comunidade pode ser caracterizada por um limite inferior e um superior para valores de dissimilaridade.

\section{O modelo baseado na mecânica estatística - Potts model}

De modo simplista, o modelo de Potts da mecânica estatística, modela um conjunto de elementos dotados de spins e dispostos em um reticulado. Os métodos previamente mencionados dependem somente da estrutura da rede para encontrar comunidades, pois nenhuma outra informação é disponível. Uma abordagem complementar desenvolvida em (Reichardt \& S.Bornholdt, 2004), combina a idéia de Fu \& Anderson (1986) de utilizar uma modificação do modelo Hamiltoniano de Ising no particionamento de grafos e o recente método de clusterização baseado no modelo de Potts para dados multivariados, proposto em (Blatt et al., 1996). Basicamente Reichardt e Bornholdt estenderam o modelo de Blatt para detecção de comunidades em redes complexas. O método é baseado na analogia a um modelo da mecânica estatística, o modelo ferromagnético de Potts. A idéia principal é mapear as comunidades de uma rede em 
mínimos locais dos domínios magnéticos dado pela equação Hamiltoniana:

$$
\mathcal{H}=-J \sum_{(i, j) \in E} \delta_{\sigma_{i}, \sigma_{j}}+\gamma \sum_{s=1}^{q} \frac{n_{s}\left(n_{s}-1\right)}{2}
$$

Na equação, $E$ é o conjunto de arestas, $\sigma_{i}$, para $i=\{1, \ldots N\}$, denota os spins individuais que podem assumir os valores, $s=1, \ldots, q$. O número de elementos que tem valor de $\operatorname{spin} s$ é denotado por $n_{s}, J$ é a força de interação ferromagnética do modelo de Potts, e $\delta$ é o delta de Kronecker, definido como uma função de duas variáveis que retorna 1 se são iguais e 0 caso contrário. O parâmetro $\gamma$ é positivo e sua escolha determina o quão forte será a correlação entre o mínimo da equação Hamiltoniana e a topologia da rede. O número de comunidades possíveis $q$ não é um parâmetro crucial para o algoritmo, a única exigência é que $q$ seja grande o bastante para acomodar todas as comunidades possíveis. A primeira somatória da equação 2.11 corresponde ao modelo ferromagnético de Potts, aqui considerando a interconexão dos vértices em uma rede. Esta parte da equação favorece a distribuição homogênea dos spins na rede. A segunda parte da equação, por outro lado, introduz diversidade através da soma de todos os possiveis pares de spins que tem mesmo valor. Tem como efeito contrabalancear a primeira somatória aumentando a energia conforme aumenta a homogeneidade da configuração dos spins. Esta segunda parte da equação pode ser vista como um inibidor global, sendo máximo quando todos os vértices têm o mesmo valor de spin, e mínimo quando todas as possibilidades de valores de spins encontram-se distribuídas igualmente na rede.

Considerando ainda a equação Hamiltoniana 2.11, para que seu estado estacionário corresponda à rede divida em comunidades, o parâmetro $\gamma$ deve ser definido de forma que, $H_{\text {homogeneo }} \geq H_{\text {dividida }}$. Dessa forma se $J$ for definido como sendo 1 , então $\gamma$ pode ser definido como sendo a média da probabilidade de conexões da rede. Dessa forma a equação 2.11 pode ser escrita como:

$$
\mathcal{H}=\sum_{i<j} \delta_{\sigma_{i}, \sigma_{j}}\left(\gamma-A_{i j}\right)
$$

Onde A corresponde à matriz de adjacência da rede. Para encontrar ou aproximar o sistema para o estado de mínima energia é utilizado simulação de Monte Carlo através do algoritmo de banho térmico (heat bath) juntamente com o método de simulated annealing com o processo de resfriamento iniciando com uma temperatura T tal que, mais que 0.95. $(N-N / q)$ dos $N$ vértices troquem seus spins a cada passo. A temperatura é decrementada de $T=\alpha T$, com $\alpha=0,99$, como sugerido pelos autores. 
Os métodos mencionados anteriormente são baseados em otimização e exigem um custo computacional muito alto, devido principalmente ao constante cálculo do valor de betweenness. Acredita-se que métodos baseados na sincronização sejam mais eficientes no processo de clusterização (Boccaletti et al., 2007). De fato, experimentos fisiológicos têm revelado fortes evidências da existência de sincronismo em atividades rítmicas do cérebro em alguns mamíferos, como gatos e macacos (ver (Engel et al., 1991; Grey et al., 1989; Murthy \& Fetz, 1992) por exemplo). Neurônios de uma mesma área ou mesmo em áreas diferentes do cérebro podem estar sincronizados se uma estimulação consistente for recebida, enquanto que, atividade sincronizada não é observada se a estimulação for inconsistente. O método proposto por Boccaletti et al. (2007) utiliza sincronização para encontrar comunidades na rede. O método consiste em associar um oscilador a cada vértice da rede. Em seguida valores iniciais para os parâmetros são dados de maneira que toda a rede fique sincronizada, então como um processo de simulated annealing, enquanto os parâmetros são afrouxados a sincronização total se desfaz em grupos sincronizados, revelando as comunidades. O método de Boccaletti et al. (2007) combina informações sobre topologia e dinâmica da rede para derivar um algoritmo dinâmico de clusterização capaz de identificar estruturas modulares. O método é baseado em um fenômeno de sincronização de clusters utilizando osciladores de fase não idênticos (Boccaletti et al., 2002), cada um associado a um vértice da rede e interagindo através das arestas da rede. Clusters de osciladores sincronizados representam um regime intermediário entre travamento de fase global e completa abstenção de sincronização, implicando em uma divisão da rede em grupos de vértices que oscilam na mesma freqüência média. A idéia principal consiste em iniciar a rede com todos os elementos acoplados, e por meio de mudanças dinâmicas nos pesos das interações entre vértices, obter uma clusterização hierárquica e progressiva que detecta totalmente os módulos (comunidades) presentes na rede. De maneira geral, dada uma rede sem peso e não dirigida com $N$ vértices e $M$ arestas, descrita pela matriz de adjacência $\mathrm{A}$, pode-se associar a cada vértice $i(i=1, \ldots, N)$ uma variável dinâmica $\left.x_{i}(t) \in\right]-\infty,+\infty[$. A dinâmica de cada vértice é governada pela equação:

$$
\dot{x}(t)=\omega_{i}+\frac{\sigma}{\sum_{j \in V_{i}} b_{i j}^{\alpha(t)}} \sum_{j \in V_{i}} b_{i j}^{\alpha(t)} \operatorname{sen}\left(x_{j}-x_{i}\right) \beta e^{-\beta\left|x_{j}-x_{i}\right|}
$$

na qual $\omega_{i}$ é a freqüência natural do vértice $i$, geralmente inicializado com valores aleatórios no intervalo [0,1], $\sigma$ é o termo de acoplamento, e $V_{i}$ é o conjunto de vértices adjacentes ao vértice $i$. O parâmetro constante $\beta$, tem o efeito de anular a interação entre vértices quando a distância de fase entre 
dois osciladores excede um determinado limiar. Note que toda interação entre dois vértices adjacentes $i$ e $j$ é ponderada pelo termo $b_{i j}^{\alpha(t)} / \sum_{j \in V_{i}} b_{i j}^{\alpha(t)}$, no qual $b_{i j}$ é o betweenneess entre os vértices $i$ e $j$, e $\alpha(t)$ é um expoente dependente do tempo, de modo que $\alpha(0)=0$. Este método, no entanto, além de utilizar osciladores que exigem condições muito específicas para sincronização, ainda depende do cálculo do betweenness.

\subsubsection{Sobreposição de comunidades}

Muitos dos sistemas complexos encontrados na natureza e na sociedade podem ser representados como uma rede complexa que descreve a intrincada rede de conexões existentes entre seus diversos pares de vértices (Watts \& Strogatz, 1998; Barabasi \& Albert, 1999). Uma questão de grande interesse é como interpretar a organização global de tais redes, bem como a coexistência de estruturas modulares associadas a partes densamente conectadas da rede. A identificação dessas comunidades, módulos funcionais desconhecidos a priori (funcionalidades relacionadas à proteínas (Ravasz et al., 2002), setores industriais (Onnela et al., 2003), grupos de pessoas (Watts et al., 2002), etc.) é crucial para o entendimento da estrutura e de propriedades funcionais da rede. Os métodos determinísticos existentes, dentre os quais alguns foram descritos anteriormente, são usados em grandes redes para encontrar comunidades disjuntas, enquanto que a maioria das redes reais constitui grandes áreas sobrepostas de vértices correlacionados, comunidades com grandes áreas sobrepostas (ver (Palla et al., 2005; Zhang et al., 2007).

A presença de comunidades em uma rede deve-se a estrutura hierárquica presente em sistemas complexos (Vicsek, 2002). Os métodos de detecção de comunidades até agora mencionados, somente são úteis se a estrutura de comunidade de uma determinada rede puder ser interpretada separadamente como na Figura 2.7(a). A maioria das redes reais, entretanto, é caracterizada por sobreposições bem formadas estatisticamente e comunidades sobrepostas. Tal afirmação pode ser demonstrada pelo número de comunidades que cada pessoa pertence, incluindo aquelas relacionas a atividades científicas, vida pessoal (escola, hobby, família) entre outras, como mostra a Figura 2.6(b). Além do que, membros de comunidades que uma determinada pessoa pertence, também pertencem a comunidades que a pessoa referida não faz parte; resultando em uma rede de comunidades extremamente complexa. Este fato, apesar de a algum tempo ter sido notado por sociólogos (Faust, 2005), só recentemente começou a ser tratado de maneira sistemática para grandes redes.

De modo geral, cada vértice $i$ da rede pode ser caracterizado por um número de membros (membership number) $m_{i}$, que corresponde ao número de comu- 

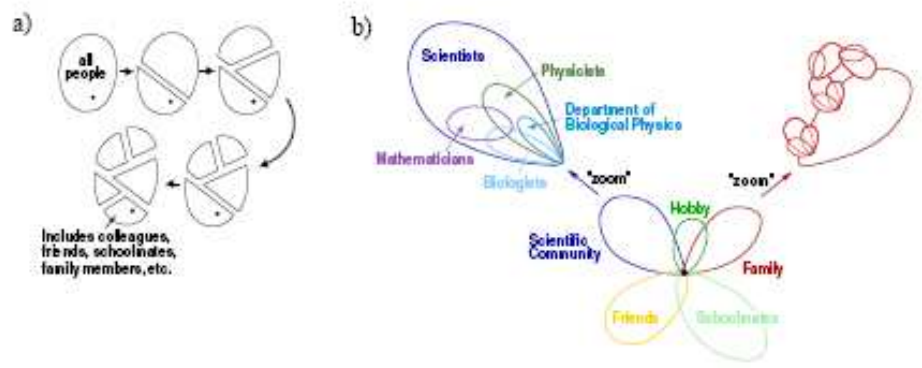

Figura 2.6: Sobreposição de Comunidades (a) Comunidades isoladas (b) Sobreposição de comunidades (Palla et al., 2005)

nidades que um determinado vértice pertence. Dessa forma, quaisquer duas comunidades, $\alpha$ e $\beta$ podem dividir $\left.S_{(} \alpha, \beta\right)^{o v}$ vértices, definido como o tamanho da sobreposição. Palla et al. propuseram visualizar as sobreposições entres as comunidades como conexões entre elas, e dessa o número de ligações desse tipo que uma comunidade $\alpha$ possui é chamado grau da comunidade $d_{\alpha}$. O tamanho de cada comunidade $S_{\alpha}$ pode ser naturalmente determinado pelo número de seus vértices. Uma vez definida essas medidas é possível caracterizar a estrutura de comunidades em grandes redes através das distribuições dessas quatro quantidades, $P(m), P\left(S^{o v}\right), P(d)$, e $P(S)$. A idéia que o método de Palla et al. (2005) para definir comunidades, é baseada no conceito de clique da teoria dos grafos. Um clique é um conjunto de vértices $V$ tal que, para cada par de vértices possíveis em $V$ existe uma aresta que os conecta. De maneira alternativa, um clique é um subgrafo induzido por $V$ que forma um grafo completo. O tamanho do clique é o número de vértices que este contém, notado aqui por $k$. Uma comunidade típica consiste em vários subgrafos completos (totalmente conectados) que tendem a compartilhar vários de seus vértices. Dessa forma, Palla et al. Definem comunidade, ou mais precisamente, uma comunidade com $k$-cliques como sendo a união de todos os $k$-cliques (subgrafos completos de tamanho $k$ ) que podem ser alcançados de um para o outro por meio de uma serie de $k$-cliques adjacentes (na qual adjacência significa compartilhar $k-1$ vértices) (Everett \& Borgatti, 1998). Esta definição tem o propósito de representar uma característica essencial de uma comunidade, o fato de que seus membros possam ser alcançados por meio de subconjuntos de vértices bem conectados. Existem outras partes da rede que não são alcançáveis por meio de um $k$-clique particular, mas essas partes potencialmente contêm outras comunidades k-cliques. Dessa forma, um único vértice pode pertencer a diversas comunidades. 


\subsection{Caminhada Aleatória}

Um passeio aleatório é qualquer processo estocástico onde a posição de uma partícula em um determinado instante depende apenas de sua posição em um instante anterior e de alguma variável randômica que determina o comprimento do passo e a direção. Casos específicos de passeios aleatórios incluem o movimento Browninano (A. J. Litchenberg, 1983) e a caminhada aleatória (Douglas Lind, 1995).

Passeios aleatórios estão relacionados a modelos de difusão e são um tópico fundamental no estudo de processos Markovianos (Hannes Risken, 1996). Muitas propriedades de passeios aleatórios tais como distribuições de dispersão e tempos de primeira passagem em reações químicas, têm sido extensivamente estudados (B. Maiti \& Sathyamurthy, 2000).

\subsubsection{Definição}

Seja $X(t)$ uma trajetória que começa na posição $X(0)=X_{0}$. Um passeio aleatório é modelado pela seguinte expressão:

$$
X(t+\tau)=X(t)+\Phi(\tau)
$$

onde $\Phi$ é uma variável aleatória que descreve a regra de probabilidade para tomar um próximo passo e $\tau$ é o intervalo de tempo entre passos. Desde que o tamanho e a direção de cada passo dependa apenas da posição $X(t)$ e não dependa de posições anteriores, dizemos que o passeio aleatório possui a propriedade Markoviana. Se por outro lado a distribuição de passos for independente do tempo e da posição o processo aleatório terá a propriedade de homogenidade (Samuel Karlin, 1975).

Passeios aleatórios podem ser definidos em qualquer número de dimensões, podem ser enviesados ou não enviesados e podem ter tempo ou espaço discretos ou contínuos. Um exemplo de caminhada aleatória, muito usada na modelagem de polímeros, é a caminhada aleatória não auto-intersectante. Tal caminhada aleatória viola a propriedade Markoviana e também viola a propriedade de homogenidade, pois caminhadas que refletem na borda ou estão restritas a uma determinada região do espaço são não homogêneas.

\subsubsection{Passeio Aleatório Unidimensional}

Considere uma partícula se movendo ao longo de uma reta, partindo da origem. A cada intervalo de tempo $\tau$, ela salta uma distância $h$ para a direita com probabilidade $p$ e uma distância $h$ para a esquerda com probabilidade $q=1-p$. Para descrever o movimento da partícula, introduzimos variáveis 
aleatórias independentes $\sigma_{1}, \sigma_{2}, \sigma_{3}, \ldots$ que tomam os valores 1 ou -1 conforme o salto seja para a direita ou para a esquerda, respectivamente. A variável $\sigma_{j}$ indica se no j-ésimo instante a partícula deve saltar para a direita ou para a esquerda e, portanto, ela toma o valor 1 com probabilidade $p$ e $-1 \mathrm{com}$ probabilidade $q$. A posição da partícula no instante $t=n \tau$ será $x=h m$ onde $m=\sigma_{1}+\sigma_{2}+\ldots+\sigma_{n}$. A média e a variância de $\sigma_{j}$ são dadas por (de Oliveira, 2001):

$$
a=\left\langle\sigma_{j}\right\rangle=p-q
$$

e

$$
b=\left\langle\sigma_{j}^{2}\right\rangle-\left\langle\sigma_{j}\right\rangle^{2}=1-(p-q)^{2}=4 p q
$$

respectivamente. A função característica $g(k)$ da variável $\sigma_{k}$ é:

$$
g(k)=\left\langle e^{i k \sigma_{j}}\right\rangle=p e^{i k}+q e^{-i k}
$$

Para obter a probabilidade $P_{n}(m)$ da partícula estar a $m$ passos da origem após $n$ intervalos de tempo, determinamos primeiro a correspondente função característica

$$
G_{n}(k)=[g(k)]^{n}=\left(p e^{i k}+q e^{-i k}\right)^{n} \sum_{l=0}^{n}\left(\begin{array}{c}
n \\
l
\end{array}\right) p^{l} q^{n-l} e^{i k(2 l-n)}
$$

e comparando com a definição de $G_{n}(k)$, dada por

$$
G_{n}(k)=\sum_{m=-n}^{n} P_{n}(m) e^{i k m}
$$

onde $m$ toma os valores $-n,-n+2, \ldots, n-2$ e $n$ e trocando a variável do somatório de $l$ para $m=2 l-n$, vemos que:

$$
P_{m}(m)=\frac{n !}{\left(\frac{n+m}{2}\right) !\left(\frac{n-m}{2}\right) !} p^{(n+m) / 2} q^{(n-m) / 2}
$$

A média e a variância são dadas por:

$$
\langle m\rangle=n a
$$

e

$$
\left\langle m^{2}\right\rangle-\langle m\rangle^{2}=m b=4 n p q
$$

Como as variáveis $\sigma_{1}, \sigma_{2}, \sigma_{3}, \ldots$ são independentes, pelo teorema central do 
limite, temos que para $n>>1$ :

$$
P_{n}(m)=\frac{1}{\sqrt{2 \pi n b}} \exp -\frac{(m-n a)^{2}}{2 n b}
$$

A densidade de probabilidade $\rho(x, t)=P_{n}(m) / h$ da variável $x$ no instante $t$ é dada por:

$$
\rho(x, t)=\frac{1}{\sqrt{2 \pi D t}} \exp -\frac{(x-c t)^{2}}{2 D t}
$$

onde

$$
c=\frac{h a}{\tau}=\frac{h(p-q)}{\tau}
$$

$\mathrm{e}$

$$
D=\frac{h^{2} b}{\tau}=\frac{h^{2} 4 p q}{\tau}
$$

Obtemos ainda os resultados:

$$
\langle x\rangle=c t
$$

$\mathrm{e}$

$$
\left\langle x^{2}\right\rangle-\langle x\rangle^{2}=D t
$$

que permitem dizer que $c$ é a velocidade média da partícula e $D$ o coeficiente de difusão.

Vamos considerar em seguida um passeio aleatório unidimensional genérico. Suponha que a cada intervalo de tempo $\tau$ uma partícula se desloca de um valor $x_{j}$ da posição onde se encontra. Supondo que ela parta da origem, a posição da partícula no mesmo instante $t=\tau n$ será $x=x_{1}+\ldots+x_{n}$. Seja $P\left(x_{j}\right)$ a densidade de probabilidade $x_{j}$ e seja $g(k)$ a correspondente função característica, isto é,

$$
g(k)=\left\langle e^{i k x_{j}}\right\rangle=\int P\left(x_{j}\right) e^{i k x_{j}} d x_{j}
$$

A função característica correspondente à variável $x$ é dada por

$$
G(k)=[g(k)]^{n}
$$

Para obter a densidade de probabilidades da variável $x$ para $n$ grande utlizamos a mesma técnica empregada na demonstração do teorema central do limite. Essa técnica equivale a expandir a função característica $g(k)$ em cumu- 
lantes até a segunda ordem, isto é:

$$
g(k)=e^{i A k-B k^{2} / 2}
$$

desde que a média $A$ e a variância $B$ de $x_{j}$ existam. Portanto,

$$
G(k)=e^{i n A k-n B k^{2} / 2}
$$

e lembrando que $t=n \tau$ e definindo $c=A / \tau$ e $D=B / \tau$, temos:

$$
G(k)=e^{i c t k-D t k^{2} / 2}
$$

de modo que a densidade de probabilidade $\rho(x, t)$ de $x$ será:

$$
\rho(x, t)=\frac{1}{\sqrt{2 \pi D t}} \exp -\frac{(x-c t)^{2}}{2 D t}
$$

É interessante notar que a densidade de probabilidade $\rho(x, t)$ para o problema do passeio aleatório unidimensional satisfaz a seguinte equação diferencial:

$$
\frac{\partial \rho}{\partial t}=-c \frac{\partial \rho}{\partial x}+\frac{\partial^{2} \rho}{\partial x^{2}}
$$

Essa é uma equação de difusão, com arrastamento, e é um caso particular das equações de Fokker-Planck (Hannes Risken, 1996).

\subsubsection{Passeio Aleatório Bidimensional}

Vamos considearar agora o caso de uma partícula se movimentando num espaço bidimensional. A cada intervalo de tempo $\tau$ a partícula se desloca da posição anterior para uma nova posição. No j-ésimo intervalo de tempo denotamos o deslocamento por $\mathbf{r}_{j}=\left(x_{j}, y_{j}\right)$. Supondo que no instante inicial a partícula esteja na origem do sistema de coordenadas a posição da partícula no instante $t=n \tau$ será $\mathbf{r}=\mathbf{r}_{1}+\ldots+\mathbf{r}_{n}$. As variáveis $\mathbf{r}_{1}, \mathbf{r}_{2}, \ldots, \mathbf{r}_{n}$ são variáveis aleatórias independentes, como uma determinada distribuição de probabilidades $P\left(\mathbf{r}_{j}\right)=P\left(x_{j}, y_{j}\right)$. A correspondente função característica $g(\mathbf{k})=g\left(k_{1}, k_{2}\right)$ será dada por (de Oliveira, 2001):

$$
g(k)=\left\langle\exp i \mathbf{k} \cdot \mathbf{r}_{j}\right\rangle=\left\langle i\left(k_{1} x_{j}+k_{2} y_{j}\right)\right\rangle
$$

ou ainda por:

$$
g(\mathbf{k})=\iint e^{i \mathbf{k r}_{j}} P\left(\mathbf{r}_{j}\right) d x_{i} d x_{j}
$$


A função $G(\mathbf{k})$ correspondente ao vetor $\mathbf{r}=(x, y)$ é dada por:

$$
G(\mathbf{k})=\left\langle e^{i \mathbf{k} \cdot \mathbf{r}}\right\rangle=\left\langle e^{i \mathbf{k} \cdot\left(\mathbf{r}_{1}+\ldots \mathbf{r}_{n}\right)}\right\rangle=\left\langle e^{i \mathbf{k} \cdot \mathbf{r}_{j}}=[g(\mathbf{k})]^{n}\right.
$$

Para obter a densidade de probabilidade do vetor aleatório $\mathrm{k}$ utilizaremos a mesma técnica utilizada para demonstrar o teorema central do limite. Esta técnica equivale a usar a expansão de $g(\mathbf{k})$ em cumulantes até ordem $k^{2}$ isto é:

$$
g(\mathbf{k})=\exp \left(i\left(a_{1} k_{1}+a_{2} k_{2}\right)-\frac{1}{2}\left(b_{11} k_{1}^{2}+2 b_{12} k_{1} k_{2}+b_{22} k_{2}^{2}\right)\right.
$$

onde

$$
a_{1}=\left\langle x_{j}\right\rangle a_{2}=\left\langle y_{j}\right\rangle
$$

são cumulantes de primeira ordem e

$$
\begin{array}{r}
b_{11}=\left\langle x_{j}^{2}\right\rangle-\left\langle x_{j}\right\rangle^{2} \\
b_{12}=b_{21}=\left\langle x_{j} y_{i}\right\rangle-\left\langle x_{j}\right\rangle x_{j}\left\langle y_{i}\right\rangle \\
b_{22}=\left\langle y_{j}^{2}\right\rangle-\left\langle y_{j}\right\rangle^{2}
\end{array}
$$

são os cumulantes de segunda ordem. Assim para $t=n \tau$ grande temos:

$$
G(\mathbf{k})=\exp i n\left(a_{1} k_{1}+a_{2} k_{2}\right)-\frac{n}{2}\left(b_{11} k_{1}^{2}+2 b_{12} k_{1} k_{2}+b_{22} k_{2}^{2}\right)
$$

A densidade de probabilidade $P_{n}(\mathbf{r})=P_{n}(x, y)$ do vetor aleatório $\mathbf{r}=(x, y)$ é obtida por:

$$
P_{n}(\mathbf{r})=\frac{1}{(2 \pi)^{2}} \iint e^{-i \mathbf{k} \cdot \mathbf{r}} G(\mathbf{k}) d k_{1} d k_{2}
$$

e será uma gaussiana bidimensional dada por:

$$
P_{n}(x, y)=\frac{1}{2 \pi \sqrt{n^{2} D}} \times \exp -\frac{1}{2 n D}\left[b_{22}(x-n a)^{2}+2 b_{12}\left(x-n a_{1}\right)\left(y-n a_{2}\right)+b_{11}\left(y-a_{2}\right)^{2}\right]
$$

onde $D=b_{11} b_{22}-b_{12}^{2}$.

\subsubsection{Caminhada Aleatória em Grafos}

Se supusermos que a grade não é mais um quadrado perfeito, em um determinado ponto a partícula pode escolher um outro ponto com uma probabilidade igual a $1 / g_{i}$ onde $g_{i}$ é o grau do vértice em questão. 
Uma caminhada aleatória em um grafo é um caso bastante especial de uma cadeia de Markov (Adler, 1992). De maneira não análoga à uma cadeia de Markov geral, uma caminhada aleatória em um grafo goza de uma propriedade chamada simetria de tempo ou reversibilidade. A grosso modo, esta propriedade, também chamada balanceamento detalhado, siginifica que as probabilidades de atravessar uma sequência de nós (um caminho) em uma determinada direção, isto é, na ordem $\left(v_{1}, \ldots, v_{n}\right)$ e na direção reversa, ou seja, na ordem $\left(v_{n}, \ldots, v_{1}\right)$ são iguais.

Desde 1980, as pesquisas tem conectado propriedades de grafos a propriedades de caminhadas aleatórias. Além da conexão de grafos com circuitos elétricos (em que cada aresta pode ser considerada como um resistor com uma determinada resistência elétrica), há importantes conexões com desigualdades isoperimétricas, e desigualdades funcionais, tais como desigualdades de Solobev e Poincaré, além de propriedades das soluções da equação de Laplace.

Uma caminhada aleatória com passos bastante pequenos é também uma aproximação para o movimento Browninano. Para ser mais preciso, se o tamanho do passo for $\epsilon$, é necessário tomar uma caminhada de tamanho $L / \epsilon^{2}$ para aproximar um movimento Browniano de tamanho L. Quando o tamanho do passo tende a zero, uma caminhada aleatória converge para o movimento Browniano em sentido próprio. Formalmente se $B$ é o espaço de todos os caminhos de tamanho $L$ com a topologia induzida pela métrica $d(u, v)=\max \{|u|,|v|\}$ e $B$ é um espaço de medida sobre $B$ então a sequência converge no espaço $M$.

Em ecologia matemática, caminhadas aleatórias são utilizadas para descrever movimentos individuais de animais para simular a biodifusão e para modelar e simular a dinâmica de populações (H. Levy, 1992).

Em neurociência, caminhadas aleatórias são utilizadas para modelar cascatas de neurônios disparando no cérebro (Nicolis, 1991). Em outros campos da matemática, caminhadas aleatórias são utilizdas para calcular soluções da equação de Laplace e para estimar uma medida harmônica para várias construções em análise combinatória (Arnold, 1995a), (Sinai, 1995), (Sinai, 1995). Também em física caminhadas aleatórias assumem um papel bastante importante em teoria dos campos quânticos (Arnold et al., 1995), (Arnold \& Givental, 1995), (Arnold, 1995b).

\subsubsection{Processos Estocásticos e Caminhadas Aleatórias}

Uma variável aleatória que depende de um parâmetro $t$ é chamada de função aleatória ou, se $t$ significa o tempo, de variável estocástica. Supondo que temos um processo estocástico que possa ser discretizado no tempo e que a variável estocástica também possa ser discretizada. Um processo estocástico fica completamente definido até o instante $l$ pela distribuição de probabilidade 
conjunta:

$$
\mathcal{P}_{l}\left(n_{0}, n_{1}, \ldots, n_{l}\right)
$$

Neste caso $x_{t}$ toma o valor $n_{0}$ no instante $t=0$, o valor $n_{1}$ no instante $t=1$ e assim por diante. Se a probabilidade condicional:

$$
\mathcal{P}_{l+1}\left(n_{l+1} \mid n_{0}, n_{1}, \ldots, n_{l}\right)
$$

for igual a:

$$
\mathcal{P}_{l+1}\left(n_{l+1} \mid n_{l}\right)
$$

então o processo estocástico é um processo Markoviano. Desta forma temos que:

$$
P_{l}\left(n_{0}, n_{1}, . ., n_{l}\right)=\mathcal{P}_{l}\left(n_{l} \mid n_{l-1}\right) \ldots \mathcal{P}_{1}\left(n_{1} \mid n_{0}\right) \mathcal{P}_{0}\left(n_{0}\right)
$$

Podemos assim definir a probabilidade $\mathcal{P}_{l}\left(n_{l}\right)$ de que a variável $x_{t}$ tome o valor $n_{l}$ no instante $t=l$ independentemente de quais valores ela tenha tomado nos instantes anteriores:

$$
\mathcal{P}_{l}\left(n_{l}\right)=\sum_{n_{0}, n_{1}, \ldots, n_{l-1}} \mathcal{P}_{l}\left(n_{0}, \ldots, n_{l}\right)
$$

se o processo for Markoviano:

$$
\mathcal{P}_{l}\left(n_{l}\right)=\sum_{n_{l-1}} \mathcal{P}_{l}\left(n_{l} \mid n_{l-1}\right) P_{l-1}\left(n_{l-1}\right)
$$

ou

$$
\mathcal{P}_{l}\left(n_{l}\right)=\sum_{n_{l-1}} T\left(n_{l}, n_{l-1}\right) P_{l-1}\left(n_{l-1}\right)
$$

$\operatorname{com} T\left(n_{l}, n_{l-1}\right)=\mathcal{P}_{l}\left(n_{l} \mid n_{l-1}\right)$.

Ou seja, dado $P_{0}\left(n_{0}\right)$ pode-se encontrar $P_{l}\left(n_{l}\right)$ em qualquer instante. A probabilidade condicional $\mathcal{P}_{l}\left(n_{l} \mid n_{l-1}\right)$ é interpretada como probabilidade de transição do estado $n_{l-1}$ para o estado $n_{l}$. Essas probabilidades podem variar com o tempo.

A discussão anterior pode ser generalizada para dimensões maiores: Seja $\mathbf{z}_{t}=\left(\mathbf{x}_{t}, \mathbf{y}_{t}\right)$ um vetor estocástico: $\mathbf{z}_{t}=\left(\mathbf{x}_{t}, \mathbf{y}_{t}\right)=\left(x_{1}(t), \ldots, x_{p}(t), y_{1}(t), \ldots, y_{p}(t)\right)$, onde $p$ é o número de componentes de $\mathbf{x}$ ou $\mathbf{y}$. A razão dos vetores terem o mesmo número de componentes é que as partículas estão caminhando no mesmo grafo e $p$ é o número de vértices do grafo. No caso, $x_{1}(t)$ é o número de visitas da partícula $x$ ao nó 1 no tempo $t, x_{2}(t)$ é o número de visitas da 
partícula $x$ ao nó 2 no tempo $t$ e assim por diante. De forma análoga $y_{1}(t)$ é o número de visitas da partícula y ao nó 1 no tempo $t, y_{2}(t)$ é o número de visitas da partícula $y$ ao nó 2 no tempo $t$ e assim sucessivamente. Assuma que cada $x_{i}(t)$ tome valores inteiros e que $t$ assuma os valores $0,1,2, \ldots, l \mathrm{Um}$ processo estocástico envolvendo o vetor $\mathrm{z}$ fica completamente determinado pela distribuição conjunta:

$$
\mathcal{P}_{l+1}\left(\mathbf{n}_{0}, \ldots, \mathbf{n}_{l}\right)
$$

Isto é, na distribuição onde $\mathbf{z}_{l}=\left(\mathbf{x}_{l}, \mathbf{y}_{l}\right)$ tome o valor $\mathbf{n}_{0}=\left(\mathbf{n}_{\mathbf{x}_{0}}, \mathbf{n}_{\mathbf{y}_{0}}\right)$ no instante $t=0$, o valor $\mathbf{n}_{1}=\left(\mathbf{n}_{\mathbf{x}_{1}}, \mathbf{n}_{\mathbf{y}_{1}}\right)$ nos instantes $t=1, \ldots, l-1$ e o valor $\mathbf{n}_{l}=\left(\mathbf{n}_{\mathbf{x}_{l}}, \mathbf{n}_{\mathbf{y}_{l}}\right)$ no instante $t=l$. Cabe observar que:

$$
\left(\mathbf{n}_{\mathbf{x}_{t}}, \mathbf{n}_{\mathbf{y}_{t}}\right)=\left(n_{x_{1}}(t), n_{x_{2}}(t), . ., n_{x_{p}}(t), n_{y_{1}}(t), n_{y_{2}}(t), \ldots, n_{y_{p}}(t)\right)
$$

Como as partículas $x$ e $y$ caminham no mesmo grafo temos que:

$$
\mathcal{P}_{l+1}\left(\mathbf{n}_{l+1} \mid \mathbf{n}_{0}, \mathbf{n}_{1}, \ldots, \mathbf{n}_{l}\right)=\mathcal{P}_{l+1}\left(\mathbf{n}_{l+1} \mid \mathbf{n}_{l}\right)
$$

Ou seja o processo de caminhada é um processo markoviano. Assim temos que:

$$
\mathcal{P}_{l}\left(\mathbf{n}_{0}, \mathbf{n}_{1}, \ldots, \mathbf{n}_{l}\right)=\mathcal{P}_{l}\left(\mathbf{n}_{l} \mid \mathbf{n}_{l-1}\right) \ldots \mathcal{P}_{2}\left(\mathbf{n}_{2} \mid \mathbf{n}_{1}\right) \mathcal{P}_{1}\left(\mathbf{n}_{1} \mid \mathbf{n}_{0}\right) \mathcal{P}_{0}\left(\mathbf{n}_{0}\right)
$$

A probabilidade de que a variável $\mathbf{z}_{t}$ assuma o valor $\mathbf{n}_{l}$ no instante $t$ independentemente de quais valores ela tenha assumido nos instantes anteriores é dada por:

$$
\begin{aligned}
\mathcal{P}_{l}\left(\mathbf{n}_{l}\right) & =\sum_{\mathbf{n}_{0}} \sum_{\mathbf{n}_{1}} \ldots \sum_{\mathbf{n}_{l-1}} \mathcal{P}_{l}\left(\mathbf{n}_{0}, \mathbf{n}_{1}, \ldots, \mathbf{n}_{l}\right) \\
& =\sum_{\mathbf{n}_{0}} \sum_{\mathbf{n}_{1}} \ldots \sum_{\mathbf{n}_{l-1}} \mathcal{P}_{l}\left(\mathbf{n}_{l} \mid \mathbf{n}_{l-1}\right) \ldots \mathcal{P}_{2}\left(\mathbf{n}_{2} \mid \mathbf{n}_{1}\right) \mathcal{P}_{1}\left(\mathbf{n}_{1} \mid \mathbf{n}_{0}\right) \mathcal{P}_{0}\left(\mathbf{n}_{0}\right)
\end{aligned}
$$

A soma é sobre todos os possíveis valores que os vetores $\mathbf{n}_{0}, \mathbf{n}_{1}, \ldots, \mathbf{n}_{l-1}$ podem assumir até o instante de tempo $t=l-1$.

A probabilidade $\mathcal{P}_{l}\left(\mathbf{n}_{l} \mid \mathbf{n}_{l-1}\right)$ é interpretada como a probabilidade de transição do estado $\mathbf{n}_{l-1}$ para o estado $\mathbf{n}_{l}$. $\mathcal{P}_{0}\left(\mathbf{n}_{0}\right)=1$ porque é a condição inicial. $\mathcal{P}_{1}\left(\mathbf{n}_{1} \mid \mathbf{n}_{0}\right)=1$ porque somente existe um transição possível para o estado inicial dado.

Para a discussão não ficar muito abstrata, vamos considerar o caso de um grafo com três nós e duas partículas mostrado na figura. Vamos calcular 


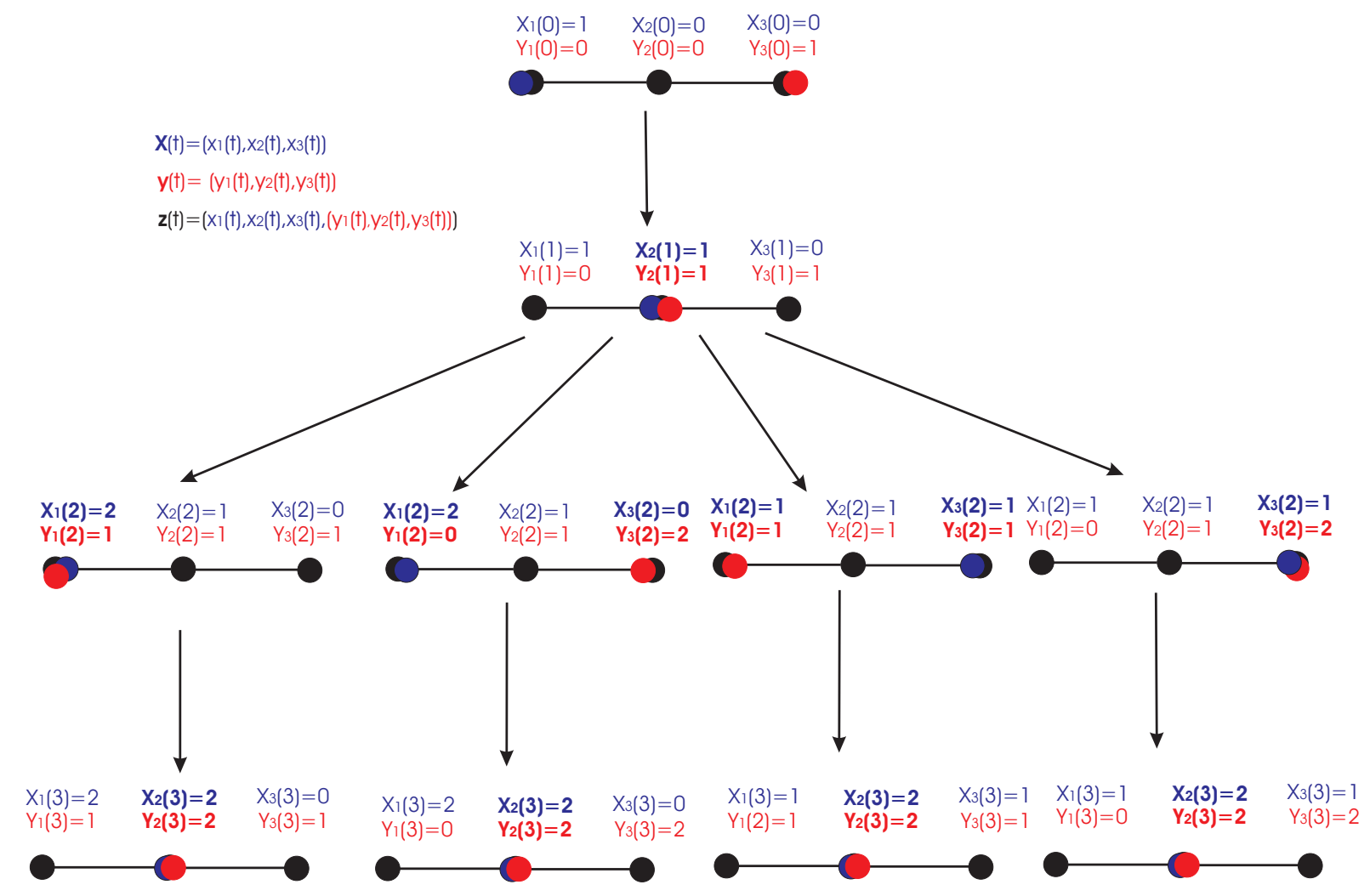

Figura 2.7: Exemplo simples de Grafo de Transição.

$\mathcal{P}_{2}\left(\mathbf{n}_{2}\right), \operatorname{com} \mathbf{n}_{2}=(2,2,0,1,2,1)$ e com $\mathbf{n}_{0}=(1,0,0,0,0,1)$

$$
\mathcal{P}_{2}\left(\mathbf{n}_{2}\right)=\sum_{\mathbf{n}_{0} \in S} \sum_{\mathbf{n}_{1} \in S} \mathcal{P}_{2}\left(\mathbf{n}_{2} \mid \mathbf{n}_{1}\right) \mathcal{P}_{1}\left(\mathbf{n}_{1} \mid \mathbf{n}_{0}\right) \mathcal{P}_{0}\left(\mathbf{n}_{0}\right)
$$

A probabilidade $\mathcal{P}_{0}\left(\mathbf{n}_{0}\right)$ é 1 porque $\mathbf{n}_{0}=(1,0,0,0,0,1)$ é o estado inicial e a probabilidade $\mathcal{P}_{1}\left(\mathbf{n}_{1} \mid \mathbf{n}_{0}\right)$ também é 1 porque a partir do estado inicial dado somente existe uma transição possível, conforme é mostrado na figura. Ficamos então com:

$$
\mathcal{P}_{2}\left(\mathbf{n}_{2}\right)=\sum_{\mathbf{n}_{1} \in S} \mathcal{P}_{2}\left(\mathbf{n}_{2} \mid \mathbf{n}_{1}\right)
$$

Assim essa probabilidade é $1 / 4$.

Um processo estocástico Markoviano fica completamente definido pela probabilidade de transição e pela probabilidade inicial. Assim é possível escrever a equação 2.53 como:

$$
\mathcal{P}_{l}(n)=\sum_{m} T(n, m) P_{l-1}(m)
$$

A matriz $T$ tem todos os elementos não negativos e a soma em uma mesma coluna tem valor 1 . Tal matriz é chamada de matriz estocástica. Se definirmos para cada $n$ o vetor $P_{l}$, isto é, $\mathcal{P}_{l}=[\mathcal{P}(0), \ldots, \mathcal{P}(n)] \mathcal{P}_{l}$, podemos reescrever a 
equação 2.61 como um produto de matrizes:

$$
P_{l}=T P_{l-1}
$$

e o problema de se determinar $\mathcal{P}_{l}(n)$ se reduz ao cálculo da $n$-ésima potência da matriz estocástica $T$.

Todo processo markoviano pode ser representado por um grafo probabilístico em que os estados são representados por vértices e as transições de um estado a outro estado são representados por arestas rotuladas com probabilidades. Assim a transição do estado $i$ para o estado $j$ é representado por uma aresta de $i$ para $j$ com rótulo $t_{i j}$ onde $t_{i j}$ é um elemento da matriz estocástica representada anteriormente.

\subsubsection{Teorema de Perron-Frobenius}

Uma discussão de processos Markovianos não seria completa sem a menção do teorema de Perron-Frobenius, (Sinai, 1995). Este teorema diz que:

- A matriz estocástica possui um autovalor igual à unidade

- Qualquer autovalor $\lambda$ satisfaz a condição $|\lambda| \leq 1$ no plano complexo.

- O autovalor $|\lambda|=1$ corresponde a um autovetor com componentes não negativas.

- O autovalor $\lambda=1$ é não degenerado.

- Com exceção do autovalor $\lambda=1$, todos os autovalores de uma matriz regular são em módulo estritamente menores do que a unidade

- Quando $l \rightarrow \infty, T^{l}$ converge para uma matriz cujas colunas são todas iguais a $P$. Daí se conclui que $P_{l}=T^{l} P_{0}$ converge para $P$ qualquer que seja $P_{0}$.

Para que o limite de $P_{l}$ exista quando $l \rightarrow \infty$ é necessário que não haja nenhum autovalor complexo sobre o círculo unitário, exceto $\lambda=1$. Entretanto para que o limite seja independente da probabilidade inicial a probabilidade estacionária deve ser única, isto é, o autovalor $\lambda$ deve ser não degenerado.

Um passeio aleatório pode ser definido em termos de cadeia de cadeia de Markov. Para enxergar isso basta considerar que a matriz de transição, neste caso é dada por $T(n-1, n)=T(n+1, n)=1 / 2$ e $T(m, n)=0$ em outros casos. Se a partícula puder permanecer no mesmo vértice ou na mesma posicão, então:

$$
T(n-1, n)=T(n+1, n)=\frac{1}{2} q
$$




$$
T(n, n)=p=1-q
$$

Assim sendo:

$$
\begin{array}{r}
P_{l+1}=T P_{l} \\
P_{l+1}(n)=\frac{1}{2} q P_{l}(n+1)+p P_{l}(n)+\frac{1}{2} q P_{l}(n-1)
\end{array}
$$

\subsubsection{Equação Mestra}

Podemos reescrever a equação que define as transições para uma cadeia de Markov como:

$$
P_{l+1}(n)=\sum_{n \neq m} T(n, m) P_{l}(m)+T(n, n) P_{l}(n)
$$

Supondo que o passo de tempo $\tau$ seja pequeno e que $T(m, n)=\tau W(m, n)$ de modo que a probabilidade de permanência no mesmo estado seja aproximadamente 1 , isto é:

$$
\begin{aligned}
T(n, m) & =\sum_{m} T(m, n)-\tau \sum_{m \neq n} T(m, n) \\
& =1-\tau \Omega(n)
\end{aligned}
$$

Com essas condições temos que:

$$
\frac{P(n, t+\tau)-P(n, l)}{\tau}=\sum_{m \neq n} W(n, m) P(m, t)-\Omega(n) P(n, t)
$$

no limite $\operatorname{com} \tau \rightarrow 0$ :

$$
\frac{d P(n, t)}{d t}=\sum_{m \neq n}[W(n, m) P(m, t)-W(m, n) P(n, t)]
$$

que é a equação Mestra. Por exemplo, num passeio aleatório em que as probabilidades da partícula se mover para direita ou esquerda são $\gamma \Delta t / 2$ e a probabilidade de ficar na mesma posição é zero a equação mestra é dada por:

$$
\frac{d}{d t} P(n, t)=\frac{\gamma}{2} P(n+1, t)+\frac{\gamma}{2} P(n-1, t)-\gamma P(n, t)
$$

A solução estacionária $P(t)$ é aquela em que $\frac{d}{d t} P(n, t)=0$. Neste caso as probabilidades de transição obedecem o chamado balanceamento detalhado, 
que corresponde à solução de equilíbrio. O balanceamento detalhado é utilizado para simular sistemas em equilíbrio termodinâmico e estudar tansições de fase e quebra de simetria.

O próprio aprendizado na rede neural de Hopfield, cujo modelo adveio de estudos de quebra de simetria em modelos Ising, é uma forma de quebra de simetria, em que um estado macroscópico simétrico (cujas propriedades são dadas pelo Hamiltoniano microscópico) de não-aprendizado é substituído após uma transição de fase, dada pelo treinamento da rede, para um estado macroscópico assimétrico, que corresponde à rede com memórias aprendidas.

\subsection{Aprendido Competitivo}

Segundo Haykin (2001) a aprendizagem em redes neurais artificiais pode ser definida como:

“A aprendizagem é um processo pelo qual os parâmetros livres de uma rede neural são adaptados através de um processo de estimulação pelo ambiente no qual a rede está inserida. O tipo de aprendizagem é determinado pela maneira pela qual a modificação dos parâmetros ocorre.”.

Na literatura são encontrados três paradigmas de aprendizagem: aprendizagem supervisionada, aprendizagem não-supervisionada e aprendizagem por reforço. Vale ressaltar que alguns autores não consideram a aprendizagem por reforço como um paradigma independente, mas sim como um modo de aprendizagem pertencente ao paradigma não-supervisionado (sem um professor) (Haykin, 2001), ou ainda como um caso particular do paradigma supervisionado (de Pádua Braga et al., 2000).

No aprendizado supervisionado um conjunto de treinamento composto de padrões de entradas associados aos seus respectivos rótulos são utilizados no treinamento da RNA. Durante o treinamento, cada padrão é apresentado à rede gerando um sinal de saída. Esse sinal gerado é comparado ao valor correspondente ao padrão apresentado (saída desejada) e com base nessa comparação é calculado um erro o qual é utilizado para a correção dos pesos da rede. Esse processo é repetido com todos os padrões do conjunto de treinamento até que o erro apresentado pela saída da rede esteja abaixo de um limiar aceitável. As redes neurais como a MLP, Adaline, perceptron, são exemplos que utilizam este paradigma de treinamento.

No aprendizado não-supervisionado não existe um crítico responsável por supervisionar o processo de aprendizagem. Desta forma, a propria rede neural deve extrair do conjunto de entradas as informações necessárias para a 
realização do mapeamento entrada-saída. São exemplos deste paradigma as redes neurais da família ART e os Mapas Auto-Organizáveis de Kohonen.

No aprendizado por reforço, uma função, definida a priori, é utilizada para indicar se a saída gerada pela rede é boa ou ruim, gerando assim um processo de recompensa ou penalização para a rede neural. O ajuste nos pesos da rede é realizado com base nesses valores de penalizações ou de recompensas obtidos a partir da função de avaliação.

\subsubsection{Redes Neurais ART}

A teoria da Ressonância Adaptativa (ART - Adaptive Resonance Theory) foi desenvolvida por Carpenter \& Grossberg (1987b) e tem sido aplicada a diversos problemas, dentre eles a clusterização de dados.

A família ART é composta por diversos modelos. O modelo ART1 foi projetado para trabalhar com entradas binárias. Um segundo modelo, o ART2 (Carpenter \& Grossberg, 1987a) foi desenvolvido para manipular dados contínuos. Dentre outros modelos: ARTMAP (Carpenter et al., 1991), Fuzzy ARTMAP (Carpenter et al., 1992), etc.

A estrutura básica do ART1, apresentado na Figura 2.8, consiste de duas camadas de neurônios denominadas $F_{1}$ e $F_{2}$ que são as camadas de entrada e saída respectivamente. Na camada $F_{2}$ são formados os clusters. Além delas, existem unidades suplementares que ajudam no treinamento da rede neural. A unidade de controle (Reset), por exemplo, controla o grau de similaridade dos padrões colocados no mesmo cluster, outras unidades suplementares são $G_{1}$ e $G_{2}$ que são descritas ao longo do texto. Todos os neurônios da camada $F_{1}$ são conectados a todos os neurônios da camada $F_{2}$ (pesos bottom-up b) e os neurônios da camada $F_{2}$ também são conectados a todos os neurônios da camada $F_{1}$ (pesos top-down t).

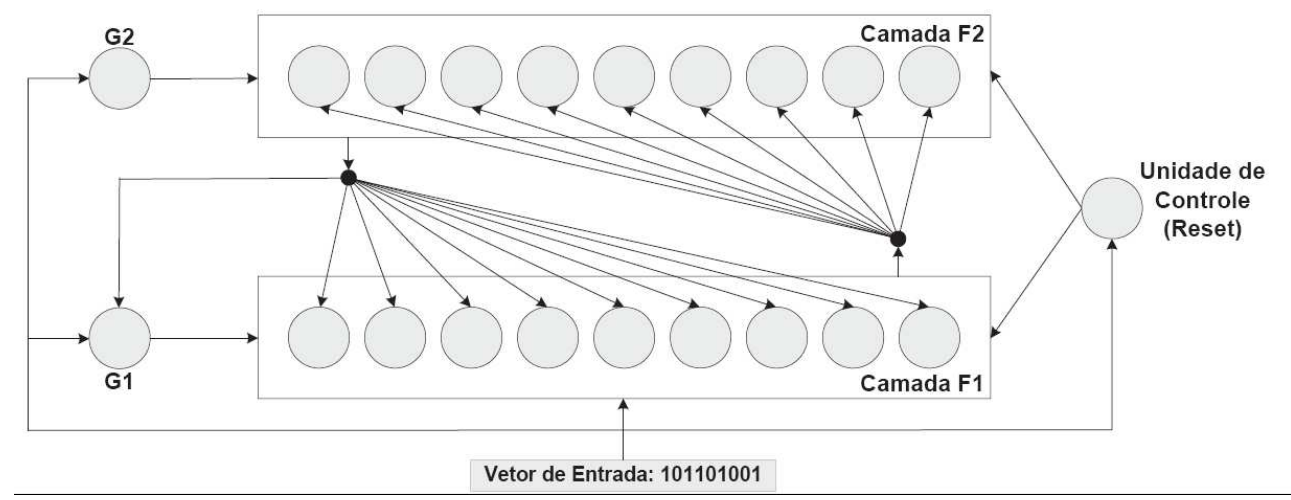

Figura 2.8: Arquitetura básica de uma rede ART1. (de Pádua Braga et al., 2000).

O treinamento da rede ART1 é realizado da seguinte forma: inicialmente, um padrão de entrada $\mathbf{e}=\left(e_{1}, \ldots, e_{i}, \ldots, e_{N}\right)$ é apresentado aos neurônios $x_{i} \leftarrow e_{i}$ 
da camada $F_{1}$ e a unidade de controle $G_{1}$ é configurada como 1 indicando que um padrão de entrada está sendo apresentado a rede. Através das conexões bottom-up esse sinal é propagado a camada $F_{2}$, onde o sinal de cada neurônio $y_{j}$ da camada de saída $F_{2}$ é representado pela seguinte equação:

$$
y_{j}=\sum_{i=1}^{N} b_{i j} x_{i}
$$

onde $N$ é a dimensão de entrada da rede, $\mathbf{b}_{j}$ é o vetor de pesos bottom-up do neurônio $j$ da camada $F_{2}$.

Como a camada $F_{2}$ é uma camada de competição, no qual apenas um neurônio é vencedor, o neurônio que obtiver o maior valor de ativação é selecionado como candidato a representar o padrão de entrada. O processo de competição é controlado pela unidade de controle $G_{2}$ que emite sinais inibitórios a todas os neurônios de $F_{2}$, exceto o neurônio candidato selecionado. Desta forma, as ativações de todos os demais neurônios da camada $F_{2}$ são ajustados para o valor zero. Neste ponto, a unidade de controle $G_{2}$ é configurada em zero e as unidades de $F_{1}$ combinam as informações do vetor de entrada e do neurônio vencedor $y_{j}$ da camada $F_{2}$ pela seguinte equação:

$$
x_{i}=e_{i} t_{j i}
$$

onde $t_{j i}$ é o peso top-down entre o neurônio $y_{j}$ da camada $F_{2}$ e o neurônio $x_{i}$ da camada $F_{1}$ e $e_{i}$ é o $i$-ésimo componente do vetor de entrada e. Como pode ser observado, existem três possíveis fontes de entrada para a camada $F_{1}$ : o próprio padrão de entrada, o sinal top-down e o sinal da unidade de controle $G_{1}$. Porém, somente dois deles são utilizados a qualquer momento. As unidades de $F_{1}$ tornam-se ativas somente se duas das três possíveis fontes de entradas estão ativas. Essa característica é chamada de regra dos 2/3 e representa um importante papel para aprendizagem correta. Se esta unidade vencedora está ou não apta a assimilar o padrão de entrada depende da similaridade entre o novo padrão de atividade $\mathbf{x}$ (camada de entrada) e o padrão apresentado e. Esta decisão é tomada pela Unidade de Controle de Reset da seguinte forma:

$$
\frac{\|\mathbf{x}\|}{\mathbf{e}} \leq p
$$

onde $p$ é o parâmetro de vigilância e \|\| representa a norma Euclidiana. Se a equação acima for satisfeita, o neurônio vencedor da camada $F_{2}$ não terá permissão para aprender e será inibido para que um novo neurônio da camada $F_{2}$ seja selecionado como candidato; caso contrário, o neurônio candidato $y_{j}$ terá seus pesos $\mathbf{b}_{j}$ e $\mathbf{t}_{j}$ modificados em função da aprendizagem do novo padrão 
de entrada e. Este ciclo de operações é repetido até que um neurônio vencedor da camada $F_{2}$ esteja apto para "aprender" seja encontrado ou até que todos os neurônios de $F_{2}$ estejam inibidos. Quando todos os neurônios habilitados da camada $F_{2}$ estiverem inibidos, um novo neurônio é alocado e seus pesos são atualizados para representar o padrão de entrada e.

Basicamente, o treinamento da rede ART1 pode ser resumido pelo Algoritmo 2.1.

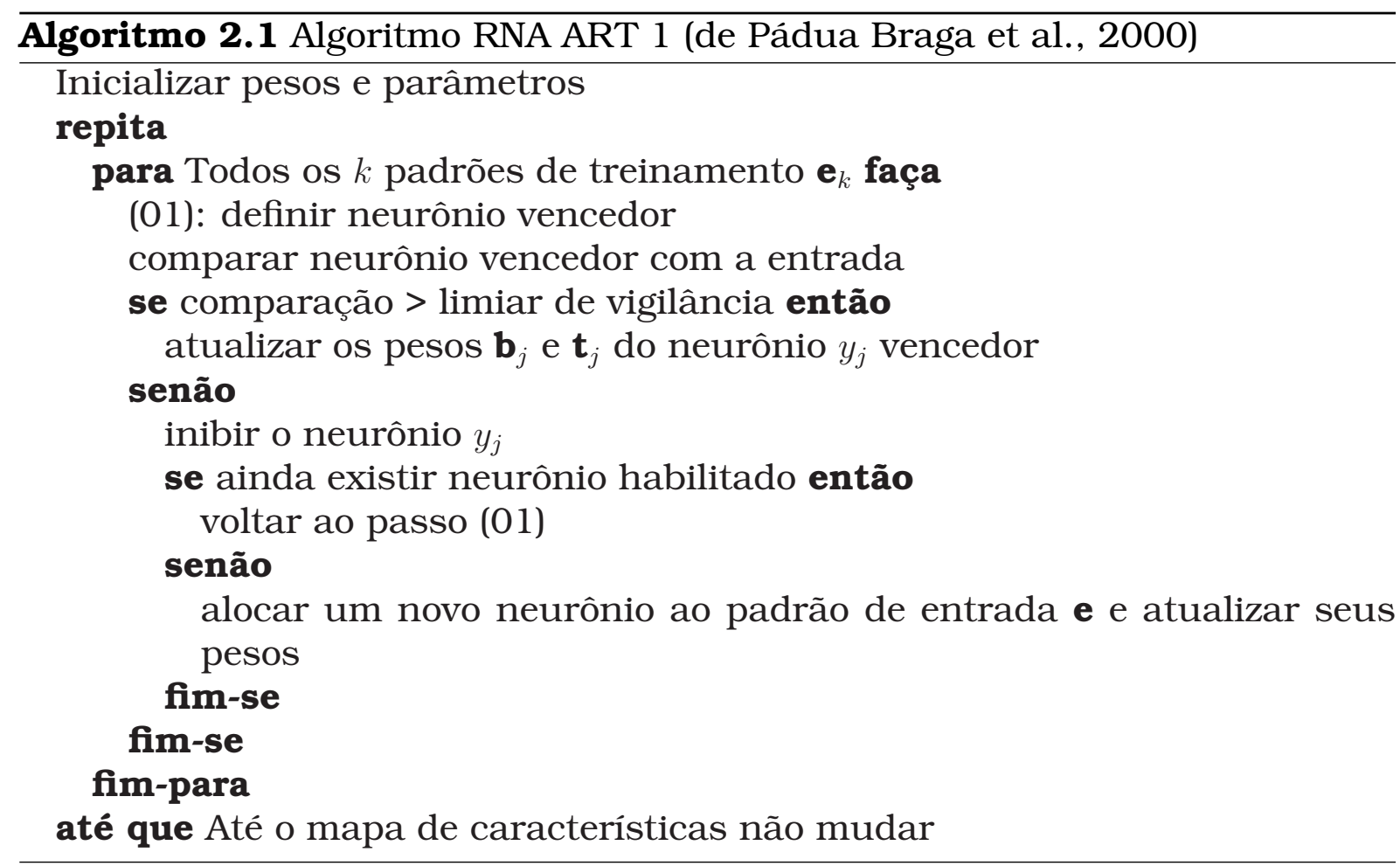

\subsubsection{Mapas Auto-Organizáveis de Kohonen (SOM)}

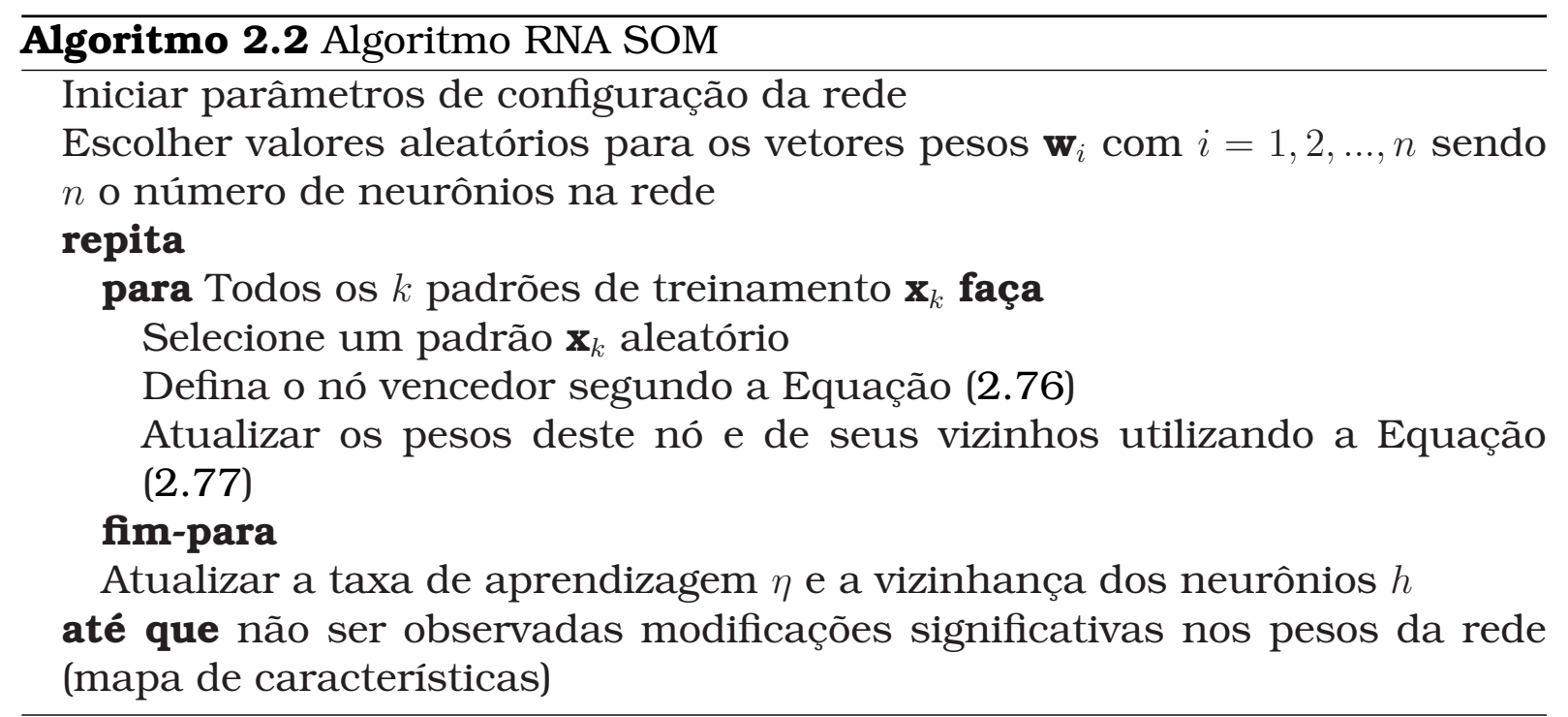

A rede neural denominada mapas de Kohonen ou SOM (Self-Organizing 


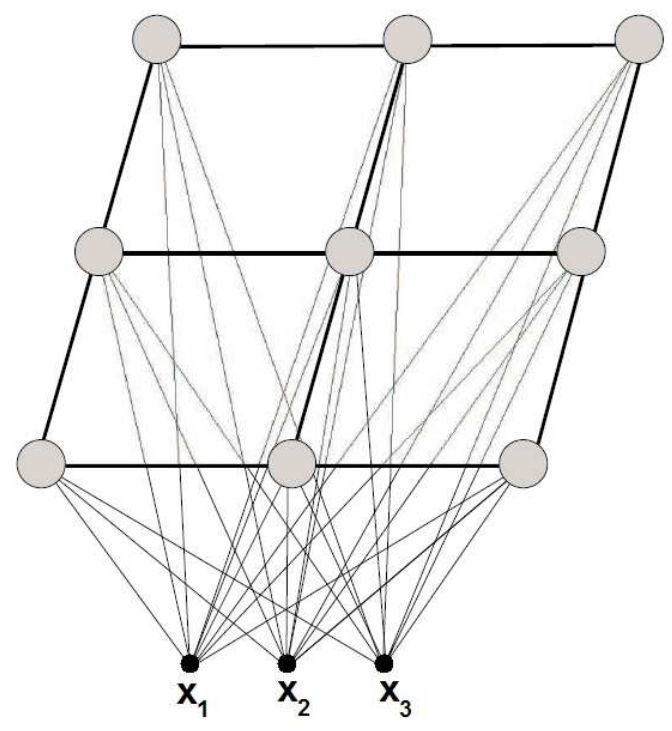

Figura 2.9: Arquitetura básica de uma rede SOM

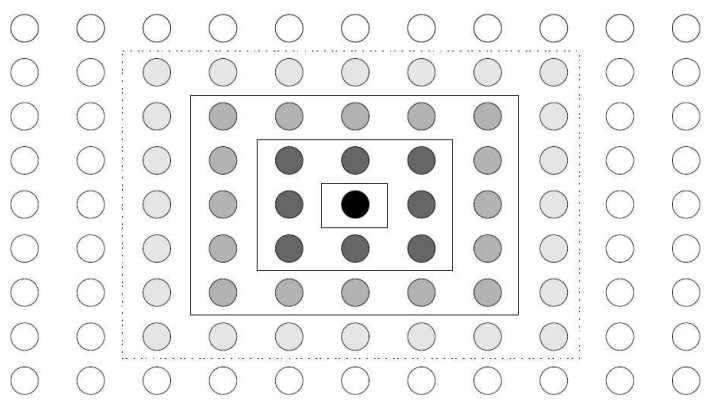

(a)

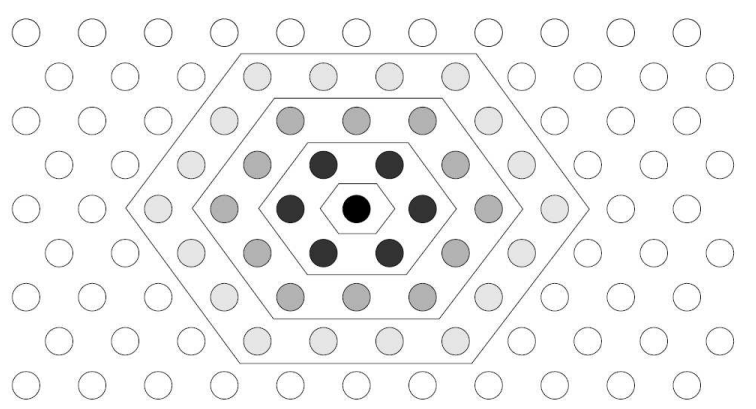

(b)

Figura 2.10: Exemplos de vizinhanças utilizadas em uma rede SOM (a) vizinhança quadrada (b) vizinhança hexagonal

Maps) tem sido largamente aplicada a tarefas de clusterização de dados e de visualização. Esta rede é formada por um mapa reticulado, geralmente, uni ou bidimensional de neurônios em uma única camada computacional, cuja arquitetura básica é apresentada pela Figura 2.9. O processo de aprendizagem adotado por este modelo é o aprendizado competitivo: os neurônios de saída da rede competem entre sí para decidir quem representará o padrão de entrada, isto é qual neurônio da rede será denominado o vencedor e se tornará ativado, com este resultado apenas um neurônio de saída (vencedor) é escolhido.

No modelo de Kohonen, o sinal de entrada, é representado por um vetor $\mathbf{x}=\left(x_{1}, x_{2}, \ldots, x_{n}\right)$, onde $x_{i}$ são escalares e $n$ é a dimensão dos padrões. Definidos com a mesma dimensão dos padrões de entrada, cada neurônio $y_{j}$ da rede é formado por um vetor de pesos $\mathbf{w}_{j}=\left(w_{1 j}, w_{2 j}, \ldots, w_{n j}\right)$ responsável por ligar $\mathbf{o}$ padrão de entrada $\mathbf{x}$ ao neurônio $y_{j}$. Neste caso, o peso $w_{i j}$ é responsável por ligar o $i$-ésimo atributo do padrão de entrada $\mathbf{x}$ ao $i$-ésimo componente do vetor de pesos $\mathbf{w}_{j}$ do neurônio $y_{j}$.

Quando um padrão $\mathbf{x}_{k}$ é apresentado à rede, a diferença entre este padrão 
e os vetores peso $\mathbf{w}_{j}$ da matriz de pesos $\mathbf{W}$ para todo neurônio $y_{j}$ é calculada segundo a equação abaixo:

$$
\left\|\mathbf{x}_{k}-\mathbf{w}_{c}\right\|=\arg \min \left(\left\|\mathbf{x}_{k}-\mathbf{w}_{j}\right\|\right) \forall j
$$

onde $c$ é o índice do neurônio vencedor $\mathrm{e} \mathbf{w}_{c}$ corresponde ao seu vetor de pesos associado, e ||| é a função de dissimilaridade utilizada, geralmente a norma Euclidiana é utilizada neste modelo de rede neural.

Uma vez encontrado a unidade vencedora, o seu vetor de pesos e os pesos de neurônios pertencentes a vizinhança $H_{c}$ são atualizados segundo a equação:

$$
\mathbf{w}_{j}(t+1)=\mathbf{w}_{j}(t)+\eta(t) H_{j, c}(t)\left(\mathbf{x}_{k}-\mathbf{w}_{j}\right)
$$

onde $\eta(t)$ é a taxa de aprendizagem e $H_{j, c}(t)$ define com que força o neurônio $y_{j}$ pertencente a vizinhança do neurônio $y_{c}$ (vencedor) será atualizado. Normalmente a taxa de aprendizagem $\eta(t)$ e a vizinhança $H_{j, c}(t)$ são reduzidas ao longo do processo de treinamento da rede. Além disso, a vizinhança de uma rede de Kohonen pode assumir diversos formatos, sendo dois deles apresentados pelas Figuras 2.10(a) e (b).

O processo de treinamento de uma rede SOM gera, através da auto-organização, clusters, onde cada cluster corresponde a um grupo de padrões (neurônios) que compartilham características similares, sendo que o centro deste grupo de neurônios corresponde ao padrão que melhor representa aquela classe. Semelhante ao sistema biológico observado nas estruturas topológicas do córtex cerebral, após o processo de treinamento, espera-se que unidades fisicamente próximas na rede representem padrões similares (Kohonen, 2001). Um resumo do algoritmo de treinamento de uma rede SOM é apresentado pelo Algoritmo 2.2.

Um dos principais problemas neste modelo de rede, análogo ao problema da definição do número de clusters do algoritmo K-Means, está na necessidade de definir a priori a arquitetura da rede, isto é, o número de neurônios que esta rede deve conter. Desta forma, independente da evolução do processo de treinamento da rede, a sua arquitetura permanecerá estática até o final do treinamento. Este problema pode ser amenizado com a utilização de redes neurais construtivas, cuja arquitetura da rede pode sofrer alterações ao longo do processo de treinamento. Um exemplo de rede neural construtiva que será apresentada na próxima Seção é denominado GNG (Growing Neural Gas). 


\subsubsection{Growing Neural Gas}

O algoritmo GNG foi proposto por Fritzke (1994, 1995). Através do algoritmo GNG é possivel criar e destruir unidades ao longo do treinamento, por isso este modelo é classificado como um mapa auto-organizável construtivo.

Este modelo surgiu principalmente com o objetivo de melhorar algumas limitações observadas no modelo básico de Kohonen (SOM). Enquanto uma rede de SOM precisa da definição de uma topologia fixa, uma GNG inicia o seu treinamento com uma arquitetura mínima e novas unidades são criadas gradualmente. Portanto, o modelo GNG, além de trabalhar com o paradigma nãosupervisionado, também é construtivo, sendo, desta forma, capaz de gerar uma topologia diferente para cada tipo de problema. Uma outra diferença em relação ao modelo de SOM está na forma de conectar as unidades. No mapa de Kohonen, as conexões criam apenas malhas retangulares (ver arquitetura das redes SOM na Figura 2.9). Já no modelo GNG, uma unidade pode ter muito mais de quatro vizinhos gerando diversas figuras geométricas e uma rede com capacidade de aprendizagem ampliada.

O processo de treinamento de uma rede GNG se inicia com apenas dois neurônios e as novas unidades vão sendo inseridas sucessivamente. Para determinar em que posição deverá ser inserida uma nova unidade, informações relacionadas ao erro são coletadas novamente durante o processo de adaptação. Cada nova unidade deverá ser inserida perto da unidade com maior erro. O algoritmo de treinamento de uma rede Growing Neural Gas é apresentado pelo Algoritmo 2.3.

\subsection{Considerações Finais}

Neste capítulo foi realizada uma revisão dos principais tópicos de relevância para o desenvolvimento desta tese. Tal revisão teve como ênfase a teoria de redes complexas focando na apresentação do estado da arte de detecção de comunidades. Também foram apresentados tópicos sobre aprendizado competitivo cuja implementação do modelo de competição será apresentada no capítulo seguinte. Foi também apresentada uma revisão sobre teoria de caminhada aleatória que pode ser considerada como um caso especial do modelo proposto no qual várias caminhadas aleatórias ocorrem de forma competitiva. Se considerássemos partículas como sinais elétricos entre neurônios, notaríamos que a demarcação de comunidades é um fenômeno global como consequência de regras de movimentações locais. Tal fenômeno, por se uma espécie de transição de fase, é análogo à aprendizagem que segundo teorias modernas consiste em uma quebra de simetria. Desta forma o estudo matemático de caminhadas aleatórias com regras de movimentação local, constitui um 
Algoritmo 2.3 Algoritmo RNA GNG: (Vargas, 2004)

1. Iniciar a rede $\mathbf{N}$ com duas unidades $c_{1}$ e $c_{2}: \mathbf{N}=\left\{c_{1}, c_{2}\right\}$

2. Iniciar os pesos com valores aleatórios no intervalo $[0,1]$

3. Iniciar o conjunto de conexões $C, C \subset \mathbf{N} \times \mathbf{N}$ por: $C=\phi$

4. Apresentar um padrão $\mathbf{x}_{i}$ à rede

5. Determinar os dois neurônios mais próximos $s_{1}$ e $s_{2}$ para o padrão $\mathbf{x}_{i}$ segundo as equações:

$$
\begin{gathered}
s_{1}=\arg \min \left\|\mathbf{x}_{i}-\mathbf{w}_{j}\right\| \forall j \in \mathbf{N} \\
s_{2}=\arg \min \left\|\mathbf{x}_{i}-\mathbf{w}_{j}\right\| \forall j \in \mathbf{N}-s_{1}
\end{gathered}
$$

onde ||| representa a distância Euclidiana

6. Se não existe uma conexão entre $s_{1}$ e $s_{2}$, então criá-la: $C=C \cup\left\{\left(s_{1}, s_{2}\right)\right\}$ e iniciar a idade desta conexão com $i d a d e_{\left(s_{1}, s_{2}\right)}=0$

7. Adicionar o quadrado da distância entre o neurônio vencedor e o padrão apresentado a uma variável de erro local: $E_{s_{1}}=E_{s_{1}}+\left\|\mathbf{x}_{i}-\mathbf{w}_{s_{1}}\right\|$

8. Atualizar o vetor de pesos de $s_{1}$ e os vetores de pesos dos seus vizinhos de acordo com as seguintes equações:

$$
\begin{gathered}
\Delta \mathbf{w}_{s_{1}}=\mu_{b}\left(\mathbf{x}_{i}-\mathbf{w}_{s_{1}}\right) \\
\Delta \mathbf{w}_{k}=\mu_{n}\left(\mathbf{x}_{i}-\mathbf{w}_{k}\right) \quad \forall k \in N_{s_{1}}
\end{gathered}
$$

onde $N_{s_{1}}$ é o conjunto dos vizinhos topológicos diretos da unidade vencedora $s_{1}, \mu_{b}$ e $\mu_{n}$ são as taxas de aprendizagem para o neurônio vencedor e para os seus vizinhos respectivamente

9. Incrementar a idade de todas as conexões de $s_{1}: \operatorname{idade}_{\left(s_{1}, k\right)}=\operatorname{idade}_{\left(s_{1}, k\right)}+$ $1 \forall k \in N_{s_{1}}$

10. Remover as conexões com idade maior que $a_{m} a x$.

11. Caso existam neurônios sem conexão, estes devem ser removidos da rede

12. Caso o número de padrões apresentados até este instante for múltiplo do parâmetro $\lambda$, uma nova unidade deve ser inserida utilizando o Algoritmo 2.4

13. Diminuir a variável de erro de todas as unidades: $\Delta E_{k}=-\beta E_{c}, \forall k \in \mathbf{N}$, onde $\beta$ é a taxa de correção de erros

14. Se o critério de parada não foi alcançado volte ao passo X, caso contrário finalize. Sendo o critério de parada o tamanho máximo da rede ou alguma outra medida de desempenho. 
Algoritmo 2.4 Algoritmo RNA GNG: Inserção de um novo elemento

1. Determinar a unidade q com o maior erro acumulado de toda a rede $q=\arg \max _{c \in \mathbf{N}}\left(E_{c}\right)$

2. Determinar, dentre os vizinhos de $q$, a unidade $f$ com maior erro acumulado $f=\arg \max _{c \in N_{q}}\left(E_{c}\right)$

3. Adicionar uma nova unidade $r$ à rede e interpolar seu vetor de pesos a partir de $q$ e $f$ de acordo com as equações:

$$
\begin{gathered}
\mathbf{N}=\mathbf{N} \cup r \\
\mathbf{w}_{r}=\frac{\mathbf{w}_{q}+\mathbf{w}_{f}}{2}
\end{gathered}
$$

4. Inserir conexões de $r$ até $q$ e de $r$ até $f$ e remover a conexão original entre $q$ e $f: C=C \cup\{(r, q),(r, f)\}-\{(q, f)\}$

5. Diminuir as variáveis de erro das unidades $q$ e $f$ em uma fração $\alpha: \Delta E_{q}=$ $-\alpha E_{q}, \quad \Delta E_{f}=-\alpha E_{f}$

6. Interpolar a variável de erro de $r$ a partir de $q$ e $f: E_{r}=\frac{E_{q}+E_{f}}{2}$

arcabouço para elaboração de novas redes neurais, onde o processo de aprendizagem pode ser investigado dinâmicamente. Nas redes neurais existentes atualmente não se pode fazer um acompanhamento dinâmico da evolução da aprendizagem em termos de conexões individuais de neurônios.

A modelagem matemática apresentada no capítulo 4, apesar de refletir bem a variação dinâmica dos potenciais com o tempo, ainda não é refinada o suficiente para considerar conexões individuais, de forma que uma abordagem matemática mais elaborada que levasse em consideração a forma da rede, deveria ser aplicada para poder conduzir a bons algoritmos de treinamento de uma rede neural baseada em competição de partículas. Neste caso as caminhadas aleatórias e o fator determinismo deveriam ser tratados com as técnicas matemáticas descritas neste capítulo. 


\section{$-3$ \\ Competição de Partículas para Detecção de Comunidades}

Os principais algoritmos de detecção de comunidades existentes atualmente possuem tempo quadrático. Existem modelos já discutidos no capítulo anterior que utilizam uma única partícula; Porém com competição de partículas, nós são checados por várias partículas ao invés de uma única, além disso o modelo proposto com várias partículas é menos sensivel à condições iniciais.

Neste trabalho, será proposto um modelo robusto e eficiente para detecção de comunidades em redes complexas via competição de partículas. No modelo proposto, partículas caminham pela rede e competem umas com as outras de maneira que cada uma delas tenta possuir o maior número de vértices possível. Além disso, estudamos o papel combinado de aleatoriedade e determinismo em dinâmica de partículas. Para isto, introduzimos uma regra para ajustar o nível de aleatoriedade no passeio da partícula na rede e descobrimos que uma pequena porção de aleatoriedade pode aumentar bastante a taxa de detecção de comunidades. Conseqüentemente, um fenômeno do tipo ressonância estocástica é observado no modelo proposto. Nossa descoberta indica que a aleatoriedade tem um papel importante em sistemas evolutivos. Ela serve para automaticamente escapar de armadilhas não desejáveis e explorar novos espaços, isto é, ela é um descobridor de novidades. Portanto, nosso resultado é contra-intuitivo (Quiles et al., 2008). 


\section{1 Descrição do Modelo}

O modelo é descrito da seguinte maneira. No início, um conjunto de $K$ partículas é aleatoriamente introduzido na rede. Existem dois tipos de dinâmicas: dinâmica de partículas e dinâmica de vértices. Cada partícula $\rho_{j}$ possui duas variáveis $\rho_{j}^{v}(t)$ e $\rho_{j}^{\omega}(t)$, onde $\rho_{j}^{v}(t)$ é usado para representar o vértice $v_{i}$ sendo visitado pela partícula $\rho_{j}$ no tempo $t$ e $\rho_{j}^{\omega}(t) \in\left[\rho_{\min }, \rho_{\max }\right]$ é o potencial da partícula que caracteriza o nível de competição ou a habilidade de exploração da partícula $j$ no tempo $t$. Especificamente, a dinâmica de partícula é governada pelas seguintes equações:

$$
\begin{gathered}
\rho_{j}^{v}(t+1)=v_{i} \\
\rho_{j}^{\omega}(t+1)=\left\{\begin{array}{ccc}
\rho_{j}^{\omega}(t) & \text { se } & v_{i}^{\rho}(t)=0 \\
\rho_{j}^{\omega}(t)+\left(\rho_{\text {max }}-\rho_{j}^{\omega}(t)\right) \Delta_{\rho} & \text { se } & v_{i}^{\rho}(t)=\rho_{j} \neq 0 \\
\rho_{j}^{\omega}(t)-\left(\rho_{j}^{\omega}(t)-\rho_{\text {min }}\right) \Delta_{\rho} & \text { se } & v_{i}^{\rho}(t) \neq \rho_{j} \neq 0
\end{array}\right.
\end{gathered}
$$

onde $\rho_{\max }$ e $\rho_{\min }$ representam o maior e o menor potencial permitido para todas as partículas, respectivamente. $\Delta_{\rho}$ é um parâmetro que controla a velocidade de incremento ou decremento do potencial de uma partícula.

Cada vértice $v_{i}$ possui três variáveis: $v_{i}^{\rho}(t), v_{i}^{\omega}(t)$ e $v_{i}^{\gamma}$. A primeira registra a partícula dona do vértice $v_{i}$ no tempo $t$, ela toma o valor $\rho_{j}$ se ocupada pela partícula $\rho_{j}$ ou 0 se o vértice $v_{i}$ está em um estado livre (o vértice ainda não foi dominado por nenhuma partícula). A segunda variável $v_{i}^{\omega}(t)$, como $\rho_{j}^{\omega}(t)$ para a partícula, é o potencial do vértice $v_{i}$ no tempo $t$, representando a força de domínio da partícula $\rho_{j}$ para o vértice $v_{i}$, i.e., um maior valor de $v_{i}^{\omega}(t)$ significa que $v_{i}$ é fortemente dominado por $\rho_{j}$, um valor menor representa uma dominância fraca e, especificamente, $v_{i}^{\omega}(t)=\rho_{\text {min }}$ indica que o vértice $v_{i}$ está em um estado livre, e será dominado pela primeira partícula que chegar. A terceira é uma variável binária $v_{i}^{\gamma}$, que toma o valor 0 se o vértice $v_{i}$ não está sendo visitado por nenhuma partícula naquele momento, ao passo que toma 1 se o vértice estiver sendo visitado por uma partícula.

As seguintes equações descrevem a dinâmica dos vértices:

$$
v_{i}^{\rho}(t+1)=\left\{\begin{array}{ccccc}
v_{i}^{\rho}(t) & \text { se } & & v_{i}^{\gamma}=0 \\
\rho_{j} & \text { se } & v_{i}^{\gamma}=1 & \text { e } & v_{i}^{\omega}(t)=\rho_{\text {min }}
\end{array}\right.
$$




$$
v_{i}^{\omega}(t+1)=\left\{\begin{array}{cll}
v_{i}^{\omega}(t) & \text { se } & v_{i}^{\gamma}=0 \\
\max \left\{\rho_{\min }, v_{i}^{\omega}(t)-\left(C \rho_{\max }-v_{i}^{\omega}(t)\right) \Delta_{v}\right\} & \text { se } v_{i}^{\gamma}=1 \quad \text { e } & v_{i}^{\rho}(t) \neq\left(\beta_{j} .4\right) \\
\rho_{j}^{\omega}(t+1) & \text { se } v_{i}^{\gamma}=1 \quad \text { e } & v_{i}^{\rho}(t)=\rho_{j}
\end{array}\right.
$$

onde $\Delta_{v}$ é um parâmetro que controla a velocidade do decremento potencial de um vértice e $C>1$ é uma constante.

O processo de detecção de comunidade através da aplicação do modelo proposto pode ser descrito da seguinte maneira. Primeiramente, $K$ partículas são colocadas em $K$ vértices da rede escolhidos aleatoriamente. Cada partícula $\rho_{j}$ tem o potencial inicial $\rho_{j}^{\omega}(0)=\rho_{\min }$ e cada vértice $v_{i}$ tem potencial inicial $v_{i}^{\omega}(t)=\rho_{\min }$ também. Ainda neste momento, todos os vértices $v_{i}$ são livres, i.e., $v_{i}^{\rho}(0)=0$. Conforme o sistema executa, cada partícula escolhe um vértice vizinho para visitar (a regra descrevendo como escolher o vizinho será detalhada abaixo) em cada iteração. A partícula encontra uma das seguintes situações para cada visita:

1. Se o nó é livre seu potencial não muda.

2. Se o vértice $v_{i}$ sendo visitado pela partícula $\rho_{j}$ ainda não tem dono $\left(v_{i}^{\rho}(t)=\right.$ 0), então o potential de $\rho_{j}$ não muda, o dono de $v_{i}$ é marcado como $\rho_{j}$, i.e., $v_{i}^{\rho}(t)=\rho_{j}$ e o potencial de $v_{i}$ recebe o potencial de $\rho_{j}$, i.e., $v_{i}^{\omega}(t)=\rho_{j}^{\omega}(t)$.

3. Se o vértice $v_{i}$ sendo visitado pela partícula $\rho_{j}$ pertence a própria partícula, i.e., $v_{i}^{\rho}(t)=\rho_{j} \neq 0$, o potencial de $\rho_{j}$ aumenta aplicando-se a segunda linha da Equação (3.2), a posse de $v_{i}$ é mantida como $\rho_{j}$ e novamente o potencial de $v_{i}$ recebe o potencial de $\rho_{j}$.

4. Se o vértice $v_{i}$ sendo visitado pela partícula $\rho_{j}$ pertence a outra partícula, um choque ocorre e a partícula $\rho_{j}$ é rejeitada pelo vértice $v_{i}$. Neste caso, o potencial de ambos a partícula $\rho_{j}$ e o vértice $v_{i}$ são diminuídos aplicandose a terceira linha da Equação (3.2) e a segunda linha da Equação (3.4), respectivamente. Se $\rho_{j}^{\omega}(t)$ é reduzido abaixo de $\rho_{\text {min }}$, ele é reiniciado para um vértice escolhido aleatoriamente e seu potencial é ajustado para o nível mínimo, $\rho_{\min }$. Se o potencial do vértice $v_{i}$ é reduzido para $\rho_{\min }$, sua posse é ajustada para 0 , indicando que o vértice pode ser ocupado por qualquer partícula. Se não existir um nó livre escolhido aleatóriamente para a partícula ocupar, a partícula desaparece e o número de partículas é decrementado.

Desta forma, a posse de um vértice é fortalecida se ele for visitado pela mesma partícula freqüentemente, e é reduzida ou mesmo mudada se ele for freqüentemente visitado por partículas que não sejam sua dona. O mesmo 
processo continua até que um estado de equilíbrio dinâmico seja atingido, isto é, tal que o potencial dos vértices não varie mais. Verifica-se que estado de equilíbrio é atingido após certo tempo proporcional ao número de vértices da rede.

Como a partícula seleciona o vértice vizinho para visitar? Primeiramente introduzimos duas regras, as quais representam os casos extremos do nosso estudo: movimento aleatório e movimento determinístico. O primeiro supõe que a partícula não tem nenhum conhecimento sobre a estrutura da rede, e portanto seleciona aleatoriamente um vizinho para visitar (retornar imediatamente para o último vértice visitado não é permitido, a menos que o grau do vértice seja um); por outro lado, o segundo caso permite que a partícula sempre visite um vértice com o maior potencial. Com o objetivo de estudar a combinação de movimento aleatório e determinístico na detecção de comunidades, definimos a probabilidade $0 \leq p_{\text {det }} \leq 1$. Em cada iteração, cada partícula tem probabilidade $p_{\text {det }}$ de escolher o movimento determinístico e probabilidade $1-p_{\text {det }}$ de escolher o movimento aleatório. Portanto, conforme $p_{d e t}$ aumenta, o movimento determinístico tem maior probabilidade de ser aplicado. Em particular, o movimento das partículas é completamente aleatório se $p_{\text {det }}=0$, enquanto ele é totalmente determinístico se $p_{\text {det }}=1$. As visitas são sempre realizadas ao longo do grafo, respeitando as conexões detes. Não é permitido à partícula pular vértices, a menos que seu potencial seja reduzido abaixo de $\rho_{\min }$.

\subsection{Simulações Computacionais}

Agora apresentamos alguns resultados de simulações computacionais no estudo de redes clusterizadas com $N$ vértices igualmente divididos em $M$ grupos. A rede é gerada pela seguinte regra: Um par de vértices é conectado com probabilidade $p_{s}$ se eles estão na mesma comunidade, enquanto vértices pertencentes a diferentes grupos são conectados com probabilidade $p_{l}$. Fica claro que uma rede apresenta clusters se $p_{s}>p_{l}$, indicando que o número de conexões dentro da comunidade é maior que o número de conexões entre diferentes comunidades. Em todas as simulações apresentadas neste trabalho, os seguintes parâmetros são mantidos constantes como $\rho_{\min }=0.05$, $\rho_{\max }=1$, e $C=3$. Há uma certa dependência dos parâmetros com o número de nós, a quantidade de partículas e o número de comunidades. Estes valores foram escolhidos porque verificou-se experimentalmente que estes valores de parâmetros conduzem a bons resultados no caso geral.

A Figura 3.1 mostra instantâneos do modelo proposto aplicado para detectar comunidades em redes clusterizadas aleatórias com quatro comunidades. A Figura 3.1(a) mostra as condições iniciais nas quais apenas quatro vértices 
são marcados como suas partículas associadas e todos os vértices vermelhos estão livres. Nas Figuras. 3.1(b)-(d) vemos que, devido ao processo de competição proposto, cada partícula é confinada dentro de uma comunidade. Desta forma, as quatro comunidades são corretamente identificadas. Esta figura foi apesentada sem taxa de correção (discutida posteriormente) pois foi a primeira simulação realizada no teste de eficiência do modelo.

A Figura 3.2 mostra a taxa de detecção correta, definida pela porcentagem de vértices corretamente classificados, para diversos valores de $p_{\text {det }}$. Quando apenas a regra aleatória é aplicada $\left(p_{\text {det }} \approx 0\right)$, as partículas permanecem migrando aleatoriamente entre vértices e as comunidades não são detectadas com precisão. Por outro lado, quando $\left(p_{\text {det }} \approx 1\right.$ ), a partícula continua caminhando dentro de uma pequena região da rede. Então a taxa de detecção correta da rede é muito baixa. Uma melhor taxa de detecção de detecção correta é alcançada quando $p_{\text {det }}$ é um valor grande mas não igual a 1, i.e., $p_{\text {det }} \approx 0.9$ (Figura 3.2). Neste caso, as partículas permanecem se movendo dentro de suas respectivas comunidades e ocasionalmente exploram novos territórios (vértices que pertençam a outras partículas). Simulações em redes de diferentes tamanhos e diferente número de comunidades foram realizadas e descobrimos que o formato da curva mostrada na Figura 3.2 não muda. Vale a pena apontar que a regra determinística por si só não é ótima. Pelo contrário, se apenas a regra determinística for aplicada $\left(p_{\text {det }} \approx 1\right)$, sempre obtemos maus resultados, como pode ser visto na Figura 3.2. É exatamente a pequena porção de aleatoriedade que faz as coisas melhorarem. Como descrito acima, o movimento determinístico mantém a partícula viajando dentro de seu próprio território e a regra de movimento aleatório tem a função de criar um comportamento exploratório, o qual permite que as partículas se movam para vértices livres ou para competir por vértices que pertencem a outras partículas. Desta forma, a aleatoriedade age como um fator importante para as partículas se adaptarem ao ambiente e melhorarem suas decisões. Este fenômeno tem certas similaridades para o processo de tomada de decisão humano: um indivíduo não tem uma decisão ótima no início. Porém, conforme ele se adapta ao ambiente, seu (ou sua) decisão será melhorada. Portanto, acreditamos que a aleatoriedade é importante para o aprendizado biológico e artificial.

A Figura 3.3(a) mostra a evolução temporal do modelo para quatro valores de $p_{\text {det }} \in\{0.0,0.3,0.9,1.0\}$. Aqui vemos que para movimentação aleatória ou para movimentação determinística completa, a taxa de detecção correta é baixa. Em todos os quatro casos, a melhor taxa é obtida quando $p_{\text {det }}=0.9$, o qual é compativel com os resultados mostrados na Figura 3.2. Figuras 3.3(b)-(c) mostram a evolução temporal dos potenciais médios de vértices e de partículas, respectivamente, para os mesmos valores de $p_{\text {det }}$. Vemos que 


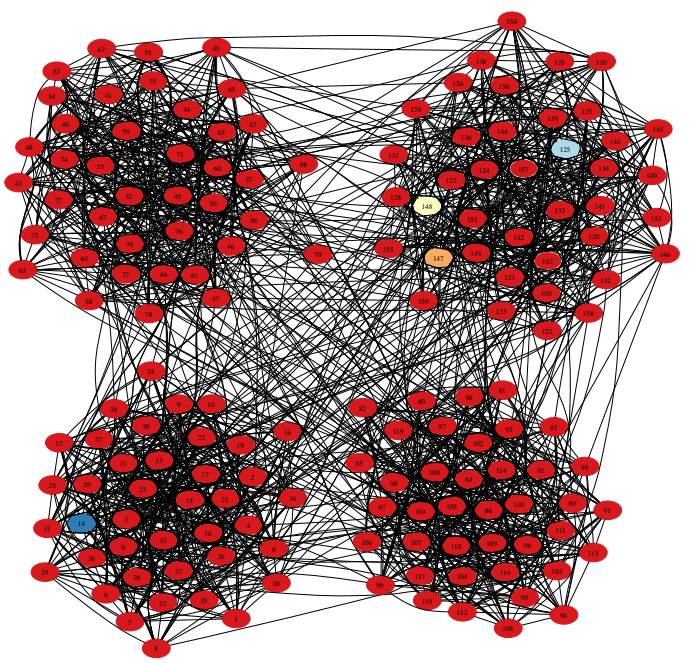

(a)

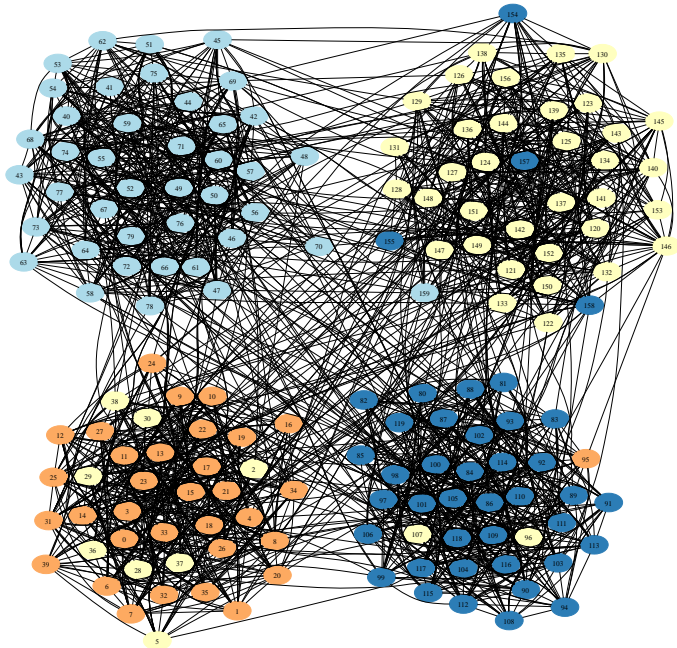

(c)

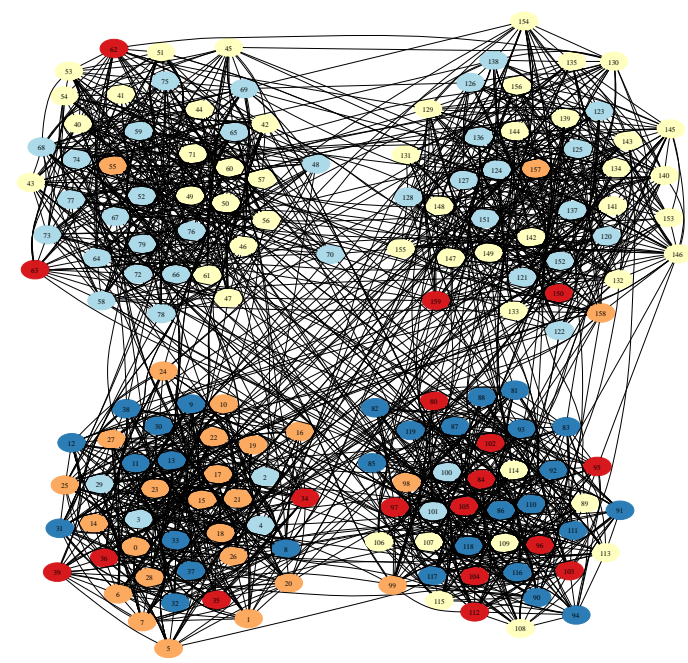

(b)

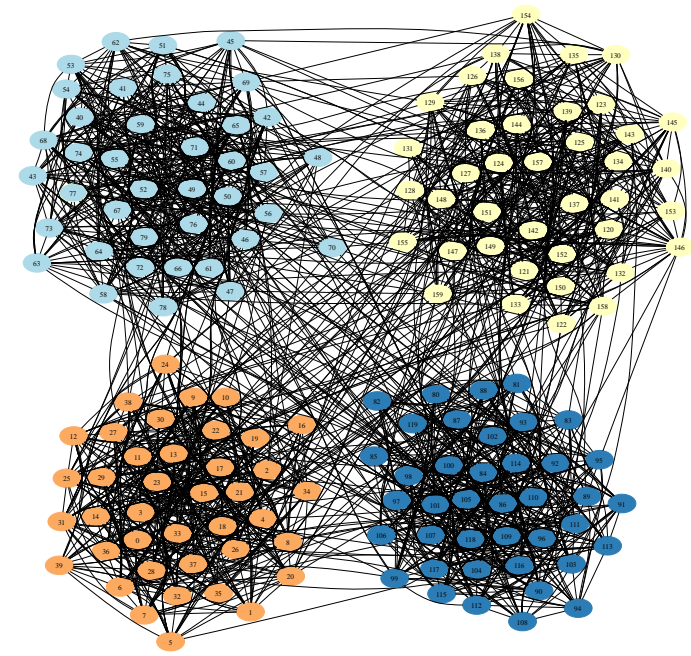

(d)

Figura 3.1: Ilustração do processo de detecção de comunidades pela movimentação de partícula. O número total de vértices é $N=160$, o número de comunidades é $M=4$. A probabilidade de intra-conexão é $p_{s}=0.8$ e a probabilidade de inter-conexão é $p_{l}=0.2$. (a) configuração inicial. Quatro partículas, representadas por azul, ciano, amarelo, e laranja, são colocadas aleatoriamente na rede. A cor vermelha representa os vértices livres. (b) um instantâneo da iteração 500. (c) um instantâneo da iteração 6000. (d) um instantâneo da iteração 13000. 


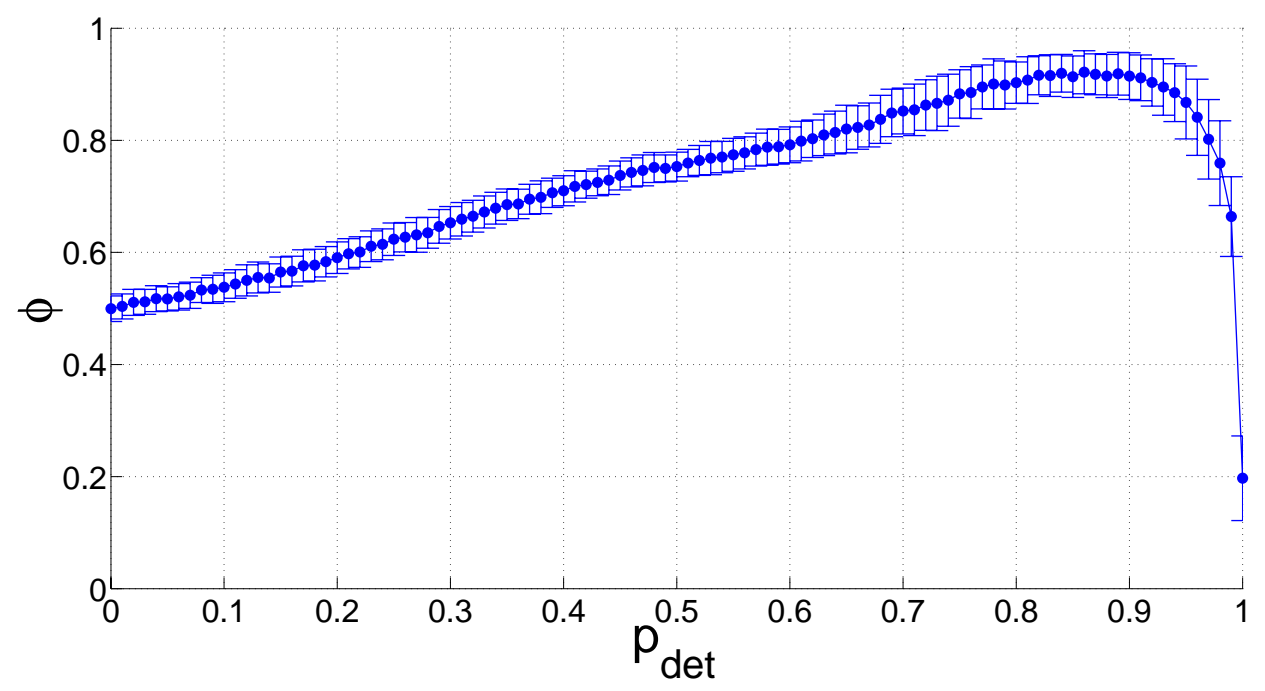

Figura 3.2: Taxa de detecção de comunidade correta $\phi$ versus probabilidade de determinismo $p_{\text {det }}$. Cada ponto na curva é a média de 200 realizações. As barras de erro representam os desvios padrões.

o comportamento da taxa de detecção correta acompanha o comportamento do potencial médio dos vértices. Ele também acompanha o comportamento do potencial médio das partículas, exceto no caso $p_{d e t}=1$. Isto é porque cada partícula fica presa em um pequeno círculo diferente, a competição não ocorre e o potencial sempre é incrementado até que $\rho_{\max }$ é atingido. Para redes onde a estrutura da comunidade é desconhecida a priori, a média de potencial dos vértices pode ser usada como uma indicação de detecção.

Agora estudaremos como o número de partículas afeta a detecção de comunidades. A Figura 3.4 mostra que a taxa de detecção de comunidades contra o número de partículas usados na detecção. O número de nós e de comunidades é variado simultaneamente para preservar a proporção entre o tamanho das comunidades em relação à quantidade de nós, isto é, a relação $N / M$. Em ambas as redes de 5 e 15 comunidades, as soluções ótimas são encontradas quando 5 e 15 partículas são usadas, respectivamente. É intuitivo que a melhor precisão pode ser obtida usando $K$ partículas quando a rede apresentada tem $K$ comunidades. Isto acontece porque vértices de diferentes comunidades estariam agrupados se menos de $K$ partículas fossem usadas e, por outro lado, os vértices pertencentes a mesma comunidade estariam divididos em pequenos grupos se mais que $K$ partículas fossem usadas. Da Figura 3.4, também vemos a correspondência entre a taxa de detecção correta e o potencial médio dos vértices. Normalmente, não temos conhecimento sobre o número de comunidades para uma dada rede. Novamente, podemos usar o nível de potencial médio dos vértices para determinar o número ótimo de partículas a serem usadas e conseqüentemente obter o número ótimo de comunidades de uma dada rede. 


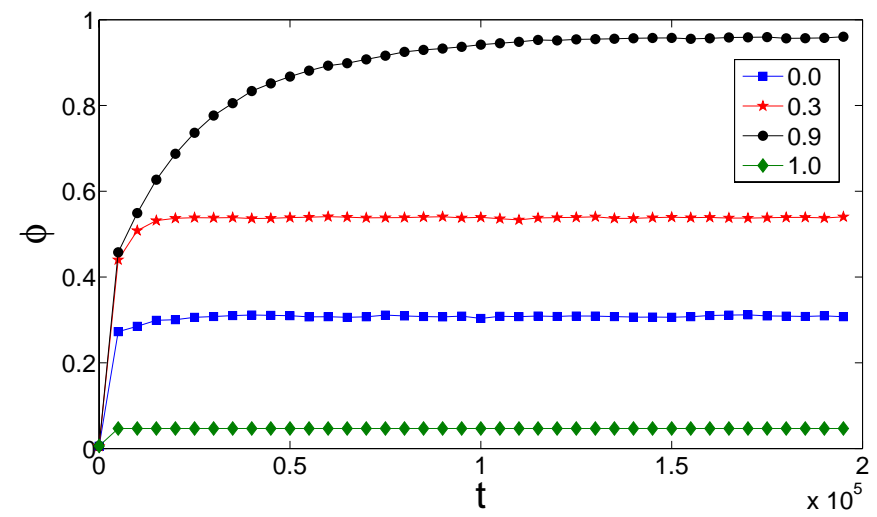

(a)

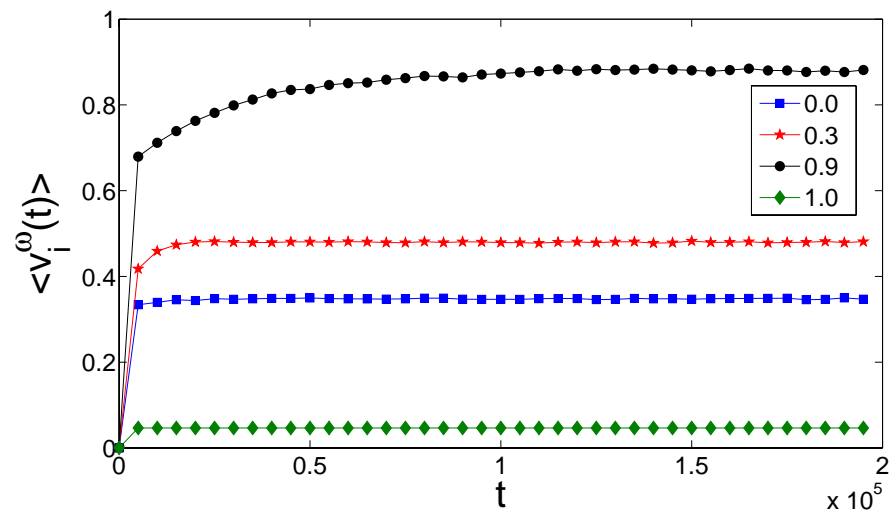

(b)

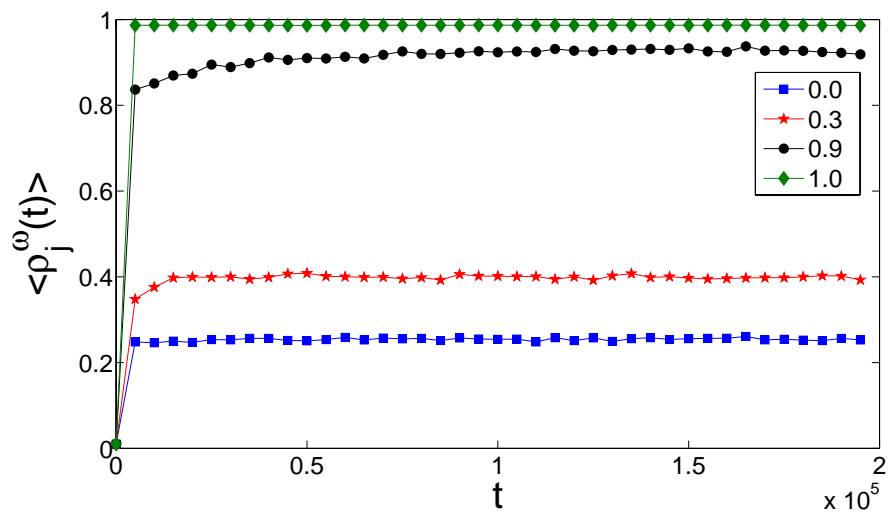

(c)

Figura 3.3: Séries temporais para diferentes valores de $p_{\text {det }}$. (a) Séries temporais da taxa de detecção correta; (b) séries temporais do potencial dos vértices; (c) séries temporais do potencial das partículas. Em todas as três figuras, as simulações são executadas na rede com $N=1000, M=5, p_{s}=0.7$ e $p_{l}=0.3$. Cada ponto na curva é a média de 200 realizações. 


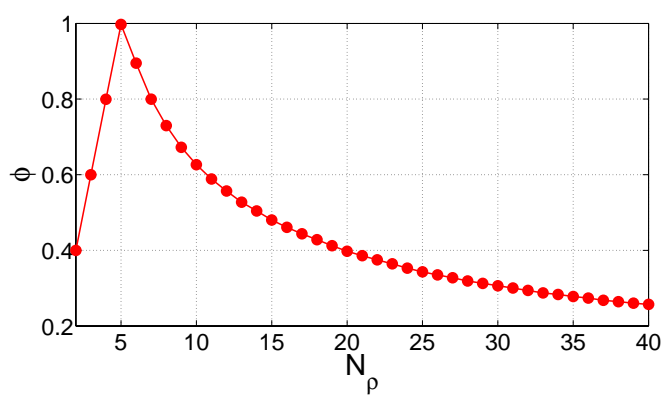

(a)

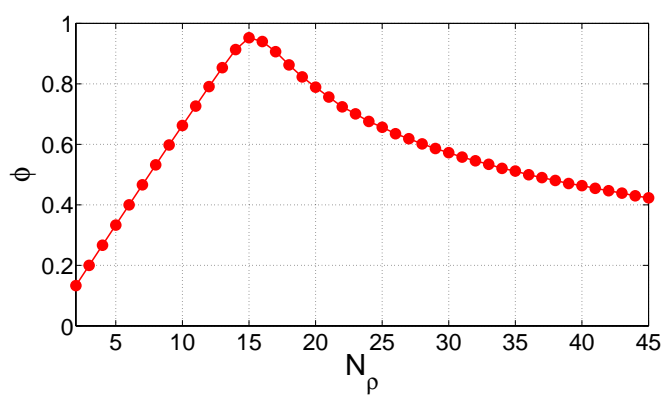

(c)

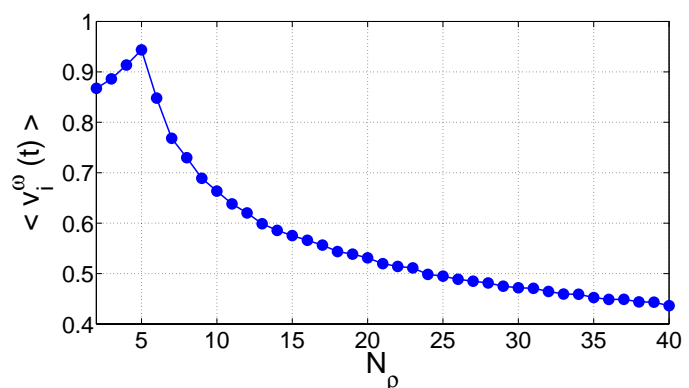

(b)

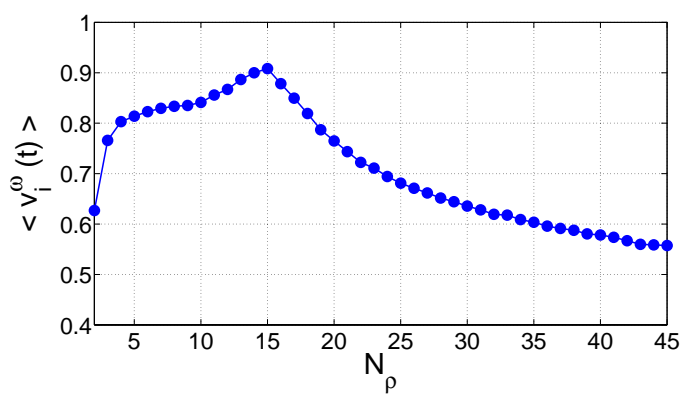

(d)

Figura 3.4: Resultados de simulação variando o número de partículas e o número de comunidades. (a) e (c) Taxa de detecção de comunidades correta versus número de partículas na rede. (b) e (d) Potencial médio dos vértices versus número de partículas na rede. Nas simulações mostradas em (a) e (b), $N=500, M=5, p_{s}=0.8, p_{l}=0.2$ e $p_{\text {det }}=0.9$. Nas simulações mostradas em (c) e (d), $N=1500, M=15, p_{s}=0.8, p_{l}=0.2$, e $p_{\text {det }}=0.9$.

Algumas simulações adicionais também foram realizadas, desta vez para comunidades de tamanho diferente com o número de partículas igual ao número de comunidades conhecidas à priori, a partir do algoritmo de geração do grafo. Nestas simulações a capacidade de movimentação da partícula chamada de taxa de espalhamento é crescente. As partículas com capacidade de movimentação maior, neste caso, ocupam comunidades maiores. Introduziu-se também nestas simulações um fator de relevância que afeta o potencial das partículas. Este fator de relevância do vértice $j$ é dado por:

$$
F_{j}=m_{j} / M_{j}
$$

Neste caso $m_{j}$ é o número de vértices vizinhos que tem o mesmo dono que a partícula visita e $M_{j}$ é numero total de vizinhos do vértice $j$. A taxa de atualização do potencial da partícula com esta nova regra é dado por:

$$
\rho_{j}^{\omega}(t+1)=\min \left\{\rho_{j}^{\omega}(t)\left(1+F_{j}\right), \rho_{\max }\right\}
$$

Se a partícula está visitando um vértice que já pertence à ela. Esta nova fórmula para atualização do potencial introduz um fenômeno de cooperação no modelo. Assim se a partícula estiver em seu domínio ou vizinhança o 
potencial do vértice é favorecido com um grande aumento, caso contrário a taxa de aumento do potencial é bem menor.

Por outro lado, se a partícula estiver visitando um vértice de que ela não é dona, o fator de relevância é calculado por:

$$
\rho_{j}^{\omega}(t+1)=\max \left\{\rho_{j}^{\omega}(t)\left(1-F_{j}\right), \rho_{\min }\right\}
$$

Note que nesse caso, se a partícula estiver numa vizinhança que tem vários vértices que ela não é dona, então $F$ é grande, isto significa que outra partícula já passou várias vezes por esse terreno. A partícula então sofre uma grande diminuição de potencial de forma a voltar ao potencial mínimo o mais rápido possível.

O potencial do vértice é também modificado por:

$$
\rho_{j}^{v}(t+1)=\rho_{j}^{v}(t)\left[k(t)+(1-k(t)) F_{j}\right]-k(t) v_{j}^{\omega}(t+1) .
$$

Onde $k(t)$ é uma função monótona decrescente com o tempo. O uso desta função possibilita uma estabilização do potencial com o tempo. No início, $k(t)=1$, e a vizinhança é ignorada. A medida que o tempo passa, há um maior peso para a vizinhança pois o termo $1-k(t)$ começa a aumentar. Paralelamente, a importância da partícula para o vértice começa a diminuir cada vez mais. Depois de algumas iterações, os potenciais dos vértices já estão estabilizados. Quando $t \rightarrow \infty, k(t)=0$ e o sistema estabiliza, pois $F_{j}$ não varia mais.

As Figuras 3.5 - 3.12 são simulações que mostram habilidade do modelo na detecção de comunidades de tamanhos diferentes. Nesses casos, as simulações foram feitas com o modelo inicial, sendo os potenciais não corrigidos ao longo das iterações. Já as Figuras 3.13 - 3.20 se referem a simulações que utilizam a taxa de correção do potencial dos vértices e a taxa de atualização dos pontencias das partículas dadas pelas Equações 3.8 e 3.7, respectivamente. Tais simulações são apresentadas somente com a taxa de correção, porém verificou-se que o algoritmo é menos eficiente quando não é utilizada a taxa de correção. Nas simulações foi utilizado um critério parada que consiste em um número máximo de iterações 1000000, porém se considerarmos a estabilização do potencial médio dos vértices como critério de parada, a solução é atingida bem antes de 1000000 de iterações. Uma característica importante do modelo é que o potencial médio dos vértices pode ser utilizado tanto para detecção de comunidades quanto para descobrir o número ótimo de partículas.

Finalmente, aplicamos nosso modelo para detectar comunidades em duas redes reais, sem taxa de correção de potencial. A Figura 3.21 mostra os resultados de simulação da rede de amizades entre indivíduos no clube de karate estudado em (Zachary, 1977). Nossos resultados diferem em apenas um nó 


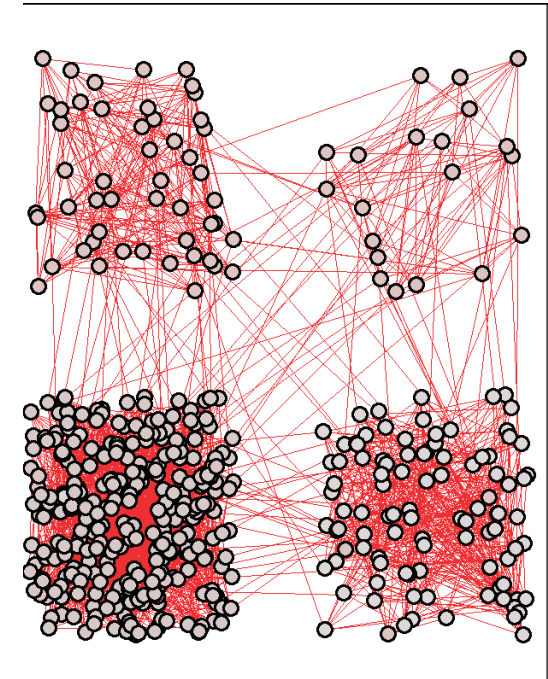

(a)

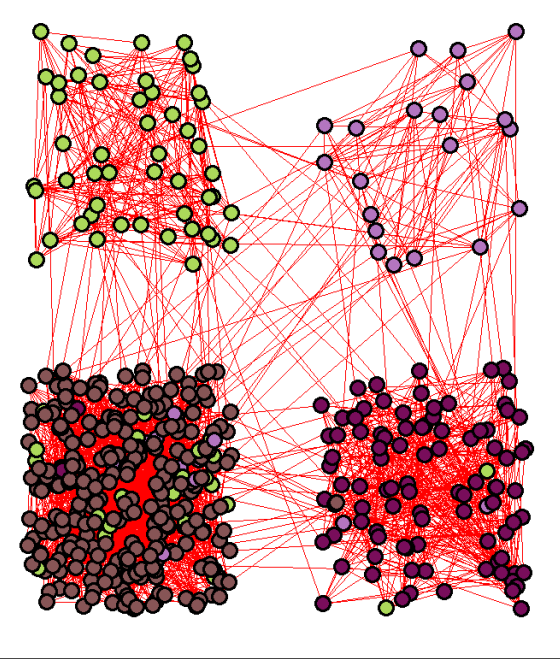

(b)

Figura 3.5: (a) Iteração inicial, $N=200, M=4, p_{s}=0.95, p_{l}=0.05$ e $p_{\text {det }}=0.90$ (b) Resultado após 1000000 iterações.

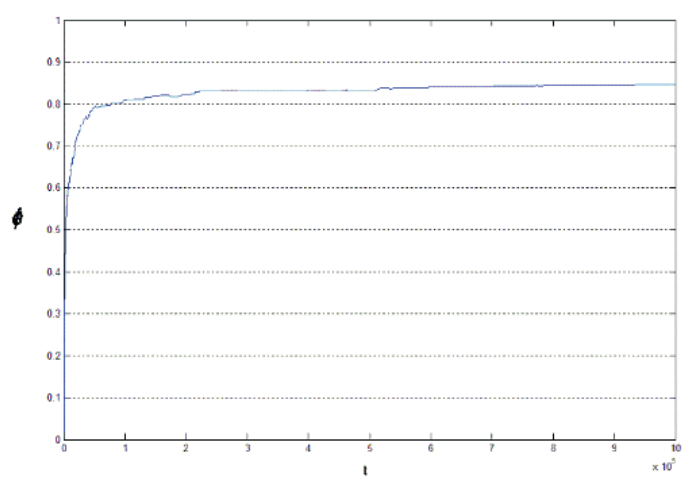

Figura 3.6: Porcentagem de acerto, calculada para a simulação mostrada na Figura 3.5.

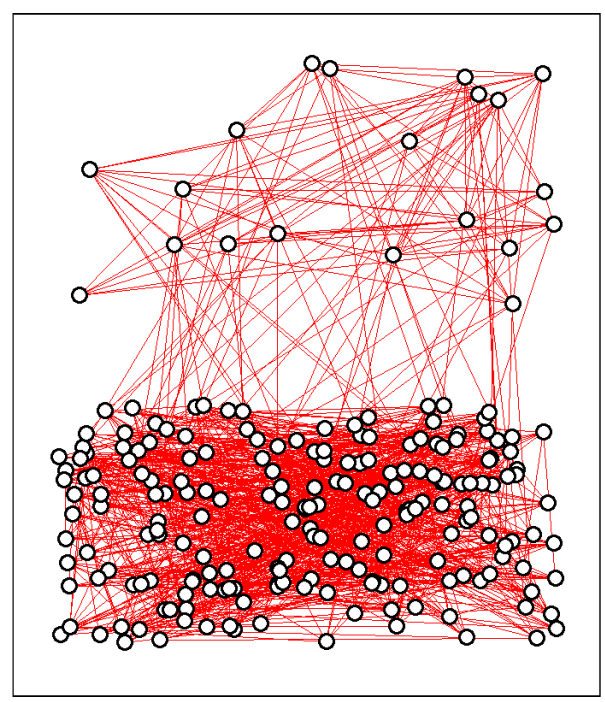

(a)

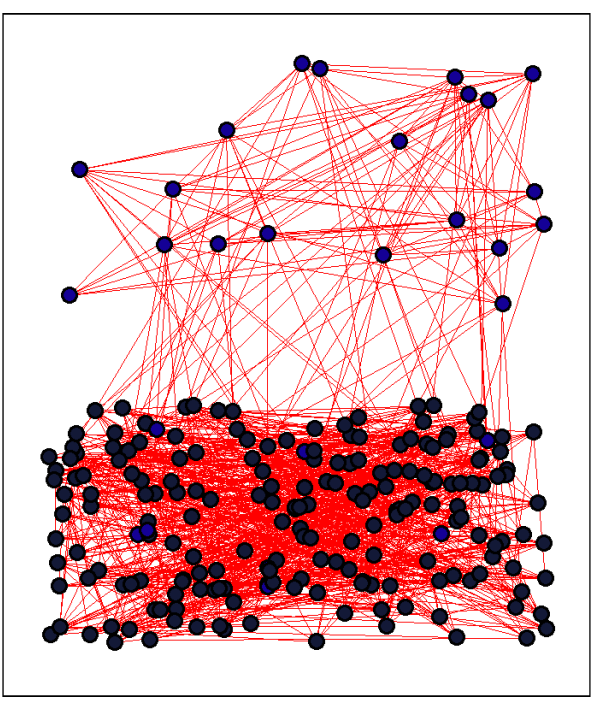

(b)

Figura 3.7: (a) Iteração inicial, $N=200, M=2, p_{s}=0.95, p_{l}=0.05$ e $p_{\text {det }}=0.90$. (b) resultado após 1000000 iterações. 


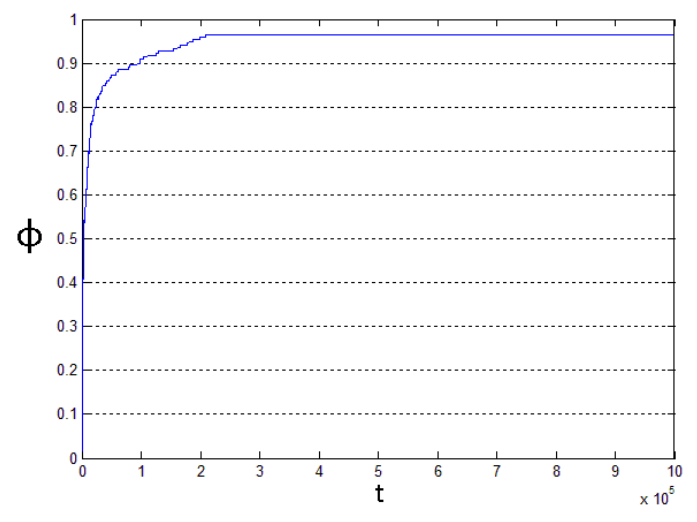

Figura 3.8: Porcentagem de acerto, calculada para a simulação mostrada na Figura 3.7.

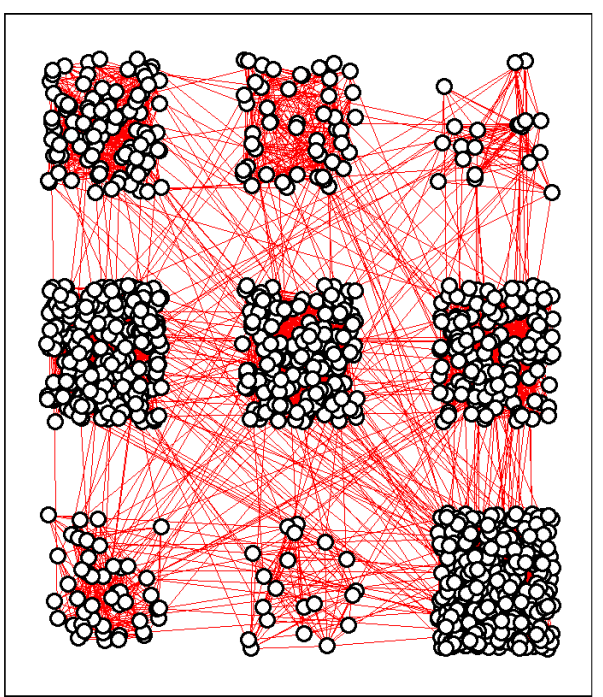

(a)

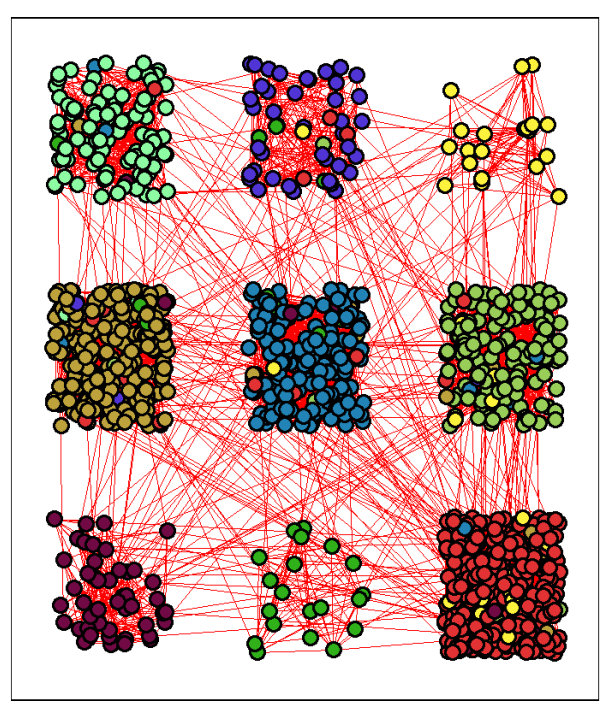

(b)

Figura 3.9: (a) Iteração inicial, $N=300, M=9, p_{s}=0.85, p_{l}=0.15$ e $p_{\text {det }}=0.90$. (b) Resultado após 1000000 iterações.

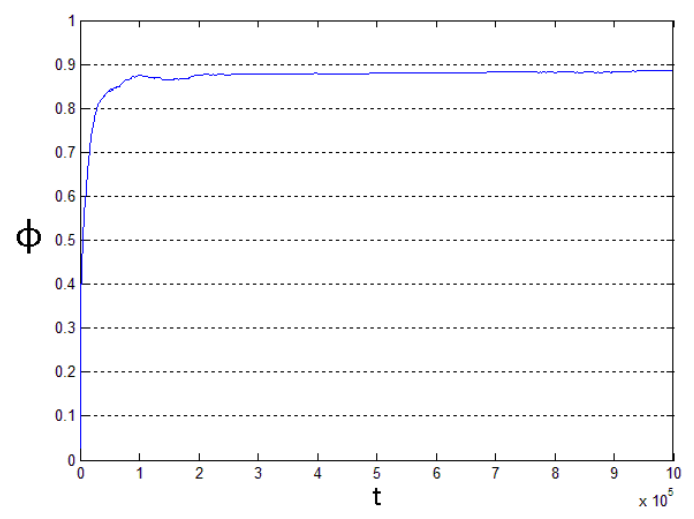

Figura 3.10: Porcentagem de acerto, calculada para a simulação mostrada na Figura 3.9. 


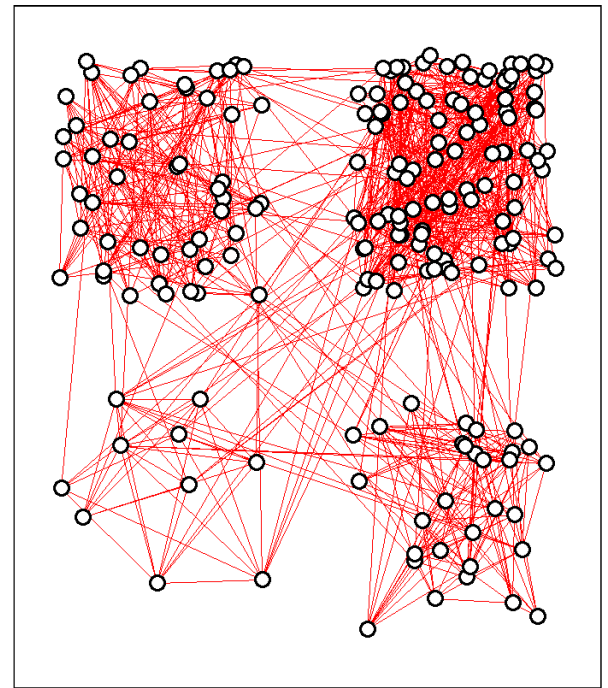

(a)

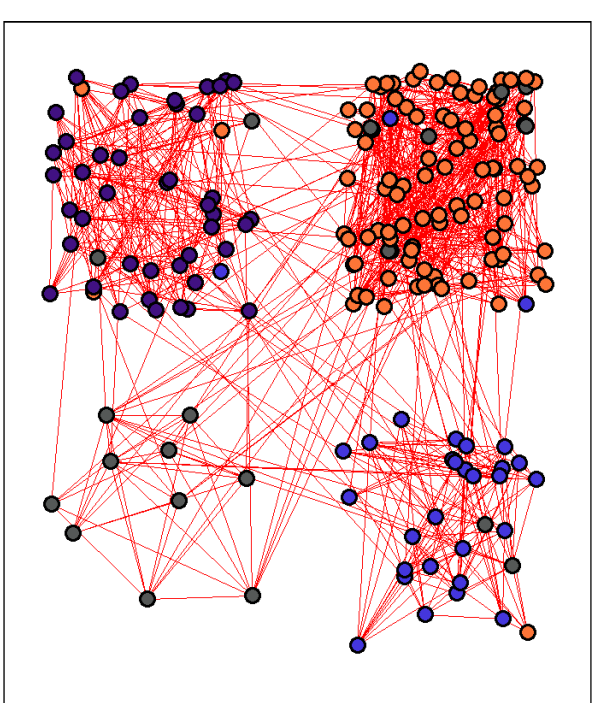

(b)

Figura 3.11: (a) Iteração inicial, $N=200, M=4, p_{s}=0.9, p_{l}=0.1$ e $p_{\text {det }}=0.90$. (b) Resultado após 1000000 iterações.

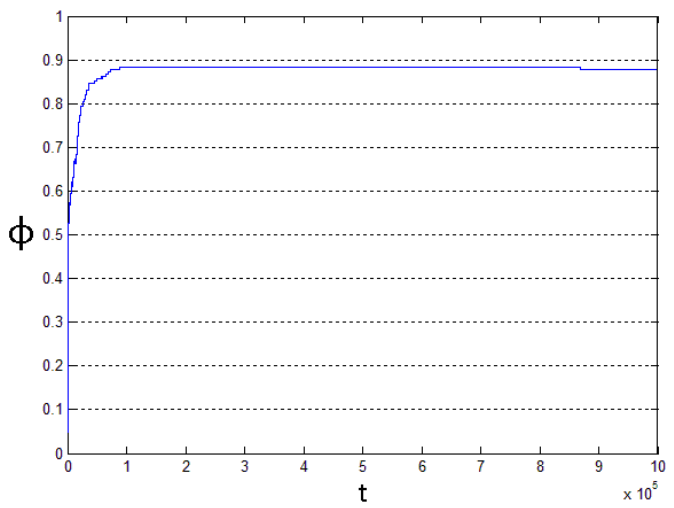

Figura 3.12: Porcentagem de acerto, calculada para a simulação mostrada na Figura 3.11.

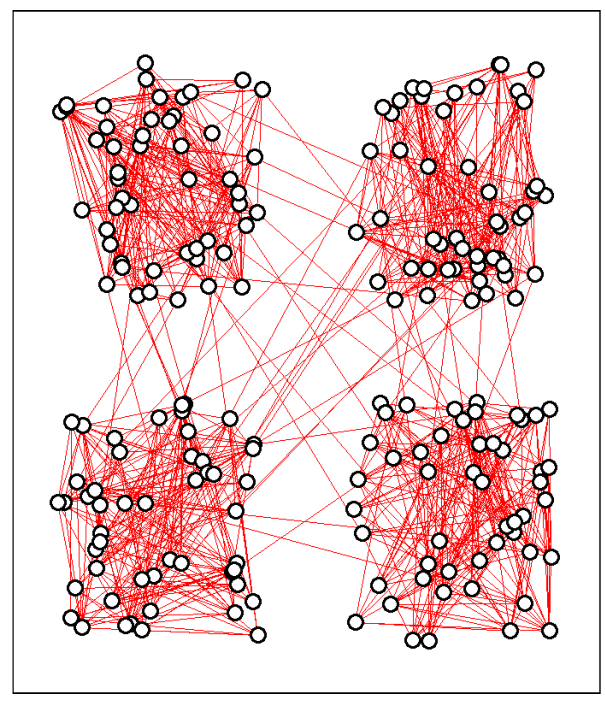

(a)

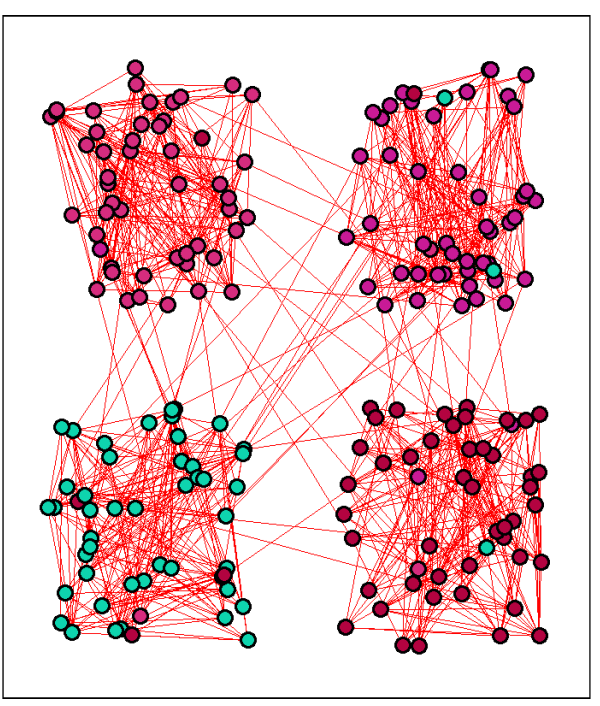

(b)

Figura 3.13: (a) Iteração inicial, $N=200, M=4, p_{s}=0.95, p_{l}=0.05$ e $p_{\text {det }}=0.90$. (b) Resultado após 1000000 iterações. 


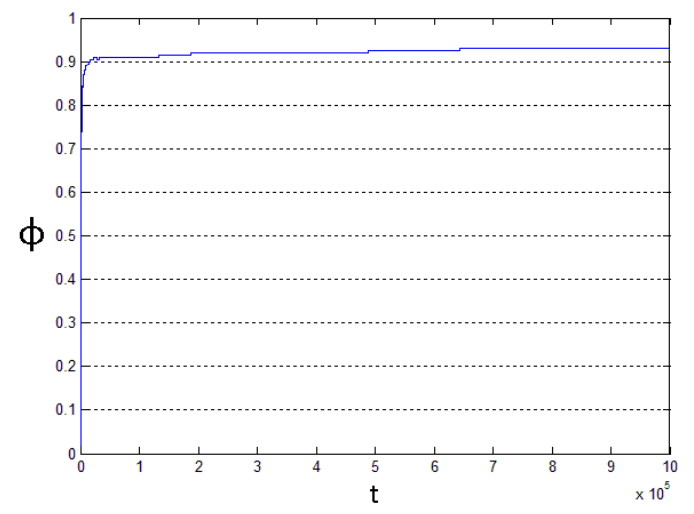

Figura 3.14: Porcentagem de acerto, calculada para a simulação mostrada na Figura 3.13.

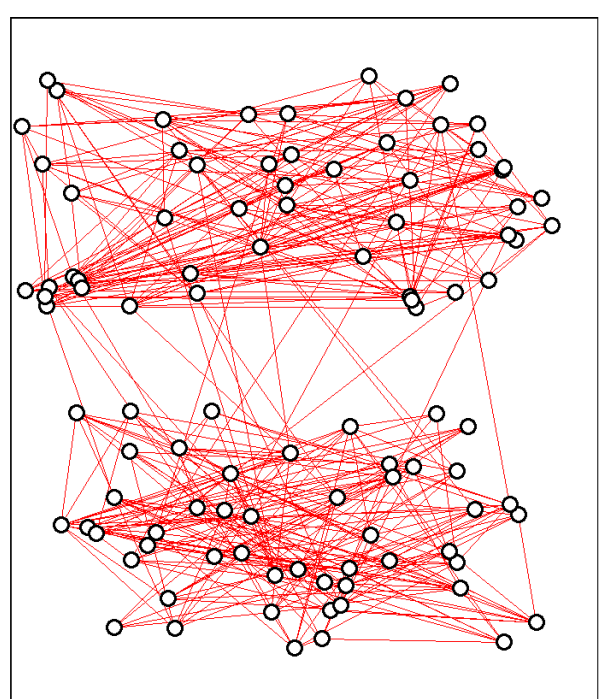

(a)

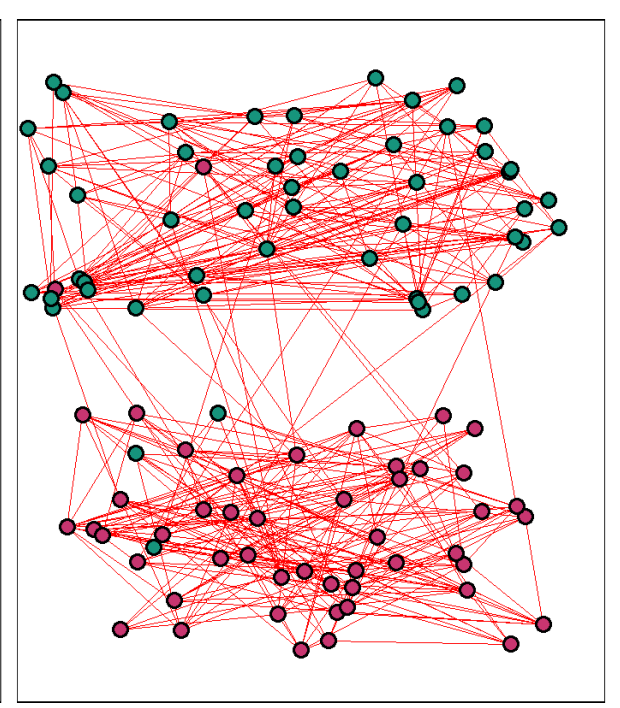

(b)

Figura 3.15: (a) Iteração inicial, $N=200, M=4, p_{s}=0.95, p_{l}=0.05$ e $p_{\text {det }}=0.90$. (b) Resultado após 1000000 iterações.

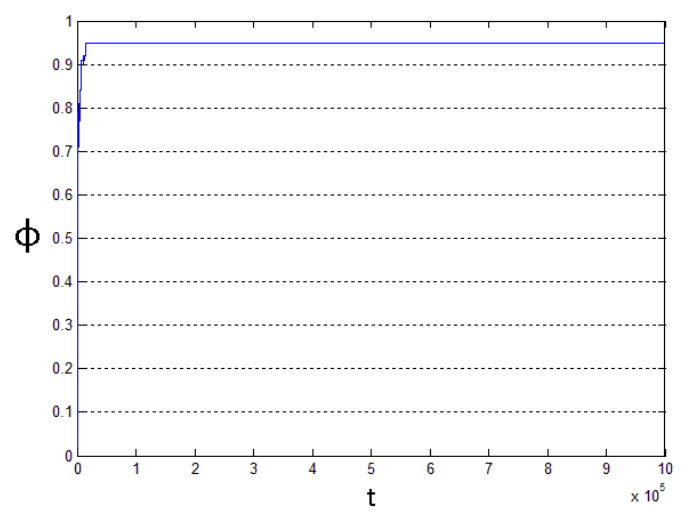

Figura 3.16: Porcentagem de acerto, calculada para a simulação mostrada na Figura 3.15. 


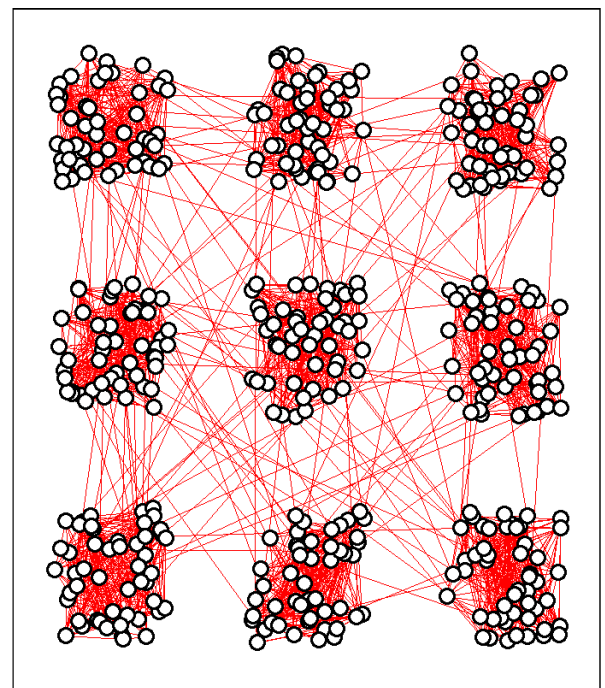

(a)

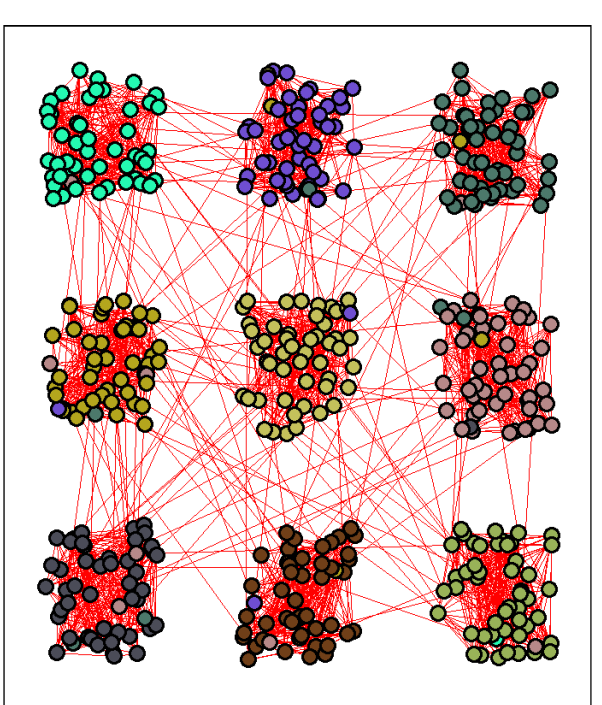

(b)

Figura 3.17: (a) Iteração inicial, $N=450, M=9, p_{s}=0.9, p_{l}=0.1$ e $p_{\text {det }}=0.90$ (b) Resultado após 1000000 iterações.

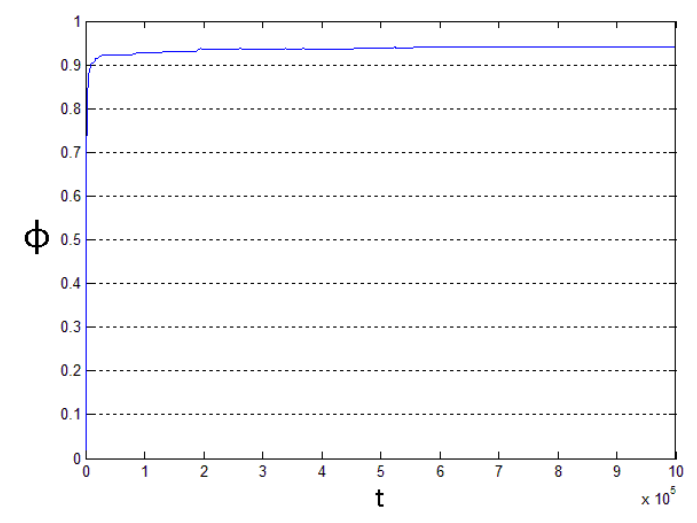

Figura 3.18: Porcentagem de acerto, calculada para a simulação mostrada na Figura 3.17.

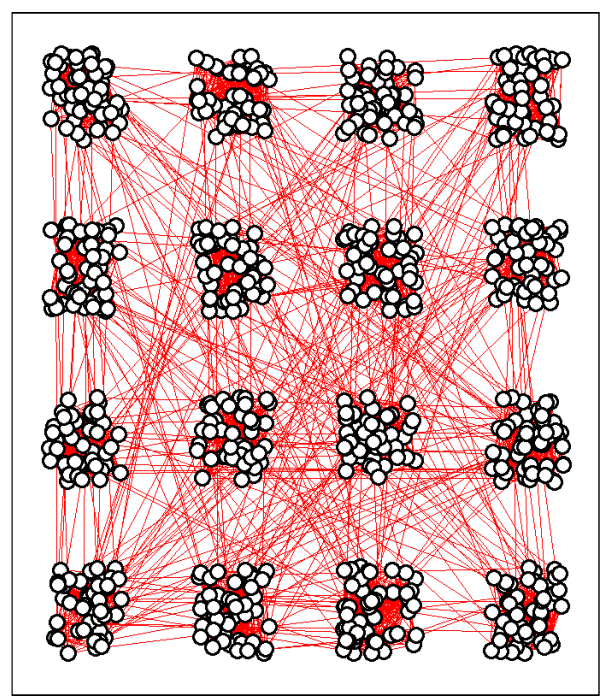

(a)

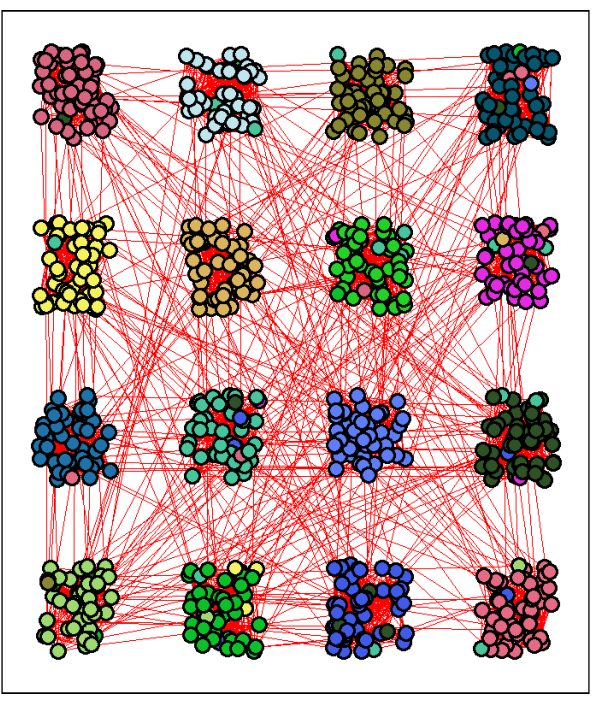

(b)

Figura 3.19: (a) Iteração inicial, $N=640, M=16, p_{s}=0.95, p_{l}=0.05$ e $p_{\text {det }}=0.90$. (b) Resultado após 1000000 iterações. 


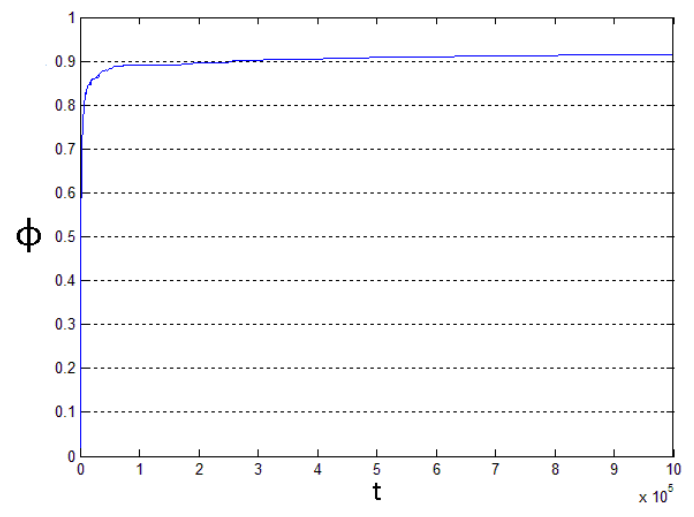

Figura 3.20: Porcentagem de acerto, calculada para a simulação mostrada na Figura 3.19.

(número 3) do resultado apresentado em (Newman \& Girvan, 2004). A segunda simulação foi executada utilizando a rede social de golfinhos (Lusseau et al., 2003), a qual foi criada baseada nos laços sociais observados em pares de golfinhos durante diversos anos dw observação direta. Devido a partida de um membro chave (número 27) da população, o grupo foi dividido em duas comunidades. Nossos resultados mostrados na Fig. 3.22 combinam perfeitamente com a divisão observada na comunidade real dos golfinhos (comunidade vermelha e comunidade azul). Nestes modelos reais foi usada a taxa de correção 0.95, pois para comunidades pequenas, isto é, redes com poucos nós essa taxa de determinismo tem pouca influência no resultado, isto é, se utilizássemos 0.9 isso não afetaria o resultado.

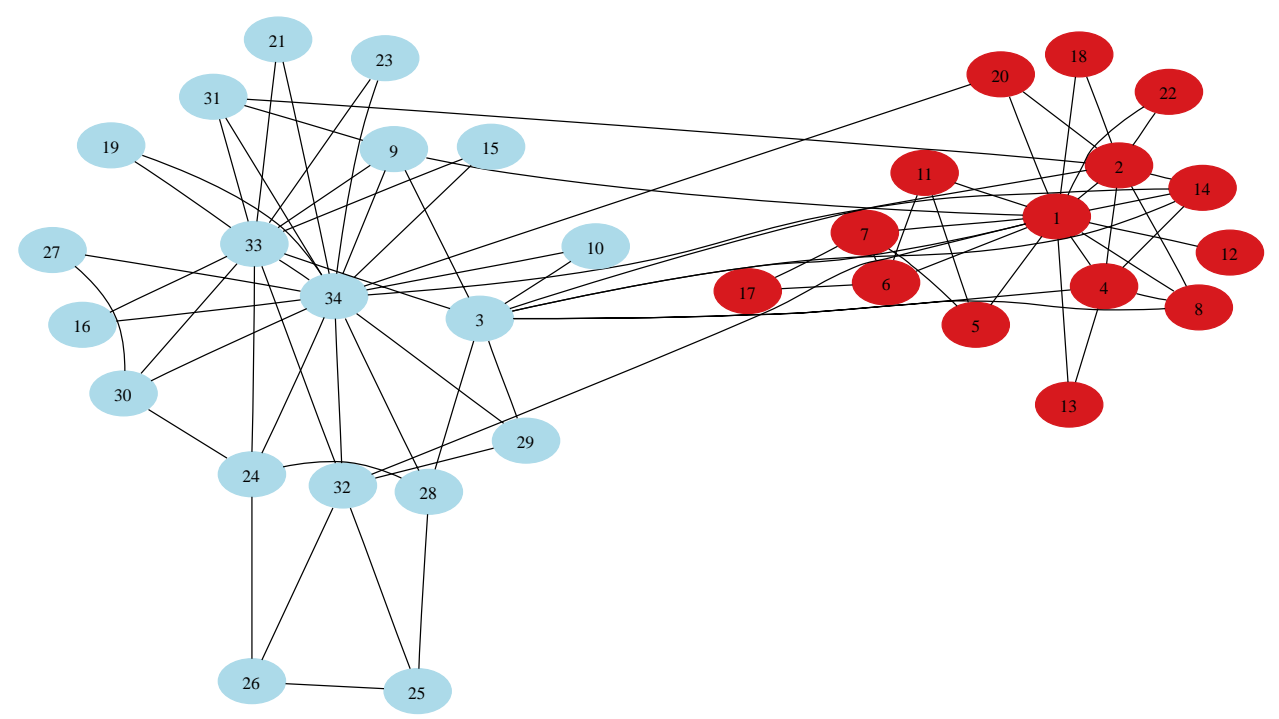

Figura 3.21: Resultados de detecção de comunidades na rede de amizades entre indivíduos no estudo do clube de karate (Zachary, 1977). $p_{\text {det }}=0.95$. 


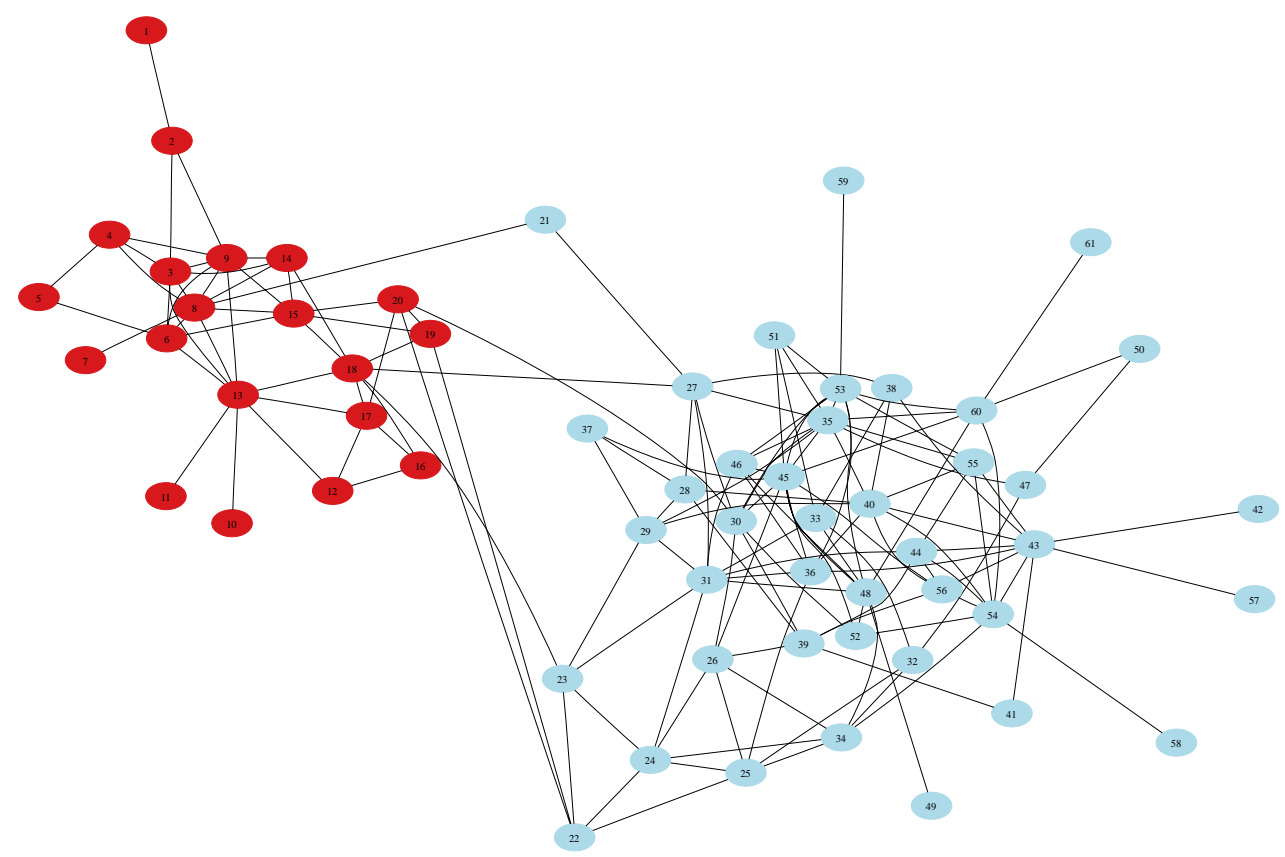

Figura 3.22: Resultados de detecção de comunidades na rede social de golfinhos (Lusseau et al., 2003). $p_{\text {det }}=0.95$.

\subsection{Considerações Finais}

As simulações mostraram que independentemente do número de comunidades, do tamanho destas comunidades ou das condições iniciais, existe sempre um estado final onde elas estão demarcadas. O número de comunidades demarcadas é sempre igual ou menor ao número de partículas e no caso destas comunidades serem previamente conhecidas a probabilidade de acerto, isto é, do algoritmo ter demarcado corretamente as comunidades pode ser estimada com uso do algoritmo e das idéias apresentadas no capítulo anterior. O modelo matemático desenvolvido no próximo capítulo para o caso de duas comunidades mostrará que este estado final em que as duas comunidades estão demarcadas é atrator do sistema e que ele independe das condições iniciais. Verifica-se experimentalmente que sempre se atinge este estado após um tempo proporcional ao número de vértices da rede. 


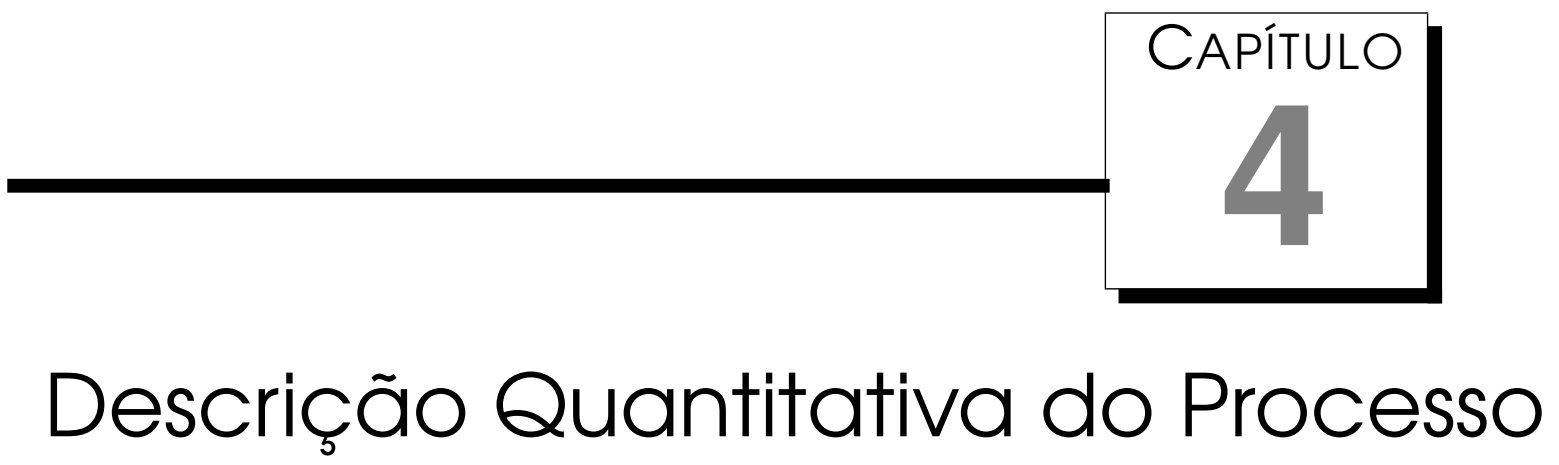

Apresentaremos neste capítulo um modelo contínuo de dinâmica para duas comunidades conectadas entre si com probabilidade $p_{l}$. O objetivo é descrever qualitativamente o processo de competição e demarcação de território realizado por estas duas partículas.

\section{1 Processos Estocásticos em Grafos}

O objetivo desta seção é mostrar que em processo estocástico com partículas transitando em um grafo não direcionado $\mathcal{G}$, vértices com maior grau recebem mais visitas. Para isso é necessário considerar dois tipos de probabilidade para um determinado vértice, a primeira probabilidade é a probabilidade de saída por uma aresta de uma partícula em um nó de uma partícula, a segunda é a probabilidade de chegada por uma aresta a um nó de uma partícula. Mostraremos primeiro como se calcula a primeira delas. Se temos um nó $i$ com $n_{i}$ arestas a probabilidade da partícula deixar o nó pela aresta $1 \leq m \leq n_{1}$ é $p_{\text {rel }}(i)=1 / n_{i}$ para todas as arestas. Essas probabilidades de saída são probabilidades relativas ao nó em questão. Se o grafo tem um total de $M$ arestas a probabilidade absoluta de uma partícula sair por qualquer aresta é igual a probabilidade relativa dividida pela soma das probabilidades absolutas, isto é:

$$
\begin{aligned}
p_{a b s}(j) & =\frac{p_{\text {rel }}(j)}{\sum_{i=1}^{M} p_{\text {rel }}(i)} \\
& =\frac{1}{n_{j} \sum_{i=1}^{M} \frac{1}{n_{i}}}
\end{aligned}
$$


Sempre que uma partícula está deixando um nó está entrando em outro nó, por isso a probabilidade absoluta de saída de um nó por uma aresta é sempre igual a probabilidade de entrada em outro nó pela mesma aresta. Assim para calcular a probabilidade de um nó ser visitado, devemos primeiramente calcular a probabilidade absoluta de saída de todas as arestas em seguida devemos considerar as arestas que entram em determinado nó e somar essas probabilidades absolutas. A probabilidade de visita daquele nó será igual a esta soma.

$$
\begin{aligned}
p_{v i s}(j) & =\sum_{k \leftrightarrow j} p_{a b s}(k) \\
& =\sum_{k \leftrightarrow j} \frac{1}{n_{k}\left(\sum_{i=1}^{M} \frac{1}{n_{i}}\right)} \\
& =\frac{1}{\sum_{i=1}^{M} \frac{1}{n_{i}}}\left(\sum_{k \leftrightarrow j} \frac{1}{n_{k}}\right) \\
& =\frac{1}{\sum_{i=1}^{M} \frac{1}{n_{i}}} S_{j}
\end{aligned}
$$

Com o símbolo $\leftrightarrow$ queremos dizer conexão, isto é, $k \leftrightarrow j$ significa todos os nós $k$ que estão conectados com $j$. Note que na passgem acima o termo de somatório no denominador é constante e portanto pode ser fatorado. Assim a fórmula acima mostra que a probabilidade de visita a um determinado nó é proporcional a soma das probabilidades relativas dos nós que estão conectados a ele. Assim sendo, suponha que $j_{1}$ tenha o maior número de conexões (maior grau), isto é, $n_{j_{1}} \geq n_{j}$ para todo $j$ no grafo. A soma $S_{j_{1}}$ terá um número maior de parcelas e cada parcela terá um denominador menor pois $n_{k} \leq n_{j_{1}}$, para todo $k$ conectado a $j_{1}$. Portanto a probabilidade $p_{v i s}\left(j_{1}\right)$ será maior do que a dos demais nós. Eliminando $j_{1}$ e procedendo por indução em $j_{2}$ tal que $n\left(j_{2}\right) \geq n_{j}$ para todo $j$ argumentamos da mesma forma acima que o número de visitas é maior. Assim sucessivamente é possível mostrar por indução que nós com maior grau são mais visitados.

\subsection{Processo de Demarcação}

Suponha que tenhamos duas comunidades como mostrado na figura 4.2, e que coloquemos uma partícula $x$ na comunidade $A$ e uma partícula $y$ na comunidade $B$. Em princípio nenhuma das duas partículas "sabe"qual região que irá demarcar, portanto o grafo que elas "enxergam"é um grafo sem comunidades, como o mostrado na figura 4.2. A medida que as partículas caminham no grafo, elas demarcam uma certa região. Portanto seja $R_{x}$ a região 


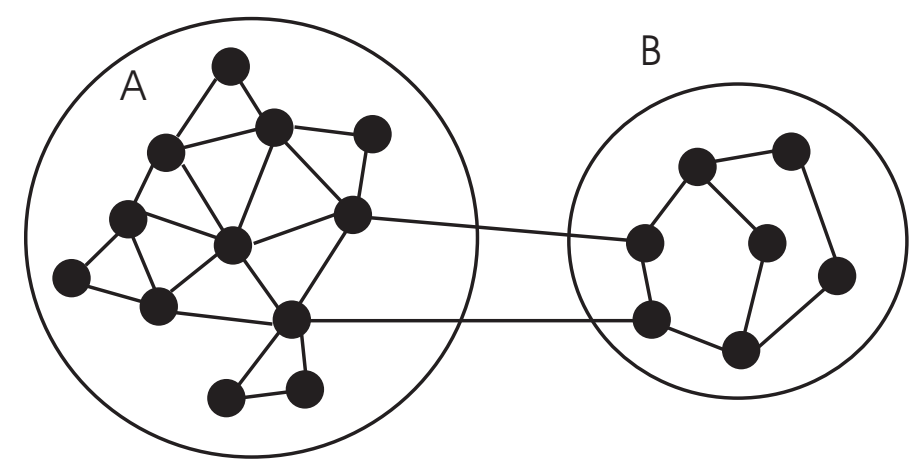

Figura 4.1: Exemplo de um Grafo com duas comunidades.

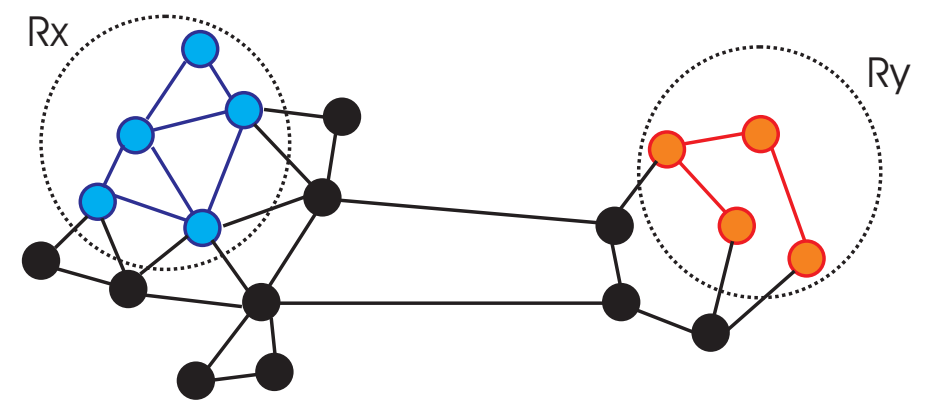

Figura 4.2: Regiões ocupadas durante o movimento de partículas.

do grafo demarcada pela partícula $x, R_{y}$ a região do grafo demarcada pela partícula $y$ e $R_{u}$ a região do grafo não demarcada. Como não estamos considerando a estrutura exata do grafo neste modelo, estas regiões podem ser pensadas como o número de vértices demarcados por cada partícula. Elas estão mostradas na figura 4.2. O grafo é então a união destas regiões, isto é, $\mathcal{G}=R_{x} \cup R_{y} \cup R_{u}$. Esperamos então que à medida que as partículas demarcam suas comunidades a região não ocupada por nenhuma partícula tende a diminui de tamanho até um limite que experimentalmente verificamos ser zero.

É necessário agora definir algumas variáveis que controlam a dinâmica do processo. Definimos então o grau de uma região, que pode ser inclusive o grafo todo, em função do tempo como sendo a soma dos graus dos nós que compõe aquela região. Assim, se uma região tem $n$ vértices, seu grau é dado por:

$$
G(R)=\sum_{i=1}^{n} g\left(v_{i}\right)
$$

onde $g\left(v_{i}\right)$ é o grau do vértice $i$. As regiões aumentam com o tempo, desta forma, o mesmo acontece com o grau destas regiões. Isto é, $G\left(R_{x}\right)=G_{R_{x}}(t)$ e $G\left(R_{y}\right)=G_{R_{y}}(t)$. Este valor tende a se estabilizar com o processo de demarcação, isto é, a partir de um dado instante $T$ a partícula $x$ terá demarcado toda uma região $R_{1}$ e esta região $R_{1}$ tenderá a pemanecer estável para $t \geq T$. 


$$
\begin{aligned}
& G_{R_{x}}(t)=G_{1}, t \geq T \\
& G_{R_{y}}(t)=G_{2}, t \geq T
\end{aligned}
$$

Portanto o grau da região $R_{1}$ demarcada pela partícula $x$ para $t \geq T$, que chamamos de $G_{1}$, também não deverá sofrer alterações para $t \geq T$.

Cabe observar agora, que a região demarcada pela partícula $x$ para $t \geq T$ não necessáriamente coincidirá com a região $A$, que é a região que delimita a comunidade $A$.

O número de vértices de uma região é então definido como $n(R)$. Assim o número de vértices ocupados pela partícula $x$ no instante $t$, Assim, por exemplo, $n_{x}(t)$ é definido como $n_{x}(t)=n\left(R_{x}(t)\right)$.

Teremos assim que $n_{x}(t)=n_{1}$ para $t \geq T$ e $n_{y}(t)=n_{2}$ para $t \geq T$, sendo $n_{1} \mathrm{o}$ número de vértices da região $R_{1}$, isto é, $n_{1}=n\left(R_{1}\right)$ e $n_{2}$ o número de vértices da comunidade $R_{2}$. Com essas definições, o número de vértices do grafo é $n=n_{1}+n_{2}$.

Verifica-se a partir de simulações que a porcentagem máxima de vértices que são corretamente demarcados pela partícula $x$, ou seja, nós da região $R_{1}$ que pertencem à comunidade $A$, ou seja, que estão em $R_{1} \cap R_{A}$ é no mínimo $p_{l} n_{A}$.

A probabilidade da demarcação ser feita com sucesso, isto é, todos os vértices de $R_{1}$ serem também vértices de $R_{A}$ é no mínimo $p_{s}=1-p_{l}$, por causa da própria maneira como o grafo $\mathcal{G}$ é construído. Para entender esta afirmação basta considerar o caso em que $p_{s}=p_{l}=0.5$. Neste caso não há comunidades, mesmo assim, as partículas terminam o processo de demarcação com regiões bem definidas. É portanto natural não esperar que as comunidades que rotulamos serão exatamente as comunidades demarcadas.

O grau médio do grafo é definido por:

$$
\langle G\rangle=\frac{\sum_{i=1}^{N} g\left(v_{i}\right)}{N}
$$

Desta forma é razoável supor que o grau da região ocupada pela partícula $x$ e o grau da região ocupada pela partícula $y$, no instante $t$ sejam aproximados por:

$$
\begin{aligned}
& G_{R_{x}}(t)=\langle G\rangle n_{x}(t) \\
& G_{R_{y}}(t)=\langle G\rangle n_{y}(t)
\end{aligned}
$$




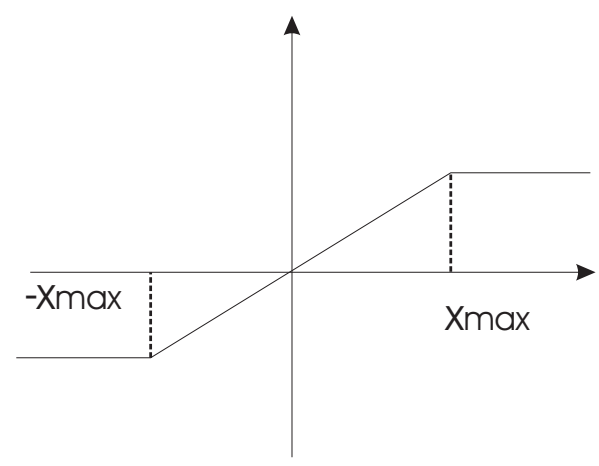

Figura 4.3: Potencial de um vértice em função do número de visitas.

$$
\begin{aligned}
& G_{R_{x}}(t)=\langle G\rangle n_{1}, t \geq T \\
& G_{R_{y}}(t)=\langle G\rangle n_{2}, t \geq T
\end{aligned}
$$

Se admitirmos que o grau de uma região cresce com $n_{x}$ e atinge o valor máximo $G_{1}$, sem considerar valores médios teríamos de forma exata:

$$
\begin{aligned}
G_{R_{x}}(t) & =G_{1} \frac{n_{x}(t)}{n_{1}} \\
G_{R_{y}}(t) & =G_{2} \frac{n_{y}(t)}{n_{2}}
\end{aligned}
$$

Seja $x(t)$ o potencial da partícula $x$ no instante $t$ e $y(t)$ o potencial da partícula $y$ no instante $t$. Na presente análise esses potenciais precisam ser redefinidos como sendo a soma dos potenciais individuais dos vértices demarcados pela partícula. Esta definição é portanto diferente das definições dadas no capítulo anterior, pois permitem uma melhor análise matemática:

$$
\begin{aligned}
& x(t)=\sum_{v \in R_{x}} \rho(v) \\
& y(t)=\sum_{v \in R_{y}} \rho(v)
\end{aligned}
$$

O potencial de cada vértice, pela definição do modelo, depende do número visitas deste vértice. Seja $\nu_{(x ; i)}(t)$ o número de visitas realizadas ao vértice $i$ no tempo $t$ pela partícula $x$. O potencial do vértice $i, \rho_{i}$ em termos do número de vistas pode ser aproximado por uma função do tipo mostrado na figura 4.2.

Como o modelo que estamos desenvolvendo é contínuo, a função da figura 4.2 , que descreve o potencial de cada vértice em função do tempo, poderia ser 
aproximada neste modelo por uma função do tipo:

$$
\rho_{v_{i}}(t)=\rho_{i}(t)=\frac{2 p_{\max }}{\pi} \arctan \left(\frac{\nu_{(x ; i)}(t)}{x_{\max }}\right)
$$

O fator $\frac{2}{\pi}$ ocorre porque o valor máximo que a função $\arctan (x)$ atinge é $\frac{\pi}{2}$, porém definimos que o potencial máximo atingido pelo nó é $\rho_{\max }$. O potencial da partícula $x$ no tempo $t$ é então definido como:

$$
x(t)=\sum_{v_{i} \in R_{x}} \rho_{v_{i}}(t)
$$

A soma de funções arco-tangentes é uma função arco-tangente. Isso pode ser demonstrado da seguinte forma: Se $m=\tan (a), n=\tan (b)$ então temos que:

$$
\begin{aligned}
\tan (a+b) & =\frac{\tan (a)+\tan (b)}{1-\tan (a) \tan (b)} \\
a+b & =\arctan \left(\frac{\tan (a)+\tan (b)}{1-\tan (a) \tan (b)}\right) \\
\arctan (m)+\arctan (n) & =\arctan \left(\frac{m+n}{1-m n}\right)
\end{aligned}
$$

Ou seja, o potencial $x(t)$ também será uma função da forma arco-tangente.

Supondo agora, de forma aproximada, que o número de visitas crescesse de forma uniforme em todos os vértices, o potencial poderia ser aproximado por:

$$
\begin{array}{r}
x(t)=\rho(t) n_{x}(t)=\frac{\rho(t) n_{1} G_{R_{x}}(t)}{G_{1}} \\
\frac{G_{1} x(t)}{n_{1} \rho(t)}=G_{R_{x}}(t)
\end{array}
$$

As fórmulas acima relacionam o potencial da região com o tamanho desta, isto é:

$$
x(t)=\rho(t) n_{x}(t)=\frac{\rho(t) n_{1} G_{R_{x}}(t)}{G_{1}}
$$

\subsection{Comunidades Separadas}

Vamos nesta seção fazer uma análise de duas comunidades separadas, isto é, um modelo de duas comunidades com $p_{l}=0$. Tal situação é mostrada na figura 4.3.

Primeiramente neste modelo não há colisões, pois não temos comunicação entre as comunidades, em outras palavras, os movimentos realizados pelas 

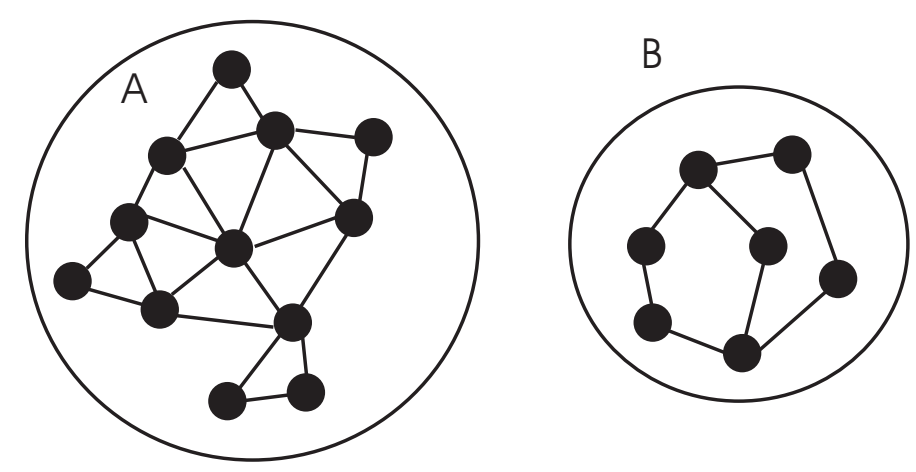

Figura 4.4: Comunidades desconectadas.

partículas são independentes. A análise portanto, pode se restringir a uma única comunidade. Desta forma quanto maior for o número de vértices dela, mais tempo a comunidade demora para ser ocupada pela partícula. Por outro lado, é também um fato conhecido que, vértices com maior grau, são mais visitados por partículas. Desta forma comunidades com grau maior tendem a "atrair"partículas fazendo com que o tempo para que elas sejam inteiramente ocupadas diminua. Pelo que foi discutido anteriormente, isto é, a soma de funções arco-tangentes é uma função arco-tangente, o potencial de uma região em função do tempo pode ser aproximado por:

$$
\begin{aligned}
& x(t)=a \arctan \left(m_{1} t\right) \\
& y(t)=b \arctan \left(m_{2} t\right)
\end{aligned}
$$

Temos então que $m_{1}=\frac{G_{1}}{n_{1}}$ e $m_{2}=\frac{G_{2}}{n_{2}}$ refletindo o fato de que comunidades maiores demoram mais tempo para serem demarcadas e aquelas com maior grau demoram menos tempo para serem demarcadas. Com essa aproximação, continuamos supondo que $G_{R_{x}}(t) \rightarrow G_{1}$ quando $t \rightarrow \infty$. Os valores de $a$ e $b$ devem respeitar os valores máximos da função, isto é:

$$
\begin{aligned}
\lim _{t \rightarrow \infty} x(t)=\lim _{t \rightarrow \infty} a \arctan \left(m_{1} t\right) & =a \frac{\pi}{2} \\
& =n_{1} \rho_{\max }
\end{aligned}
$$

assim:

$$
\begin{aligned}
& a=\frac{2 n_{1} \rho_{\max }}{\pi} \\
& b=\frac{2 n_{2} \rho_{\max }}{\pi}
\end{aligned}
$$

Como exemplo de aplicação da técnica quantitativa descrita na seção an- 
terior, vamos calcular o tempo $T$ para que uma comunidade seja inteiramente ocupada. Esse valor é aproximadamente igual ao valor para o qual cada vértice da comunidade tenha uma visita. Este valor é o valor para o qual $x(t)=n_{1}$. Portanto podemos achar o valor de $T$ resolvendo a equação:

$$
\begin{array}{r}
x(t)=\frac{\rho(t) n_{1} G_{R_{x}}(t)}{G_{1}}=n_{1} \\
\frac{n_{1} \rho_{\max } \arctan \left(\frac{G_{1}}{n_{1}} T\right) G_{1}}{G_{1}}=n_{1} \\
T=\frac{n_{1}}{G_{1}} \tan \left(\frac{1}{\rho_{\max }}\right)
\end{array}
$$

A partir deste instante de tempo $T$, se $t<T$ a variação do potencial de $x$ e de $y$ é grande, porém após o instante $T$ termos as partículas tendendo cada vez mais visitar nós já visitados ou sofrer colisões, no caso de $p_{l}>0$, caso este que será estudado na seção seguinte. Desta forma, a partícula sofrerá cada vez menos variações de potencial a partir de $t \geq T$.

Assim, o tempo $T$ para a partícula $x$ ocupar toda a comunidade $A$ é inversamente proporcional ao grau de $A$. Quanto maior portanto for o tamanho da região $A$ e menor for o grau da região $A$ (mais conectada estiver, maior for $p_{s}$ ), mais rapidamente a partícula $x$ em $A$ fará $G_{R_{x}}$ atingir seu máximo. Este máximo, estamos considerando que é igual a $G_{1}$ no caso genérico, porém no caso em que duas comunidades não estão conectadas o valor de $G_{1}$ será exatamente igual a $G_{A}$ pois a partícula terminará por demarcar toda a comunidade.

Um fato que deve ser observado é que o modelo não está considerando a estrutura do grafo, de modo que quando as comunidades estiverem conectadas e não houver colisões não temos, com o modelo aqui desenvolvido, como prever o valor exato de $G_{1}$ no caso geral, isto é, com $p_{l} \neq 0$. Isto acontece porque quando $p_{s}=p_{l}=0.5$ não há comunidades, porém o modelo demarca comunidades e esta demarcação nem sempre corresponderá às comunidades corretas, conforme foi explicado anteriormente. Podemos contudo fazer a aproximação $G_{1} \approx G_{A}$ a fim de fazer uma análise quantitativa relativa à questões de tempo e de convergência do modelo.

A derivada do potencial em relação ao tempo é dada por:

$$
\frac{d x(t)}{d t}=\frac{a}{\left(1+m_{1}^{2} t^{2}\right)}
$$

da mesma forma para $y(t)$ temos:

$$
\frac{d y(t)}{d t}=\frac{b}{\left(1+m_{2}^{2} t^{2}\right)}
$$

A derivada então mostra que em um processo sem competição, isto é, como 
uma única comunidade ou com duas comunidades separadas, como o potencial de cada vértice sempre atinge um valor máximo e o grafo é finito, a taxa de variação do grau da região demarcada por uma partícula, isto é sua derivada, deve decair com o tempo de forma quadrática (porque o grafo é plano).

Confirmamos assim o fato esperado de que uma função boa para representar o crescimento de $x(t)$ ou $y(t)$ com o tempo seria algo como $x(t)=$ $a \arctan \left(\frac{t G_{A}}{n_{1}}\right)$ e $y(t)=b \arctan \left(\frac{t G_{B}}{n_{2}}\right)$, sendo $G=G_{A}+G_{B}$.

Considerando então que estamos fazendo a aproximação $G_{1} \approx G_{A}$, o potencial da região demarcada por $x$ deverá atingir o valor $n_{1} \rho_{\max }$ e o potencial da região demarcada por $y$ deverá atingir o valor $n_{1} \rho_{\text {max }}$. Em outras palavras, se:

$$
\begin{aligned}
\lim _{t \rightarrow \infty} G_{R_{x}}(t) & =G_{A} \\
\lim _{t \rightarrow \infty} G_{R_{y}}(t) & =G_{B}
\end{aligned}
$$

então:

$$
\begin{aligned}
& \lim _{t \rightarrow \infty} x(t)=n_{1} \rho_{\max } \\
& \lim _{t \rightarrow \infty} y(t)=n_{2} \rho_{\max }
\end{aligned}
$$

Nesta seção assumimos que o potencial é expresso como uma função contínua do número de visitas que aquele nó recebeu até o tempo $t$ e chegamos à forma do potencial de uma comunidade não conectada à outra em função do tempo. As equações 4.36 e 4.37 formam um sistema de equações diferenciais não-autônomas independentes.

\subsection{Modelagem com Taxas de Crescimento}

O fato da função que descreve o potencial de $x$ obedecer a forma de uma função $f(t)=a \arctan (m t)$ tem uma outra explicação em termos de dinâmica de crescimento.

Quando uma partícula $x$ toma posse de um nó ou quando a partícula $x$ visita um nó já visitado por ela, aumentando portanto o potencial deste nó, é como se um novo indivíduo de uma espécie $x$ tivesse nascido. Apesar de não estarmos gerando novas partículas neste modelo, o potencial da partícula está sendo incrementado, por isso podemos fazer uma correspondência do potencial de uma partícula com o número de individuos de uma população.

Quando após um determinado passo de tempo o potencial de todos os nós são decrementados, é como se indivíduos tanto da espécie $x$ quanto da espécie $y$ estivessem morrendo. Por outro lado quando uma partícula $x$ choca-se com 
um nó ocupado por uma partícula $y$ diminuindo o potencial da partícula $y$, é como se um indivíduo da espécie $x$ tivesse matado um indivíduo da espécie $y$ e vice-versa. Desta forma as partículas $x$ e $y$ agem tanto como indivíduos geradores quanto como indivíduos aniquiladores.

Para construir um modelo matemático, inicialmente notamos o que acontece quando as comunidades estão separadas. Neste caso, supondo que a partícula $x$ ocupe a comunidade $A$, temos que a taxa de crescimento é sempre positiva. A equação que descreve esta dinâmica é então:

$$
\frac{d x}{d t}=\frac{n}{G}\left[\rho_{\max } n-x\right]
$$

ou de uma forma qualitativa:

$$
\frac{d x}{d t}=p_{s}\left[\rho_{\max } n-x\right]
$$

Com a condição inicial $x(0)=x_{0}=1$. Esta equação pode ser resolvida por separação de variáveis:

$$
\begin{aligned}
\frac{d x}{a x+b} & =d t \\
\int_{0}^{t} \frac{d x}{a x+b} & =\int_{0}^{t} d t \\
\frac{1}{a} \ln (a x+b) & =t+K \\
\ln (a x+b) & =a t+a K \\
a x+b & =e^{a K} e^{a t} \\
a x & =-b+e^{a K} e^{a t} \\
x & =-b / a+\frac{e^{a K}}{a} e^{a t} \\
x & =-b / a+C e^{a t}
\end{aligned}
$$

Substituindo: $a=-p_{s}, b=p_{s} \rho_{\max } n$ temos:

$$
x(t)=\rho_{\max } n+C e^{-p_{s} t}
$$

Se $x(0)=\rho_{\text {min }}$, temos que:

$$
x(t)=\rho_{\max } n+\left(\rho_{\min }-\rho_{\max } n\right) e^{-p_{s} t}
$$

Porém esta equação não representa um modelo perfeito, porque como as partículas tem preferência por visitar nós já visitados, existe um efeito de 
cruzamento. Ele pode ser entendido como indivíduos da espécie $x$ cruzando-se com indivíduos da espécie $x$, gerando através de reprodução, outros indivíduos da espécie $x$. Isso induz uma taxa de crescimento quadrática em $x$. Assim, da mesma forma que na equação logística, podemos descrever a dinâmica de crescimento de $x$, considerando o efeito de cruzamento como:

$$
\frac{d x}{d t}=p_{s} x\left(\rho_{\max } n-x\right)
$$

Da mesma forma que no exemplo anterior, a equação pode ser resolvida por separação de variáveis:

$$
\begin{array}{r}
\frac{d x}{p_{s} x\left(\rho_{\max } n-x\right)}=d t \\
\int_{0}^{t} \frac{d x}{p_{s} x\left(\rho_{\max } n-x\right)}=\int_{0}^{t} d t
\end{array}
$$

Como:

$$
\int \frac{d x}{a x^{2}+b x+c}=\left\{\begin{array}{l}
\frac{2}{\sqrt{4 a c-b^{2}}} \tan ^{-1} \frac{2 a x+b}{\sqrt{4 a c-b^{2}}} \\
\frac{1}{\sqrt{b^{2}-4 a c}} \ln \left(\frac{2 a x+b-\sqrt{b^{2}-4 a c}}{2 a x+b+\sqrt{b^{2}-4 a c}}\right)
\end{array}\right.
$$

e $a=p_{s} \rho_{\max } n, b=p_{s}$ e $c=0, b^{2}-4 a c=b^{2}$ (pois $\mathrm{c}=0$ ) escolhemos a segunda das equações e obtemos:

$$
\begin{aligned}
\int \frac{d x}{-a x^{2}+b x} & =\frac{1}{b} \ln \left(\frac{-2 a x}{-2 a x+2 b}\right) \\
& =\frac{1}{b} \ln \left(\frac{a x}{b-a x}\right)
\end{aligned}
$$

então: 


$$
\begin{aligned}
\frac{1}{b} \ln \left(\frac{a x}{b-a x}\right) & =t+K \\
\ln \left(\frac{a x}{b-a x}\right) & =b t+b K \\
\frac{a x}{b-a x} & =e^{b K} e^{b t} \\
a x & =(b-a x) C e^{b t} \\
a x & =b C e^{b t}-a x C e^{b t} \\
a x+a x C e^{b t} & =b C e^{b t} \\
x\left(a+a C e^{b t}\right) & =b C e^{b t} \\
x & =\frac{b}{a} \frac{C e^{b t}}{\left(1+C e^{b t}\right)} \\
x(t) & =\frac{b}{a} \frac{C}{\left(e^{-b t}+C\right)}
\end{aligned}
$$

Substituindo as constantes mencionadas acima temos:

$$
x(t)=\left(\rho_{\max } n\right) \frac{C}{e^{-p_{s} \rho_{\max } n t}+C}
$$

Como $x(0)=\rho_{\min }$ temos:

$$
\begin{aligned}
\rho_{\text {min }} & =\frac{\rho_{\max } n C}{1+C} \\
\rho_{\min }(1+C) & =\rho_{\max } n C \\
\rho_{\text {min }}+\rho_{\min } C-\rho_{\max } n C & =0 \\
C\left(\rho_{\min }-\rho_{\max } n\right) & =-\rho_{\min } \\
C & =\frac{\rho_{\text {min }}}{\rho_{\max } n-\rho_{\min }}
\end{aligned}
$$

\subsection{Duas comunidades conectadas}

Continuando a análise, se a partícula $x$ fosse colocada na comunidade $A$, a partícula $y$ fosse colocada na comunidade $B$ e não houvessem ligações entre as duas comunidades, isto é $p_{l}=0$, esperíamos que o potencial da partícula $x$, $x(t)$,se estabilizasse em um dado valor.

Esperaríamos também que a partícula demarcasse toda a comunidade já que sendo as comunidades disjuntas, não haveria choque de partículas com vértices demarcados, nem invasão de uma comunidade demarcada por uma partícula por outra partícula que demarcou outra comunidade.

O valor de tempo para o qual o potencial se estabiliza, depende dos mesmos fatores que influenciam a estabilização do grau de $G_{R_{x}}(t)$, pois vimos que as 
duas funções estão relacionadas, mas como não haverão choques, os potenciais das partículas são exatamente dados pelas fórmulas mostradas na seção anterior.

No caso considerado nesta seção, existem colisões. Na existência de colisões, verificamos experimentalmente que os potenciais da partículas se estabilizam em um determinado valor, da mesma forma que no caso anterior.

Com o primeiro fato, o sistema atinge o equilíbrio, isto é, vértices demarcados por $x$ em $A$ tendem a estabilizar seu potencial, o mesmo acontecendo com vértices demarcados por $y$ em $B$. Por causa disto, admitimos que mesmo no caso em que existem colisões, o sistema atinge uma situação de equilíbrio que é análoga à sitiação de duas comunidades separadas. É necessário portanto mostrar isso matemáticamente, o que faremos na próxima seção.

Entretanto, teremos que descontar tanto da taxa de crescimento ou decrescimento de $x(t)$ e de $y(t)$ o valor relativo à colisões, isto é, o processo competitivo entre as duas comunidades que faz com que o potenciais de $x$ e de $y$ diminua.

Por causa disso temos que:

$$
\begin{aligned}
& \frac{d x(t)}{d t}=\frac{a m_{1}}{1+m_{1}^{2} t^{2}}-C(x, y) \\
& \frac{d y(t)}{d t}=\frac{b m_{2}}{1+m_{2}^{2} t^{2}}-C(x, y)
\end{aligned}
$$

O termo $C(t)$ que representa as colisões no modelo acima, é na verdade composto por dois outros termos $C(t)=C_{x y}(t)+C_{y x}(t)$.

Definimos assim $C_{x y}(t)$ como sendo o número de colisões que a partícula $x$ teve com nós demarcados pela partícula $y$ até o tempo $t$ e $C_{y x}$ como o número de colisões que a partícula $x$ teve com nós demarcados pela partícula $y$ até o tempo $t$.

Ou seja, o conjunto de equações acima nos diz que a taxa de variação de $x(t)$ menos a taxa de variação das colisões que contribuem negativamente, tanto ao aumento de $x(t)$, como ao aumento de $y(t)$ é igual a taxa de variação da região ocupada por $x$ ou do potencial de $x$. O mesmo valendo, mutatis mutandis, para a partícula $y$.

Precisamos agora definir uma fórmula para a taxa de variação das colisões, ou seja, como o número de colisões de partículas entre as duas comunidades varia com o tempo.

Verificamos então que:

- Quanto maior for $G_{R_{y}}$ ou $G_{R_{x}}$ maior será o número de choques $C_{x y}$ ou $C_{y x}$.

- Quanto maior for $\frac{G_{A}}{G_{A}+G_{B}}$ maior será o número de choques $C_{y x}$ pois com 
$G_{A}$ maior a partícula $y$ é mais atraída para $A$ do que para $B$ e portanto choca-se mais com a região marcada por $x$

- Quanto maior for $\frac{G_{B}}{G_{A}+G_{B}}$ maior será o número de choques $C_{x y}(t)$ pois, mutatis mutandis, com $G_{B}$ maior a partícula $x$ é mais atraída para $B$ do que para $A$ e portanto choca-se mais com a região marcada por $y$.

- Quanto maior for $p_{l}$ maior será o número de choques tanto $C_{x y} \operatorname{com} C_{y x}$ pois mais conectadas estão $A$ e $B$ e maior será o grau da região de fronteira entre $A$ e $B$.

- Quanto maior for $G_{R_{u}}$ menos choques ocorrerão pois a probabilidade da partícula ocupar um nó não demarcado ou demarcado por ela mesma é maior do que a dela chocar-se com um nó já demarcado por outra partícula.

A primeria argumentação é que quanto maior for o grau da comunidade $A$ em relação ao grafo, isto é, a relação $\frac{G_{A}}{G_{A}+G_{B}}$, maior for $p_{l}$ e menos vértices tiver $B$ maior será o número de choques da partícula $y$ em $B$ com vértices marcados por $x$ em $R_{x}$. Denotando $C_{y x}(t)$ o número de choques da partícula $y \mathrm{em} B$ com a partícula $x$ em $A$ e mutatis mutandis para a partícula $x$ em $A$ temos, pelas considerações acima, as seguintes fórmulas:

$$
\begin{aligned}
C_{y x}(t) & =\frac{G_{A} C(x, y)}{G_{A}+G_{B}} \\
C_{x y}(t) & =\frac{G_{B} C(x, y)}{G_{A}+G_{B}}
\end{aligned}
$$

As colisões podem ser dadas então por:

$$
C(x, y)=p_{l} x y
$$

Com isso as equações que descrevem o modelo podem ser dadas por:

$$
\begin{aligned}
\frac{d x(t)}{d t} & =\frac{a m_{1}}{1+m_{1}^{2} t^{2}}-p_{l} x y \\
\frac{d y(t)}{d t} & =\frac{b m_{2}}{1+m_{2}^{2} t^{2}}-p_{l} x y
\end{aligned}
$$

O sistema 4.80 é um sistema de equações diferenciais não autônomo, isto é, onde o tempo aparece explicitamente no modelo. Podemos transformá-lo num sistema autônomo fazendo a substituição $z(t)=t$. Assim temos: 


$$
\begin{aligned}
\frac{d x(t)}{d t} & =\frac{a m_{1}}{1+m_{1}^{2} z^{2}}-p_{l} x y \\
\frac{d y(t)}{d t} & =\frac{b m_{2}}{1+m_{2}^{2} z^{2}}-p_{l} x y \\
\frac{d z(t)}{d t} & =1
\end{aligned}
$$

\subsection{Modelagem como sistema autônomo}

A modelagem das colisões poderia ser feita como um sistema de equações diferenciais autômomo de forma direta, utilizando as idéias apresentadas na seção onde foi feita análise de taxas de crescimento. A vantagem deste tipo de sistema é que ele torna mais fácil a análise matemática. O sistema autônomo de duas equações que descreve o modelo, quando este é modelado em termos de taxa de crescimento é dada por:

$$
\begin{aligned}
& \frac{d x}{d t}=p_{s} x\left(n_{1} \rho_{\text {max }}-x\right)-p_{l}\left(x y-n_{1} n_{2} \rho_{\text {max }}^{2}\right) \\
& \frac{d y}{d t}=p_{s} y\left(n_{2} \rho_{\max }-y\right)-p_{l}\left(x y-n_{1} n_{2} \rho_{\text {max }}^{2}\right)
\end{aligned}
$$

Quando modelado desta forma, o ponto de equilíbrio, que é o ponto onde $\left(x^{\prime}, y^{\prime}\right)=(0,0)$, pode ser obtido resolvendo-se o sistema:

$$
\begin{aligned}
& p_{s} x\left(n_{1} \rho_{\max }-x\right)-p_{l}\left(x y-n_{1} n_{2} \rho_{\text {max }}^{2}\right)=0 \\
& p_{s} y\left(n_{2} \rho_{\max }-y\right)-p_{l}\left(x y-n_{1} n_{2} \rho_{\text {max }}^{2}\right)=0
\end{aligned}
$$

Este é um sistema de equações algébricas não linear e de difícil solução, porém da forma que está escrito, podemos checar que a solução deste sistema é dada por $\left(x_{0}, y_{0}\right)=\left(\rho_{\max } n_{1}, \rho_{\max } n_{2}\right)$.

\subsection{Análise do Ponto de Equilíbrio}

Em geral, não é possível resolver analíticamente sistemas de equações diferenciais não lineares. Assim não é possivel encontrar explicitamente uma solução analítica, tanto para o sistema 4.82 quanto para o sistema 4.85. Porém é possivel fazer uma análise do ponto de equilíbro destes sistema, isto é, o ponto em que as duas derivadas se tornam iguais a zero. O que permite esta análise, é um teorema em sistemas dinâmicos denominado teorema de Hartman-Grobmann (Robinson, 1998), que afirma que topológicamente um 
sistema nas vizinhaças do ponto de equilíbrio pode ser dado por um sistema linear. Este teorema também permite afirmar se o ponto de equilíbrio é um poço (isto é um atrator), um ponto de sela ou uma fonte (isto é, um ponto repulsor). Faremos então para o sistema 4.85 uma análise do ponto de equilíbrio e mostraremos que este é um ponto estável, isto é, os autovalores da matriz Jacobiana no ponto tem parte real negativa.

Um sistema não-linear e não-autonomo de primeira ordem é dado genericamente por:

$$
\begin{array}{r}
x^{\prime}=f(x, y)+f(t) \\
y^{\prime}=g(x, y)+g(t)
\end{array}
$$

esse sistema pode ser representado de forma matricial como:

$$
\mathbf{x}^{\prime}=\mathbf{A x}+\mathbf{F}(t)
$$

No problema estudado o sistema tem a forma acima, com $f(t)$ e $g(t)$ sendo funções constantes. O sistema não-linear homogêneo equivalente é dado por:

$$
\begin{aligned}
x^{\prime} & =f(x, y) \\
y^{\prime} & =g(x, y)
\end{aligned}
$$

As funções $f(x, y)$ e $g(x, y)$ podem ser dadas em série de Taylor por:

$$
\begin{aligned}
& f(x, y) \approx f\left(x_{0}, y_{0}\right)+\left.\frac{\partial f(x, y)}{\partial x}\right|_{\left(x_{0}, y_{0}\right)}\left(x-x_{0}\right)+\left.\frac{\partial f(x, y)}{\partial y}\right|_{\left(x_{0}, y_{0}\right)}\left(y-y_{0}\right) \\
& g(x, y) \approx g\left(x_{0}, y_{0}\right)+\left.\frac{\partial g(x, y)}{\partial x}\right|_{\left(x_{0}, y_{0}\right)}\left(x-x_{0}\right)+\left.\frac{\partial g(x, y)}{\partial y}\right|_{\left(x_{0}, y_{0}\right)}\left(y-y_{0}\right)
\end{aligned}
$$

Assim o sistema não linear poderia ser aproximado por:

$$
\left(\begin{array}{l}
x \\
y
\end{array}\right)^{\prime}=\left(\begin{array}{c}
f\left(x_{0}, y_{0}\right) \\
g\left(x_{0}, y_{0}\right)
\end{array}\right)+\left(\begin{array}{cc}
\frac{\partial f}{\partial x}\left(x_{0}, y_{0}\right) & \frac{\partial f}{\partial y}\left(x_{0}, y_{0}\right) \\
\frac{\partial g}{\partial x}\left(x_{0}, y_{0}\right) & \frac{\partial g}{\partial y}\left(x_{0}, y_{0}\right)
\end{array}\right)\left(\begin{array}{c}
x-x_{0} \\
y-y_{0}
\end{array}\right)
$$


No ponto de equilíbrio em que $f\left(x_{0}, y_{0}\right)=0$ e $g\left(x_{0}, y_{0}\right)=0$. Assim:

$$
\left(\begin{array}{l}
x \\
y
\end{array}\right)^{\prime}=\left(\begin{array}{ll}
\frac{\partial f}{\partial x}\left(x_{0}, y_{0}\right) & \frac{\partial f}{\partial y}\left(x_{0}, y_{0}\right) \\
\frac{\partial g}{\partial x}\left(x_{0}, y_{0}\right) & \frac{\partial g}{\partial y}\left(x_{0}, y_{0}\right)
\end{array}\right)\left(\begin{array}{c}
x-x_{0} \\
y-y_{0}
\end{array}\right)
$$

Fazendo a substituição $u=x-x_{0}$ e $v=y-y_{0}$ temos:

$$
\left(\begin{array}{c}
u \\
v
\end{array}\right)^{\prime}=\left(\begin{array}{cc}
\frac{\partial f}{\partial x}\left(x_{0}, y_{0}\right) & \frac{\partial f}{\partial y}\left(x_{0}, y_{0}\right) \\
\frac{\partial g}{\partial x}\left(x_{0}, y_{0}\right) & \frac{\partial g}{\partial y}\left(x_{0}, y_{0}\right)
\end{array}\right)\left(\begin{array}{c}
u \\
v
\end{array}\right)
$$

A matriz acima é a matriz Jacobiana no ponto. Temos os seguintes resultados da teoia de sistemas dinâmicos em função dos autovalores da matriz Jacobiana:

- Se os autovalores são negativos complexos com parte real negativa então a ponto é um poço (atrator). Se os autovalores forem complexos a solução irá oscilar antes de convergir para este valor.

- Se os autovalores são positivos ou complexos com parte real positiva então o ponto é uma fonte (repulsor). Se os autovalores forem complexos a solução irá oscilar antes de divergir deste valor.

- Se os auto-valores forem números reais ou complexos com diferentes sinais, então o ponto de equilíbrio é um ponto de sela.

- Se um dos autovalores for igual a zero a estabilidade é indefinida.

Para o sistema que iremos analisar temos:

$$
\begin{aligned}
& \frac{d x}{d t}=p_{s} x\left(n_{1} \rho_{\text {max }}-x\right)-p_{l}\left(x y-n_{1} n_{2} \rho_{\text {max }}^{2}\right) \\
& \frac{d y}{d t}=p_{s} y\left(n_{2} \rho_{\text {max }}-y\right)-p_{l}\left(x y-n_{1} n_{2} \rho_{\text {max }}^{2}\right)
\end{aligned}
$$

Calculando as derivadas parciais temos:

$$
\begin{aligned}
& \frac{\partial f}{\partial x}=p_{s} n_{1} \rho_{\max }-2 p_{s} x-p_{l} y \\
& \frac{\partial f}{\partial y}=-p_{l} x \\
& \frac{\partial g}{\partial x}=-p_{l} y \\
& \frac{\partial g}{\partial y}=p_{s} n_{2} \rho_{\max }-2 p_{s} y-p_{l} x
\end{aligned}
$$


A matriz Jacobiana é portanto:

$$
\mathbf{J}=\left(\begin{array}{cc}
p_{s} n_{1} \rho_{\max }-2 p_{s} x-p_{l} y & -p_{l} x \\
-p_{l} y & p_{s} n_{2} \rho_{\max }-2 p_{s} y-p_{l} x
\end{array}\right)
$$

Substituindo o ponto $\left(x_{0}, y_{0}\right)=\left(\rho_{\max } n_{1}, \rho_{\max } n_{2}\right)$ temos que a matriz Jacobiana é dada por:

$$
\begin{aligned}
\mathbf{J} & =\left(\begin{array}{cc}
p_{s} n_{1} \rho_{\max }-2 p_{s} n_{1} \rho_{\max }-p_{l} n_{2} \rho_{\max } & -p_{l} n_{1} \rho_{\max } \rho_{\max } \\
-p_{l} n_{1} \rho_{\max } & p_{s} n_{2} \rho_{\max }-2 p_{s} n_{2} \rho_{\max }-p_{l} n_{1} \rho_{\max }
\end{array}\right) \\
& =\left(\begin{array}{cc}
-p_{s} n_{1} \rho_{\max }-p_{l} n_{2} \rho_{\max } & -p_{l} n_{1} \rho_{\max } \rho_{\max } \\
-p_{l} n_{1} \rho_{\max } & -p_{s} n_{2} \rho_{\max }-p_{l} n_{1} \rho_{\max }
\end{array}\right)
\end{aligned}
$$

Para calcular os autovalores da matriz Jacobiana temos que resolver a equação:

$$
\operatorname{det}(\mathbf{J}-\lambda \mathbf{I})=0
$$

Assim, resolvendo :

$$
\left|\begin{array}{cc}
\left(-p_{s} n_{1} \rho_{\max }-p_{l} n_{2} \rho_{\max }\right)-\lambda & -p_{l} n_{1} \rho_{\max } \\
-p_{l} n_{1} \rho_{\max } & \left(-p_{s} n_{2} \rho_{\max }-p_{l} n_{1} \rho_{\max }\right)-\lambda
\end{array}\right|=0
$$

Chegamos na seguinte equação quadrática:

$$
\left[\left(-p_{s} n_{1} \rho_{\max }-p_{l} n_{2} \rho_{\max }\right)-\lambda\right]\left[\left(-p_{s} n_{2} \rho_{\max }-p_{l} n_{1} \rho_{\max }\right)-\lambda\right]+p_{l}^{2} n_{1} n_{2} \rho_{\max }^{2}=0
$$

Que pode ser reescrita como:

$$
\left[\left(p_{s} n_{1}+p_{l} n_{2}\right)+\frac{\lambda}{\rho_{\max }^{2}}\right]\left[\left(p_{s} n_{2}+p_{l} n_{1}\right)+\frac{\lambda}{\rho_{\max }^{2}}\right]+p_{l}^{2} n_{1} n_{2}=0
$$

Fazendo $u=\frac{\lambda}{\rho_{\max }^{2}}$ temos:

$$
\begin{array}{r}
u^{2}+\left(p_{s} n_{1}+p_{l} n_{2}+p_{s} n_{2}+p_{l} n_{1}\right) u+\left(p_{s} n_{1}+p_{l} n_{2}\right)\left(p_{s} n_{2}+p_{l} n_{1}\right)+p_{l}^{2} n_{1} n_{2}=0 \\
u^{2}+n u+\left(p_{s} n_{1}+p_{l} n_{2}\right)\left(p_{s} n_{2}+p_{l} n_{1}\right)+p_{l}^{2} n_{1} n_{2}=0
\end{array}
$$

Notamos agora, que se $p_{s}+p_{l}=1$ temos que $\left(p_{s} n_{1}+p_{l} n_{2}+p_{s} n_{2}+p_{l} n_{1}\right)=n$, portanto os autovalores são: 


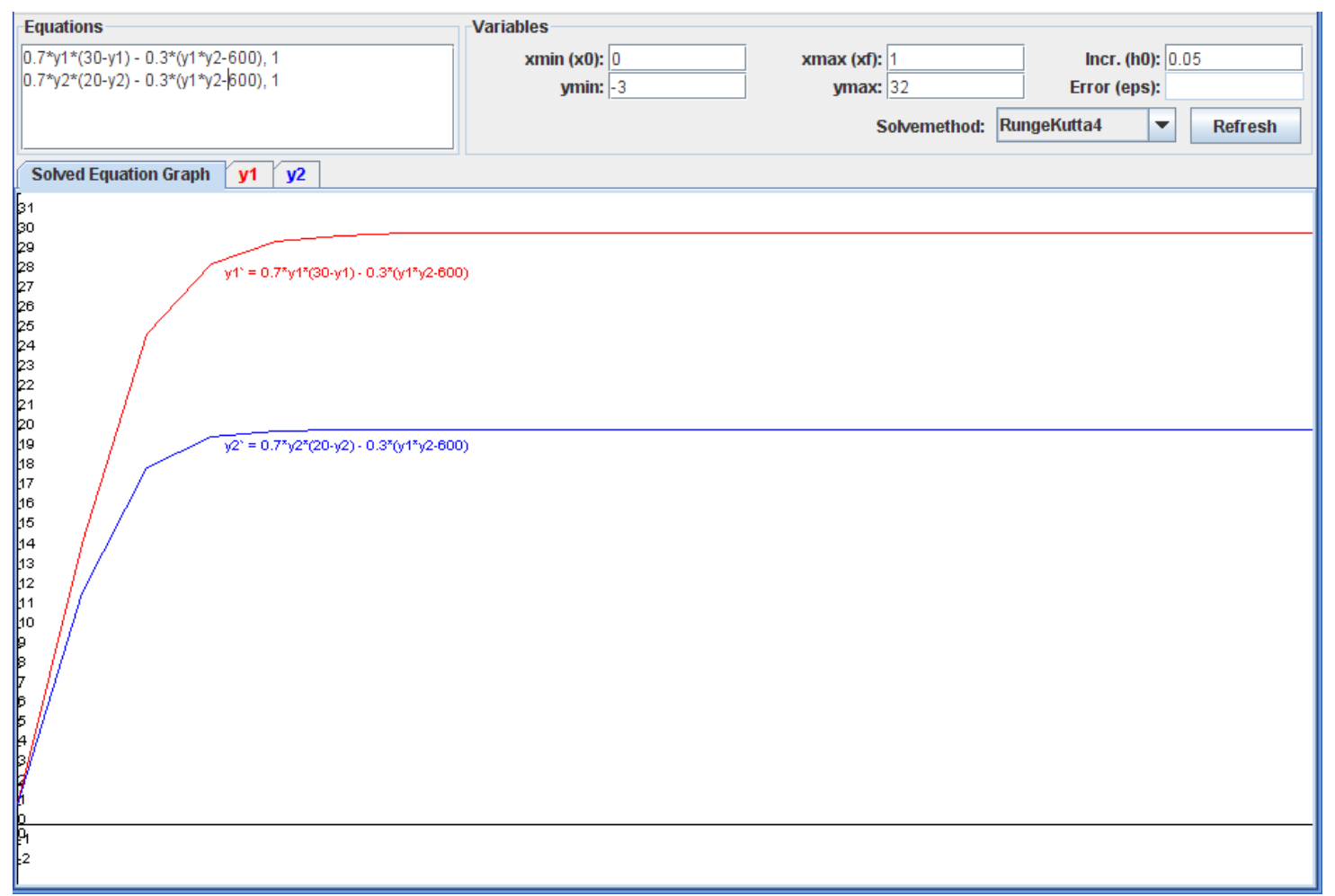

Figura 4.5: Exemplo de Integração numérica de um sistema com três partículas competindo.

$$
\begin{aligned}
u & =\frac{-n \pm \sqrt{n^{2}-4\left[\left(p_{s} n_{1}+p_{l} n_{2}\right)\left(p_{s} n_{2}+p_{l} n_{1}\right)+p_{l}^{2} n_{1} n_{2}\right]}}{2} \\
\lambda & =\frac{\rho_{\max }}{2}\left[-n \pm \sqrt{n^{2}-4\left[\left(p_{s} n_{1}+p_{l} n_{2}\right)\left(p_{s} n_{2}+p_{l} n_{1}\right)+p_{l}^{2} n_{1} n_{2}\right]}\right]
\end{aligned}
$$

Como eles tem parte real negativa, notamos que o ponto de equilírio para este sistema é estável, porém podem oscilar um pouco antes de convergirem, dependendo dos demais parâmetros.

\subsection{Modelagem para mais de duas comunidades}

No caso de haverem mais de duas comunidades, por exemplo, $A, B$ e $C$ o sistema seria dado por:

$$
\begin{aligned}
& \frac{d x}{d t}=p_{s_{1}} x\left(\rho_{\max } n_{1}-x\right)-p_{l_{12}}\left(x y-\rho_{\max }^{2} n_{1} n_{2}\right) \\
& \frac{d y}{d t}=p_{s_{2}} y\left(\rho_{\max } n_{2}-y\right)-p_{l_{23}}\left(y z-\rho_{\max }^{2} n_{2} n_{3}\right) \\
& \frac{d z}{d t}=p_{s_{3}} z\left(\rho_{\max } n_{2}-z\right)-p_{l_{31}}\left(z x-\rho_{\max }^{2} n_{3} n_{1}\right)
\end{aligned}
$$

Neste caso supomos que a comunidade 1 está conectada a comunidade 2 


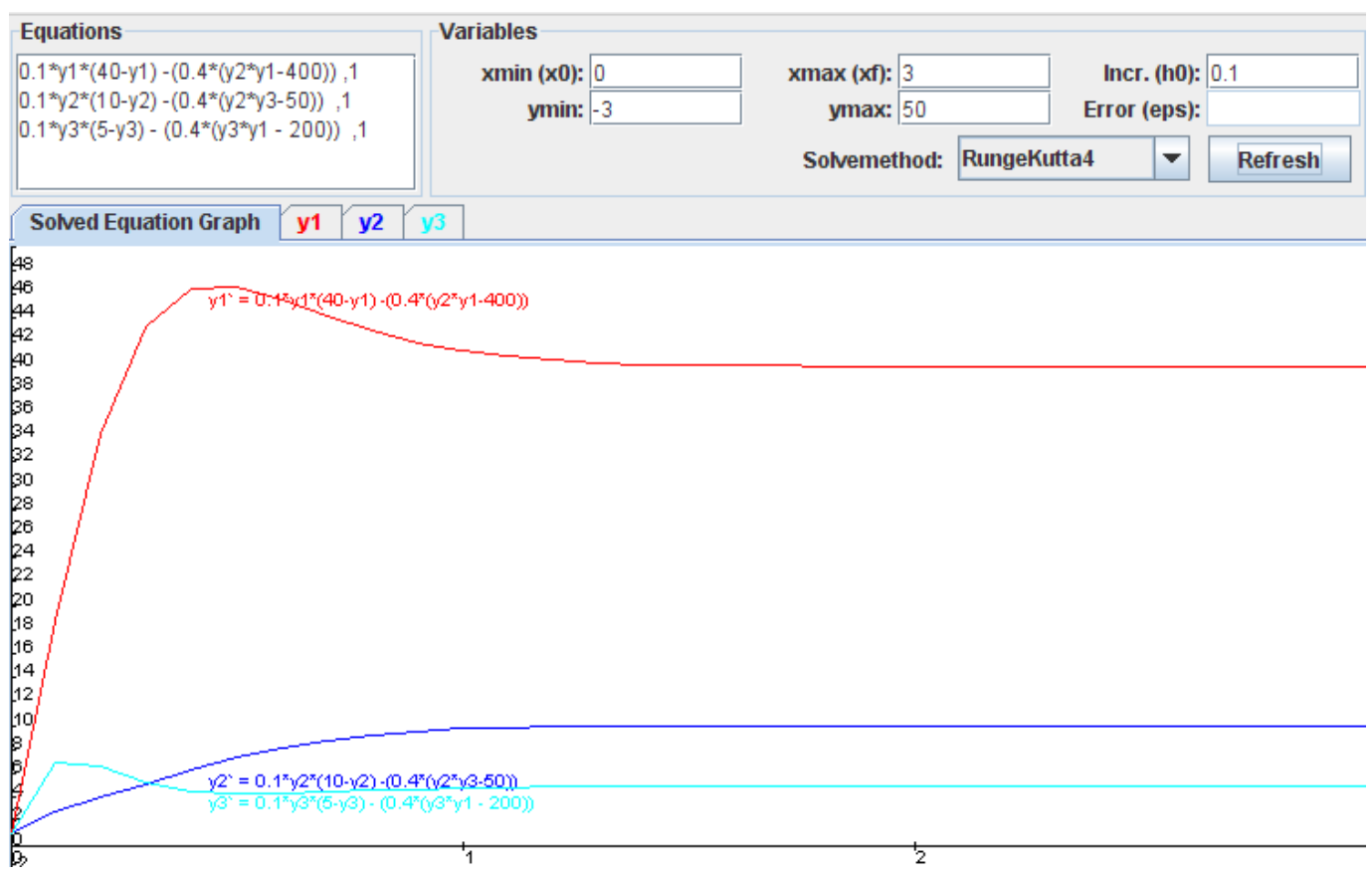

Figura 4.6: Exemplo de Integração numérica de um sistema com três partículas competindo.

com probabilidade $p_{l_{12}}$, que a comunidade 2 está conectada à comunidade 3 com probabilidade $p_{l_{23}}$ e que a comunidade 3 está conectada à comunidade 1 com probabilidade $p_{l_{31}}$. A figura mostra a integração númeria de um sistema destes com três comunidades. Podemos ver que as soluções de fato convergem para valores fixos, apesar de oscilarem.

\subsection{Considerações Finais}

No presente capítulo foram propostos dois modelos de equações diferenciais, um autônomo e outro não autônomo para modelar o processo de competição de partículas e demarcação de comunidades. Um destes modelos, o autônomo, foi resolvido e mostrou como um modelo matemático simples com inúmeras aproximações pode descrever o processo de competição e demarcação do território em um grafo com duas partículas. Mostramos que o modelo proposto possui uma solução de equilíbrio e que esta solução representa um equilíbrio estável, que é atingido após um tempo suficientemente longo. Foi também mostrado como modelar o sistema de competição para o caso de mais de duas comunidades. 


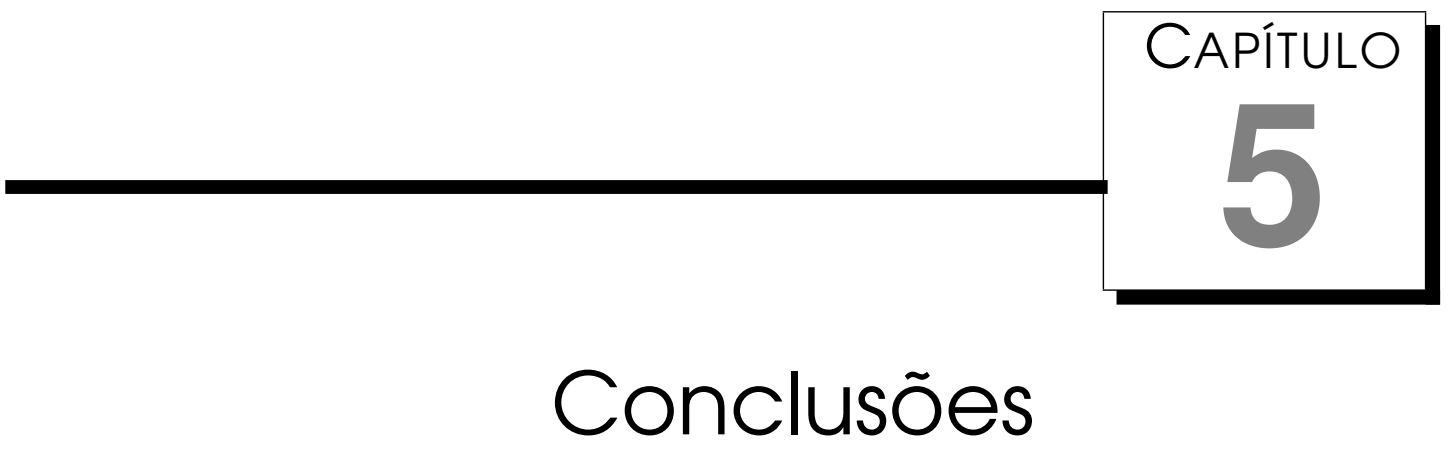

Neste trabalho, foi proposto um sistema de competição de partículas para detectar comunidades em redes complexas. A dinâmica do modelo é similar ao processo natural de animais lutando por recursos de modo que as partículas e nós representam animais e recursos, respectivamente. No modelo proposto, também introduzimos uma regra para controlar o nível de aleatoriedade do passeio da partícula. Descobrimos que o melhor resultado, isto é, aquele que tem a porcentagem de acerto de comunidades maior, é obtido quando partículas caminham quase deterministicamente, mas como um pouco de aleatoriedade. Simulações computacionais mostram que resultados são satisfatórios. Mais ainda, uma análise quantitativa foi conduzida para um sistema de duas particulas. O resultado de análise confirma a dinâmica prevista da modelagem.

\subsection{Conclusões}

Através do desenvolvimento desta tese, podemos tirar as seguintes concluções:

- Este trabalho mostrou detecção de comunidades por meio de dinâmica de partículas. A partir deste exemplo concreto e pensando em forma mais geral, isso implica o estudo de redes complexas pode combinar a estrutura, função e dinâmica em um esquema interegrado. Portanto, redes complexas são uma ferramenta poderosa para modelar e analisar muitos problemas reais, principalmente quando queremos relacionar estrutura e função em um ambiente dinâmica, por exemplo, interação de proteinas, 
sistema de transito, clusterização e classificação dinâmica, etc.;

- Em muitas situações reais, a aleatoriedade é considerada como uma incerteza ou mesmo uma confusão que impede os seres humanos de tomar a decisão correta. Neste trabalho, nós estudamos o papel combinado de aleatoriedade e determinismo. Neste modelo, nós introduzimos uma regra para controlar o nível de aleatoriedade do passeio da partícula e concluímos que a aleatoriedade é essencial para exploração de espaços de soluções, em outras palavras, uma pequena porção de aleatoriedade pode aumentar bastante a taxa de detecção de comunidades. Nossa descoberta indica que a aleatoriedade tem um papel importante em sistemas evolutivos. Ela serve para automaticamente escapar de armadilhas não desejáveis e explorar novos espaços, isto é, ela é um descobridor de novidades. Portanto, nossa observação é contra-intuitiva;

- O processo de competição de partículas no modelo proposto é similar a muitos processos naturais e sociais, tais como competição de animais por recursos, exploração territorial por humanos (animais), campanhas eleitorais, etc. Portanto, o modelo proposto neste trabalho pode ser considerado como um técnica de aprendizado de máquina inspirado pelos sistemas biológicos e pela natureza. Tal a modelgem generaliza várias redes neurais artificiais, tais como modelo de Hopfield, Mapa AutoOrganizável, no sentido que o aprendizado de máquina ocorre em redes de grande escala e de topologia geral.

\subsection{Trabalhos Futuros}

A seguir, são descritos alguns trabalhos futuros baseado do desenvolvimento desta tese:

- O modelo poderia ser estendido considerando-se grafos com peso. Neste caso a regra de movimentação consideraria os pesos das arestas locais. Também poderia-se estender o modelo para grafos direcionados. Grafos direcionados com peso são importantes no estudo de funções de energia. Neste caso os rótulos em uma determinada direção indicam um determinado fluxo ou probabilidade naquela direção. Fazendo-se então uma analogia do grafo com um sistema de canos, os canos tem dois rótulos: Um deles indica a máxima vazão no cano e o outro indica a vazão que realmente está ocorrendo. O problema então consiste em determinar quais canos devem ser totalmente abertos e ter sua vazão máxima para que um fluxo de uma fonte (vértice fonte) para um poço (vértice 
poço) tenha sua vazão máxima. É sempre possível para uma determinada função de energia se construir um grafo tal que a escolha de um conjunto mínimo de arestas neste grafo, tais que se elas forem eliminadas elas causam uma desconexão do grafo e tal que a escolha destas arestas corresponde ao máximo fluxo no grafo. A recíproca também é verdadeira, isto é, é possível escolher um conjunto máximo de arestas, tal que se elas forem eliminadas elas causam uma desconexão do grafo e tal que a escolha destas arestas determina o mínimo fluxo no grafo. O conjunto de arestas mencionado é chamado de corte. É possível então escolher estender o modelo para que ele realize cortes em um grafo direcionado para que haja minimização de uma função.

- O modelo matemático elaborado não mostra a dependência da forma da solução com a estrutura do grafo, isto é, apenas mostra como os potenciais para duas partículas variam com o tempo, isto é, apenas mostra como estes potenciais convergem para um certo valor ou divergem deste. Não mostram portanto como potenciais individuais são afetados no decorrer do tempo nem como comunidades são definidas a partir de potneciais invidivuais. É possivel com o uso de um conjunto de equações mestras modelar a dinâmica da variação de potenciais em vértices individuais e mostrar como esta dinâmica varia com o tempo e delimita as comunidades. Este modelo todavia é bastante complexo e as equações além de nem sempre possuírem solução analítica às vezes não permitem análise de um ponto de equilíbrio como a que foi apresentada no capítulo anterior. Poder-se ia analisar do ponto de vista matemático a probabiliade de uma partícula permanecer em uma determinada comunidade, estando estas comunidades definidas à priori. Como o as probailidades de movimentação local dependem do tempo em virtude do processo de demarcação e da regra de movimentação, é de se esperar que as probabilidades de transição também dependeriam do tempo. Neste caso teríamos uma equação que relacionaria a probailidade de transição da população 1 para a comunidade $B$ e da população 2 para a comunidade $A$. Tal regra poderia ser considerada Markoviana em um intervalo de tempo $\Delta t$ pequeno e a variação desta probabilidade mostraria como cada população tenderia a ficar em sua comunidade e desta forma não migrar para a outra comunidade.

- Poderia-se aplicar o modelo desenvolvido para agrupoamento de dados. O processo de clusterização ocorre com os seguintes passos: inicialmente, um conjunto de dados de entrada é representado por uma rede, onde cada vértice da rede representa um item de dado do conjunto e os vértices são interligados por critérios de similaridade entre si; em seguida, a rede 
é particionada em comunidades produzindo clusters. A vantagem de agrupamento de dados via detecção de comunidades é na identificação de forma arbitrária de clusters. 


\section{Referências Bibliográficas}

A. J. Litchenberg, M. A. L. (1983). Regular and Stochastic Motion (1 ed.), Volume 38 of Applied Mathematical Sciences. New York, Heidelberg, Berlin: Springer-Verlag.

Adler, R. (1992, December). Symbolic Dynamics and Its Applications (Contemporary Mathematics, Vol 135) (First Edition ed.). American Mathematical Society.

Albert, R., I. Albert, \& G. L. Nakarado (2004). Structural vulnerability of the north american power grid. Physical Review E 69, 025103 (1-4).

Albert, R. \& A.-L. Barabási (2002). Statistical mechanics of complex networks. Reviews of Modern Physics 74, 47 - 97.

Albert, R., H. Jeong, \& A.-L. Barabási (1999). Diameter of the world wide web. Nature 401, 130-131.

Arenas, A., A. Díaz-Guilera, \& C. J. Pérez-Vicente (2006). Synchronization reveals topological scales in complex networks. Physial Review Letters 96, $114102(1-4)$.

Arnold, V. (1995a). Dynamical Systems I - Ordinary Differential Equations (1 ed.), Volume I of Enciclopedia of Mathematical Sciences. Berlin, Heidelber, New York, London, Paris, Tokyo: Springer-Verlag.

Arnold, V. (1995b). Dynamical Systems V - Theory of Bifurcations, The theory of catastrophes (1 ed.), Volume V of Enciclopedia of Mathematical Sciences. Berlin, Heidelber, New York, London, Paris, Tokyo: Springer-Verlag.

Arnold, V. \& A. B. Givental (1995). Dynamical Systems IV - Symplectic Geometry, Geometric Quantization, Integrable Systems (1 ed.), Volume VI of Enciclopedia of Mathematical Sciences. Berlin, Heidelber, New York, London, Paris, Tokyo: Springer-Verlag. 
Arnold, V., V. V. Kozlov, \& A. I. Neishtadt (1995). Dynamical Systems III Mathematical Aspects of Classical and Celestial Mechanics (1 ed.), Volume III of Enciclopedia of Mathematical Sciences. Berlin, Heidelber, New York, London, Paris, Tokyo: Springer-Verlag.

B. Maiti, S. M. \& N. Sathyamurthy (2000, July 1). A time-dependent quantum mechanical investigation of dynamical resonances in three-dimensional heh and hehd + systems. The Journal of Chemical Physics 113(1), 59-66.

Barabasi, A.-L. \& R. Albert (1999). Emergence of scaling in random networks. Science 286, 509-512.

Biggs, N.; Lloyd, E. \& R. Wilson (1986). Graph Theory (1º ed.). Oxford University Press.

Blatt, M., S. Wiseman, \& E. Donamy (1996). Clustering data through an analogy to the potts model. Advances in Neural Information Processing Systems 8 , 416-422.

Boccaletti, S., M. Ivanchenko, V. Latora, A. Pluchino, \& A. Rapisarda (2007). Detection of complex networks modularity by dynamical clustering. Physical Review E 75, 045102 (1-5).

Boccaletti, S., J. Kurths, G. Osipov, D. Valladares, \& C. Zhou (2002). The synchronization of chaotic systems. Physics Reports 366, 1-101.

Bornholdt, S. \& H. G. Schuster (2003). Handbook of graphs and networks: from the genome to the internet. Wiley-vch.

Burns, T. (1959). Darwinism and the study of society. Nature 183, 1562-1564.

Carpenter, G. A. \& S. Grossberg (1987a). Art2: Self-organization of stable category recognition codes for analog input patterns. Applied Optics 26, 4919-4930.

Carpenter, G. A. \& S. Grossberg (1987b). A massively parallel architecture for a self-organizing neural pattern recognition machine. Computer Vision, Graphics and Image Processing 37(1), 54-115.

Carpenter, G. A., S. Grossberg, N. Markuzon, J. H. Reynolds, \& D. B. Rosen (1992). Fuzzy artmap: A neural network architecture for incremental supervised learning of analog multidimensional maps. IEEE Transactions on Neural Networks 3(5), 698-713.

Carpenter, G. A., S. Grossberg, \& J. H. Reynolds (1991). Artmap: Supervised real-time learning and classification of nonstationary data by a selforganizing neural network. Neural Networks 4(5), 565-588. 
Clauset, A. (2005). Finding local community structure in networks. Physical Review E 72, 026132 (1-7).

Cormen, T. H., C. E. Leirserson, R. L. Rivest, \& C. Stein (2001). Introduction to Algorithms (2 ed.). MA,USA: MIT Press.

da Costa, L. F., F. A. Rodrigues, G. Traviesso, \& P. R. V. Boas (2007). Characterization of complex networks: a survey of measurements. Advances in Phisycs 56(1), 167-242.

Danon, L., J. Duch, A. Arenas, \& A.Díaz-Guilera (2007). Large Scale Structure and Dynamics of Complex Networks: From Information Technology to Finance and Natural Science, Chapter Community structure identification, pp. 93113. World Scientific.

Danon, L., J. Duch, A. Arenas, \& A. Díaz-Guilera (2005). Comparing community structure identification. Journal of Statistical Mechanics: Theory and Experiment, P09008.

Daw, N. D., J. P. O’Doherty, P. Dayan, B. Seymour, \& R. J. Dolan (2006). Cortical substrates for exploratory decisions in humans. Nature 441, 876879.

Dawkins, R. (1990). The Selfish Gene (Second ed.). Oxford University Press.

de Oliveira, T. T. M. J. (2001). Dinâmica Estocástica e Irreversibilidade ( $1^{\circ}$ ed.). EdUSP.

de Pádua Braga, A., T. B. Ludermir, \& A. C. P. de Leon Ferreira Carvalho (2000). Redes Neurais Artificiais: Teoria e aplicações. LTC.

Dorogovtsev, S. N. \& J. F. F. Mendes (2003). Evolution of Networks: From Biological Nets to the Internet and WWW. Oxford University Press.

Douglas Lind, B. M. (1995, November 24). An Introduction to Symbolic Dynamics and Coding (First Edition ed.). Cambridge University Press.

Engel, A. K., P. König, A. K. Kreiter, \& W. Singer (1991). Interhemispheric synchronization of oscillatory neuronal responses in cat visual cortex. Science 252, 1177-1178.

Erdős, P. \& A. Rényi (1959). On random graphs. Publicationes Mathematicae 6, 290-297.

Erdős, P. \& A. Rényi (1961). On the strength of connectedness of a random graph. Acta Mathematica Hungarica 12, 261-267. 
Everett, M. \& S. Borgatti (1998). Analyzing clique overlap. Connections 21, 49-61.

Faloutsos, M., P. Faloutsos, \& C. Faloutsos (1999). On power-law relationship of the internet topology. In C. C. Rev. (Ed.), ACM SIGCOMM 99, Volume 29, pp. 251-260.

Faust, K. (2005). Models and methods in social network analysis. Cambridge University Press.

Flake, G. W., S. Lawrence, C. L. Giles, \& F. M. Coetzee (2002). Self-organization and identification of web communities. Computer 35, 66-71.

Fredrickson, A. \& G. Stephanopoulos (1981). Microbial competition. Science 213, 972-979.

Fritzke, B. (1994). Fast learning with incremental rbf networks. Neural Processing Letters 1(1), 2-5.

Fritzke, B. (1995). A growing neural gas networks learns topologies. Advances in Neural Information Processing Systems 7, 625-632.

Fu, Y. \& P. Anderson (1986). Application of statistical mechanics to npcomplete problems in combinatorial optimization. J. Physics A: Mathematical and General 19, 1605-1620.

Grey, C., P. König, A. Engel, \& W. Singer (1989). Oscillatory responses in cat visual cortex exhibit inter-columnar synchronization which reflects global stimulus properties. Nature 338, 334-337.

Guimera, R., S. Mossa, A. Turtschi, \& L. A. N. Amaral (2003). The worldwide air transportation network: Anomalous centrality, community structure, and cities' global roles. Proceedings of the National Academy of Sciences USA 102, 7704-7709.

H., E., M. L.I., \& B. S. (2002). Scale-free topology of e-mail networks. Physical Review E 66, 035103.

H. Levy, F. L. (1992, September 11). Finite Difference Equations (Reprint edition ed.). Dover Pubns.

Han, J.-H., S. A. Kushner, A. P. Yiu, C. J. Cole, A. Matynia, R. A. Brown, R. L. Neve, J. F. Guzowski, A. J. Silva, \& S. A. Josselyn (2007). Neuronal competition and selection during memory formation. Science 316, 457-460.

Hannes Risken, T. F. (1996). The Fokker-Planck Equation: Methods of Solutions and Applications ( $2^{\circ}$ ed.). Springer. 
Hartwell, L. H., J. Hopfield, S. Leibler, \& A. Murray (1999). From molecular to modular cell biology. Nature 402, C47-C52.

Haykin, S. (2001). Redes Neurais: Princípios e prática (2ºd.). Bookman.

Hebb, D. O. (1949). The Organization of Behavior. Wiley: New York.

Jeong, H., S. Mason, A.-L. Barabási, \& Z. Oltvai (2001). Lethality and centrality in protein networks. Nature 411, 41-42.

Jeong, H., B. Tombor, R. Albert, Z. N. Oltvai, \& A.-L. Barabási (2000). The large scale organization of metabolic networks. Nature 607, 651-654.

Kernighan, B. W. \& S. Lin (1970). A efficient heuristic procedure for partitioning graphs. Bell System Technical Journal 49, 291-307.

Kohonen, T. (2001). Self-Organizing Maps (3th Edition ed.). Information Science. Springer.

Lee, D. (2006). Best to go with what you know? Nature 441, 822-823.

Liljeros, F., C. Edling, H. Stanley, \& L. Amaral (2003). Social networks (communication arising): sexual contacts and epidemic thresholds. Nature 423, 605-606.

Lusseau, D., K. Schneider, O. J. Boisseau, P. Haase, E. Slooten, \& S. M. Dawson (2003). The bottlenose dolphin community of doubtful sound features a large proportion of long-lasting associations. Behavioral Ecology and Sociobiology 54, 396-405.

Milgram, S. (1967). The small world problem. Psychology Today 1(1), 60-67.

Mitchell, T. (1997). Machine Learning. McGraw Hill.

Mizruchi, M. S. (1982). The american corporate network. Sage, Beverly Hills, CA.

Montoya, J. M. \& R. V. Solé (2002). Small world patterns in food webs. Journal of Theoretical Biology 214, 405-412.

Murthy, V. N. \& E. Fetz (1992). Coherent 25- to 35-hz oscillations in the sensorimotor cortex of awake behaving monkeys. Proceedings of the National Academy of Sciences of the United States of America 89(12), 5670-5674.

Newman, M. E. J. (2003). The structure and function of complex networks. SIAM Review 45(2), 167 - 256. 
Newman, M. E. J. (2004). Fast algorithm for detecting community structure in networks. Physical Review E 69(6), 066133(1-5).

Newman, M. E. J. \& M. Girvan (2004). Finding and evaluating community structure in networks. Physical Review E 69(2), 026113(1-15).

Nicolis, J. (1991, January). Chaos and Information Processing. Phd, Massachussets Institute of Technology.

Onnela, J.-P., A. Chakraborti, K. Kaski, J. Kertész, \& A. Kanto (2003). Dynamics of market correlations: taxonomy and portfolio analysis. Physical Review E 68, 056110(1-12).

Palla, G., I. Derényi, I. Farkas, \& T. Vicsek (2005). Uncovering the overlapping community structure of complex networks in nature and society. $\mathrm{Na}$ ture 435, 814-818.

Pfeifer, R., M. Lungarella, \& F. Iida (2007). Self-organization, embodiments, and biologically inspired robotics. Science 318, 1088-1093.

Pothen, A., H. Simon, \& K.-P. Liou (1990). Partitioning sparse matrices with eigenvectors of graphs. SIAM Journal on Matrix Analysis and Applications 11(3), 430-452.

Price, D. J. S. (1965). Network of scientific papers. Science 140, 510-515.

Quiles, M. G., L. Zhao, R. L. Alonso, \& R. A. F. Romero (2008). Particle competition for complex network community detection. CHAOS, accepted for publication.

Ravasz, E. \& A.-L. Barabási (2003). Hierarchical organization in complex networks. Physical Review E 67, 026112(1-7).

Ravasz, E., A. Somera, D. Mongru, Z. Oltvai, \& A.-L. Barabási (2002). Hierarchical organization of modularity in metabolic networks. Science 297, 1551-1555.

Reichardt, J. \& S. Bornholdt (2006). Statistical mechanics of community detection. Physical Review E 74, 016110(1-14).

Reichardt, J. \& S.Bornholdt (2004). Detecting fuzzy community structures in complex networks with a potts model. Physical Review Letters 93(21), 218701(1-4).

Robinson, C. (1998). Dynamical Systems, Stability, Symbolic Dynamics and Chaos (Second Edition ed.). CRC Press. 
Samuel Karlin, H. M. T. (1975). A First Course in Stochastic Processes (2 ed.). Academic Press.

Shannon, C. E. (1948). A mathematical theory of communication. Bell System Technical Journal 27, 379-423.

Sinai, Y. G. (1995). Dynamical Systems II - General Ergodic Theory of Groups and Measure Preserving Transformations (1 ed.), Volume II of Enciclopedia of Mathematical Sciences. Berlin, Heidelber, New York, London, Paris, Tokyo: Springer-Verlag.

Strogatz, S. H. (2001). Exploring complex networks. Nature 410, 268-276.

Vargas, E. C. (2004). Recuperação de informação por similaridade utilizando técnicas inteligentes. Tese de Doutorado, Universidade de São Paulo - ICMCUSP, Brasil.

Vicsek, T. (2002). The bigger picture. Nature 418, 1.

Watts, D., P. Dodds, \& M. Newman (2002). Identity and search in social networks. Science 296, 1302-1305.

Watts, D. J. \& S. H. Strogatz (1998). Collective dynamics of "small-world" networks. Nature 393, 440-442.

West, G. B., J. H. Brown, \& B. J. Enquist (1999). A general model for the structure, and allometry of plant vascular systems. Nature 400, 122-126.

White, C., E. Southgate, J. Thompson, \& S. Brenner (1986). The structure of the nervous system of the nematode c. elegans. Philosophical Transactions of the Royal Society of London 314, 1-340.

Zachary, W. W. (1977). An information flow model for conflict and fission in small groups. Journal of Anthropological Research 33, 452-473.

Zhang, S., R.-S. Wang, \& X.-S. Zhang (2007). Identification of overlapping community structure in complex networks using fuzzy c-means clustering. Physica A 374, 483-490.

Zhou, H. (2003a). Distance, dissimilarity index, and network community structure. Physical Review E 67, 061901(1-10).

Zhou, H. (2003b). Network landscape from a brownian particle's perspective. Physical Review E 67, 041908(1-5). 